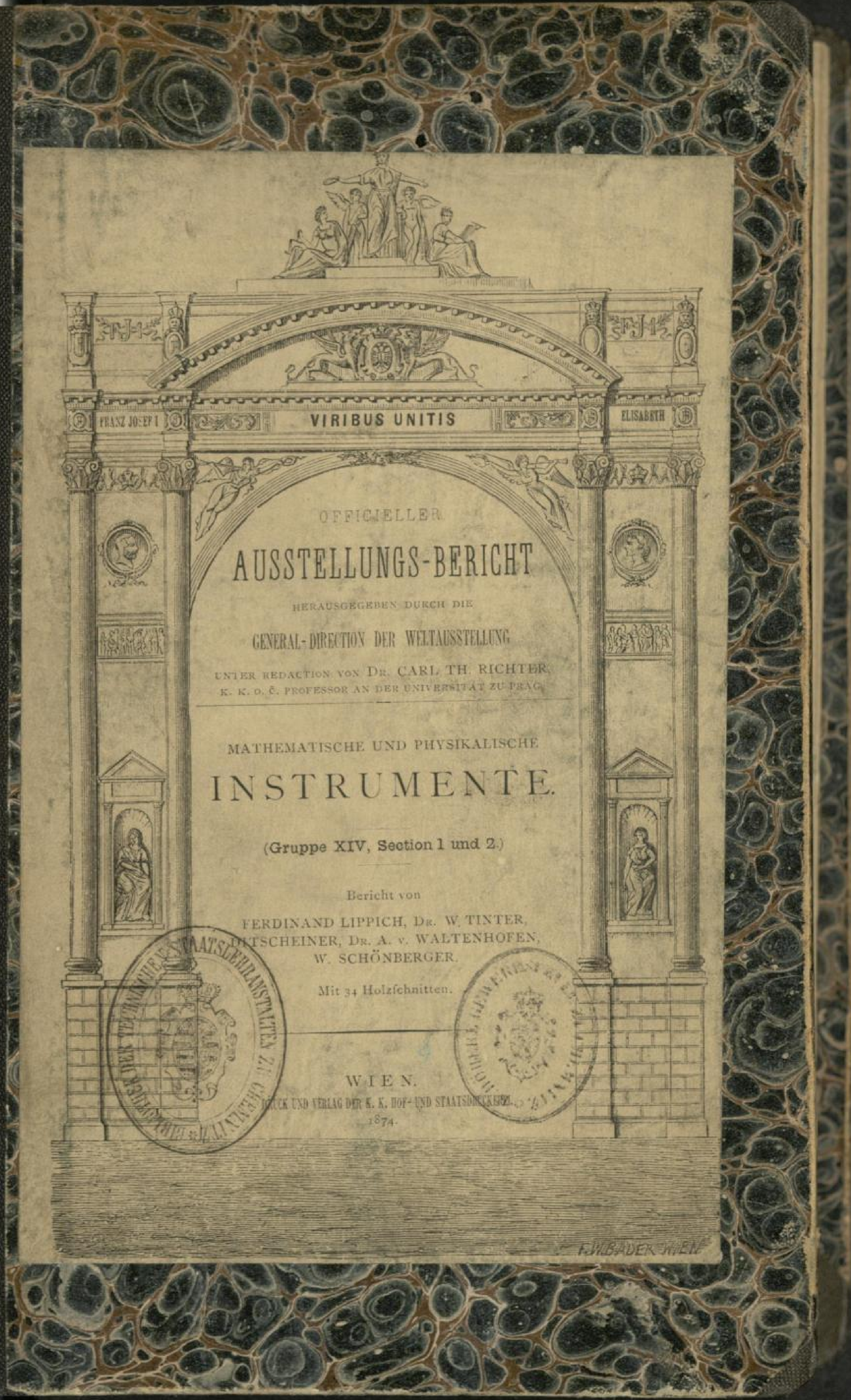


1.38.

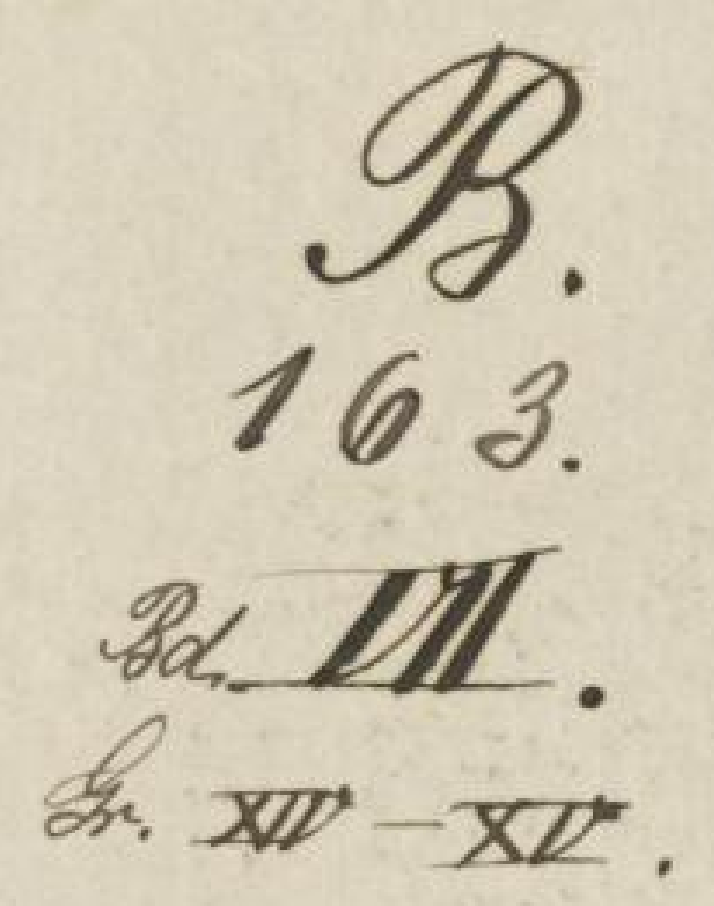




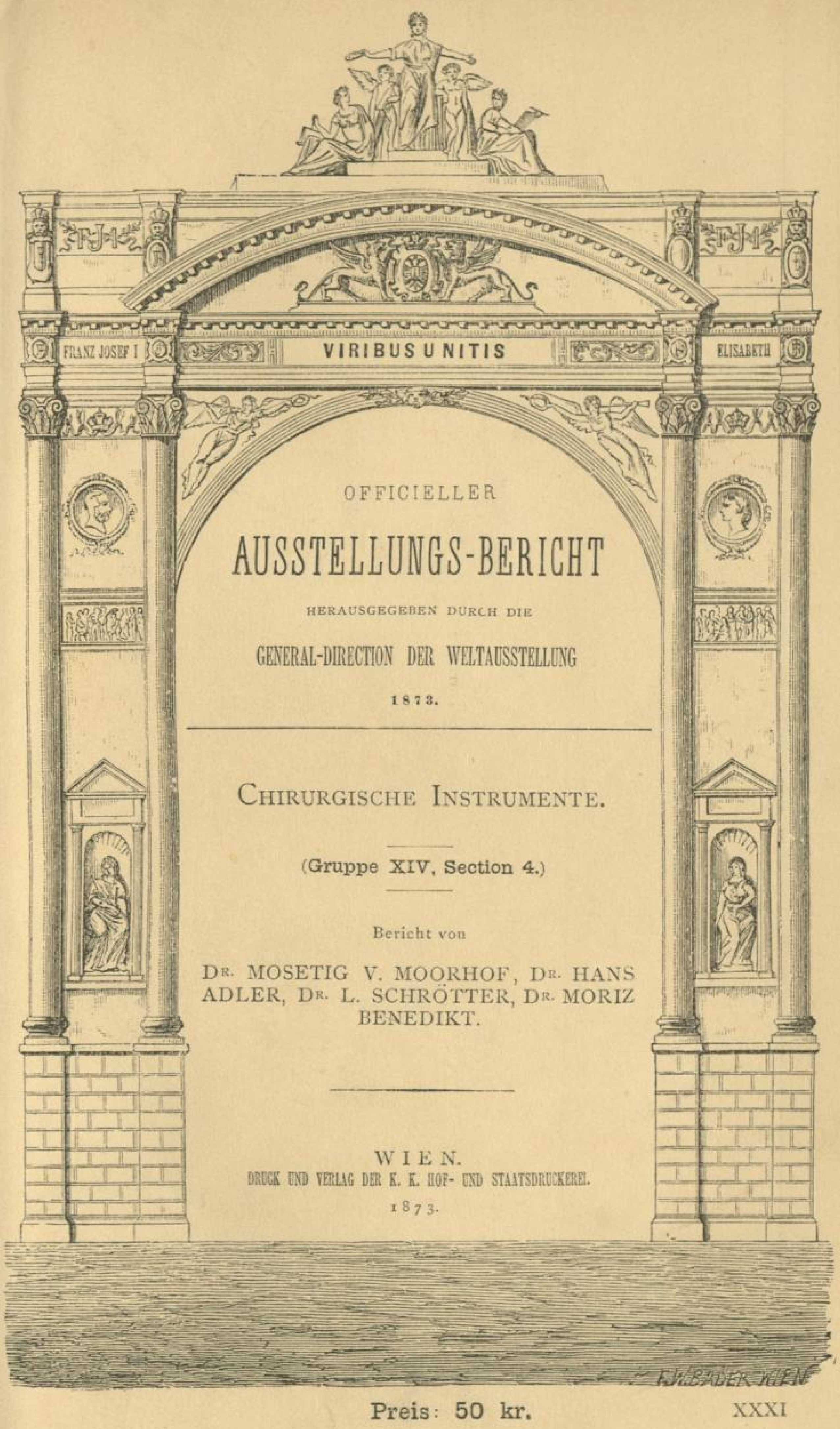



O F F I C I E L L E R

\title{
AUSSTELLUNGS-BERICHT
}

HERAUSGEGEBEN DURCH DIE

GENERAL-DIRECTION DER WELTAUSSTELLUNG 18773.

\section{CHIRURGISCHE INSTRUMENTE.}

\author{
(Gruppe XIV, Section 4.) \\ BERICHT
}

บ 0 N

$D^{R}$. Mosetig v. Moorhof, $D^{R}$. Hans Adler, D ${ }^{R}$ L. Schrötter, DR. MORIZ BENEDIKT.

\section{W I E N.}

DRUCK UND VERLAG DER K. K. HOF. UND STAATSDRUCKEREI.

1873. 


\section{VORWORT.}

Der gefertigte Redacteur des officiellen Berichtes über die Wiener Weltausftellung wurde am 30. März I873 für feine fchwierige Aufgabe nach Wien berufen, und nach kurzen vorhergehenden Berathungen ganz allein mit der Durchführung des grofsen Werkes betraut. Das Programm der officiellen Berichterftattung, Ende April von derGeneraldirection angenommen, wurde am 25. Juni 1873 , Zahl 686 H. M., von Seiten des hohen k. k. Handelsminifteriums genehmigt. Erft von diefer Zeit an war der gefertigte Redacteur im Stande, officiell an die Einladungen zu gehen und Berichterftatter für den officiellen Bericht zu gewinnen. Es ift jetzt nach dem Schluffe der Weltausftellung an der Zeit, an diefe kurze Gefchichte der Redaction des officiellen Berichtes zu erinnern.

In den erften Tagen des Auguft erfchien mit dem Berichte "Der Pavillon des kleinen Kindes" von Dr. Ferdinand Stamm das erfte Heft des officiellen Berichtes. In rafcher Aufeinanderfolge find bis zum Schluffe der Ausftellung 29 Hefte erfchienen und kann man darnach ficherlich weder den Herren Berichterftattern, die mit hingebender Liebe an das patriotifche Werk und an die Erfüllung der fchwierigen Aufgabe gingen, noch der Redaction den Vorwurf machen, dafs fie fich nicht bemühten, das officielle Programm der Berichterftattung, welches beftimmte, dafs der officielle Bericht ,noch während der Feier des internationalen Feftes abgefafst und aufgelegt werden" folle, zur Wahrheit zu machen. Was die Arbeitskraft des Einzelnen vermag, das haben die Herren Berichterftatter wirklich geleiftet, und Alle, ebenfo wie die gefertigte Redaction müfen ihnen zu Dank ver- 
pflichtet fein. Was ein Einzelner, dem die Redaction eines fo grofsen und vielfeitigenWerkes, welches der officielle Bèricht ift, allein anvertraut worden ift, was ein Einzelner unter fo fchwierigen Umftänden leiften kann, um den Befuchern der Ausftellung zu dienen, das hat der gefertigte Redacteur verfucht zu leiften. Mit der Neige des Jahres 1873 wird der officielle Bericht in feiner ganzen grofsen Ausdehnung und in feiner erften Ausgàbe vollendet fein.

Ich glaube, dafs die Herren Berichterftatter den Dank des Publicums verdienen, die gefertigte Redaction wenigftens keinen Tadel zu furchten hat.

Professor DR. CARL TH. Richter. Chefredacteur des officiellen Berichtes. 


\title{
CHIRURGISCHE INSTRUMENTE.
}

\author{
(Gruppe XIV, Section 4.)
}

\section{CHIRURGISCHE INSTRUMENTE, BANDAGEN UND PROTHETISCHE APPARATE.}

Bericht von

\author{
DR. MOSETIG VON MOORHOF, \\ k. k. Primararat und Univerjitätsdocent.
}

Indem wir im Folgenden einen Bericht iber die zur Gruppe XIV, Section 4, gehörigen Objecte geben, miffen wir zur Orientirung des Lefers bemerken, dafs hiebei blofs jene Gegenftände ins Auge gefafst wurden, welche feit der Parifer Weltausftellung des Jahres 1867 neu erdacht oder wenigftens einer wefentlichen Modification unterzogen und ausgeftellt worden find.

Die vierte Section der XIV. Gruppe umfafste alle jene Gegenftände, welche in das Gebiet der Medicin und Chirurgie gehören, und therapeutifche Zwecke verfolgen; mithin Apparate, Inftrumente, Bandagen, kosmetifche und prothetifche Objecte. Sie reihen fich ein in die Gebiete der Chirurgie im engeren Sinne, der Augen- und Zahn-Heilkunde, der Laryngofkopie, der Electrotherapie und der Anthropologie.

Die Specialfächer der Augen-Heilkunde, der Laryngofkopie und der Elektrotherapie haben aber im letzten Decennium, ja letztere erft im verfloffenen Quinquennium eine derartige Ausbreitung gefunden, dafs kaum ein einziger Arzt alle diefe Gebiete gründlich zu umfaffen vermag. Die Berichterftattung hiertiber wurde demnach auch Fachmännern übertragen, und haben: Profeffor Dr. B ene. dikt die Berichterftattung über elektro-therapeutifche Apparate, der ordinirende Augenarzt des k. k. Wiedner Krankenhaufes Herr Dr. A dler das Referat über oculiftifche Gegenftïnde, und Docent Herr Dr. v. Schrötter, jenes uber Laryngofkopie zu übernehmen die Güte gehabt.

Mein Referat begrenzt fich demnach auf chirurgifche Inftrumente, Bandagen und prothetifche Apparate, und auf zahnärztliche Gegenftände. Diefsbezüglich haben faft alle Staaten ausgeftellt mit Ausnahme der Türkei, Chinas und Japans; die meiften, fchönften und neueften Producte der Inftrumenten- und Bandagentechnik hat aber unftreitig Frankreich durch $\mathrm{C}$ ollin und M a th i e u zur Anfchauung gebracht, und diefs wird wohl dem Lefer die Erklärung geben, warum faft der Haupttheil meines Referates über franzöfifche Erzeugniffe handelt. England hat leider in diefen Fächern fo gat wie gar nichts ausgeftellt; in der Zahn. Heilkunde hingegen gebthrt Amerika und in zweiter Reihe England die Palme. 
Würdig vertreten waren ferner Oefterreich-Ungarn, Italien durch L oll in i und Dänemark durch Nyrop, wogegen Deutfchland und die übrigen Länder weniger reich ausgeftellt hatten.

Neu im Gebiete der chirurgifchen und zahnärztlichen Inftrumente ift das Vernickeln derfelben, und heben wir diefes befonders hervor, weil die letzte Parifer Ausftellung diefe Zurichtungsmethode, wenigftens fo weit ich mich zu ent finnen weifs, nicht zur Anfchauung gebracht hat. Sie befteht in dem Ueberziehen des Stahles mit Nickelmetall auf galvanoplaftifchem Wege, und hat den Vortheil, das Roften der Inftrumente zu verhuiten. Wie wichtig und praktifch diefe amerikanifche Erfindung für alle jene ftählernen Inftrumente fein mufs, welche viel mit Flüffigkeiten in Berührung kommen, bedarf wohl keiner näheren Begründung. Amerika, England, Frankreich und Dänemark ftellten faft lauter fo behandelte Inftrumente aus, wogegen die übrigen Staaten diefs nicht fo ausfchliefslich thaten.

Diefs vorausgefchickt, wollen wir nun die einzelnen Gegenftände nach Gruppen geordnet, welche ihre Anwendung betreffen, anführen.

\section{Männliche Sexual- und Harnorgane.}

Stricturen. Zur Erkennung und Behandlung von Harnröhren-Verengerungen mit Beihilfe des Auges hat bekanntlich fchon Déformeaux im Jahre 1865 das Endofkop erfonnen - im Wefentlichen aus einer Röhre und einem Beleuchtungsapparate beftehend. Collin (Frankreich) hat nun letzteren verein. facht, wodurch der ganze Apparat zwei wefentliche Vortheile erhielt, einmal hat er weniger Gewicht, und läfst fich demzufolge viel leichter handhaben, und ferner ift er viel billiger (135 Francs gegen 225) herzuftellen, wodurch möglicherweife die gröfsere Verbreitung diefer Unterfuchungsmethode gefördert werden könnte, da der Collin'fche Beleuchtungsapparat auch zu gleicher Zeit zu laryngofko. pifchen und otiatrifchen Unterfuchungen verwendet werden kann.

Zur Unterfuchung der Harnröhre und Blafe hat Collin einen fehr tompendiöfen Sondenapparat erdacht, welcher für die Praxis fich vielleicht empfehlen düifte. Nach dem Mufter der Trouffe a u'fchen Oefophagusfonde mit ElfenbeinKnopf hat er für die Harnröhre eine dünne elaftifche Bougie conftruirt, an deren Ende fich gröfsere oder kleinere olivenförmige Metallknöpfchen (nach der $\mathrm{C}$ a rrièr e'fchen Scala numerirt) ficher befeftigen laffen. Es ift wohl klar, dafs man damit fowohl Verengerungen der Harnröhre, als auch in einzelnen Fällen Blafenfteine erkennen kann, ja Coll in hat feiner Bougie auch zwei äufserft dünne Kupferdrähte eingefchaltet, auf dafs man elektrifche Ströme durchzuleiten vermöge.

Gummifonden neuer Art wurden von $\mathrm{Benas}$ und $\mathrm{Chofe}$ (Frankreich) ausgeftellt. Sie find mit Fifchbein-Stäben oder Bleidrähten im Inneren verfehen, wodurch fie mit Beibehaltung der Biegfamkeit und Weichheit eine gewiffe Refiftenzfähigkeit erlangen. Weiters fanden wir cylindrifche Gummikatheter mit fteifem Schnabel, dem die Mercie r'fche Krümmung gegeben ift. Dadurch, dafs der Schnabel ftarr ift, mag das Einführen diefer Katheter bei gewiffen Fällen von Proftatatumoren oder ftark entwickelter Valvule musculaire erleichtert werden. Den conifchen Gummikathetern ift eine fteife Spitze (Bleifüllung) angebracht, der die beliebigfte Form gegeben werden kann. Die Nelaton'fchen RingwürmKatheter aus weichem Kautfchuck find allgemein gekannt, neu ift aber eine Art conifcher Gummikatheter mit langem (Katheterlänge), dünnen und fpitzzulaufenden Conductor, der eine Fortfetzung des Kathederendes darftellt. Er bahnt dem Katheter den Weg, und rollt fich in der Blafe zufammen.

Zurinneren Urethrotomie fanden wir den bekannten, fo vorzüglichen Apparat vom Maiffonneuve (Frankreich), beftehend aus Leitbougie, daran anfchraubbarer, an den concaven Seiten gefurchten katheterförmigen Metallfonde und dem 
dreieckigen, an den Spitzen ftumpfen, und nur an den Kanten fchneidenden Mefferchen, das in der Sondenrinne lauft Es ift gewifs das befte und ficherfte Inftrument, welches bis jetzt zur inneren Urethrotomie erdacht wurde und das einzige, welches mit Sicherheit nur die verengten Stellen durchtrennt, die normalen Theile der Harnröhre dagegen nicht im geringften verletzt.

Einen neuen Stricturentrenner fanden wir in dem Dilatatore ad arco von Corradi (Italien). Eine fehr dünne gekrümmte und nur an der concaven Seite des Schnabels gerinnte Metallfonde, beherbergt im Inneren der Rinne einen dünnen, aber feften Metallfaden. Durch Schraubenwirkung läfst fich nun diefer fo weit hervorziehen, dafs er aus der Rinne vortritt, und fich endlich im Maximum der Spannung, wie die Sehne zum Bogen des Sondenfchnabels ftellt. Durch diefen gradatim fich anfpannenden Metallfaden foll die Strictur durchtrennt werden.

Zur rafchen Ausdehnung der Stricturen fanden wir nebft den bekannten Dilatatoren von Rigault, Voillemier, Reybard, Perrève, Holt, Berkeley Hill, Dittel und Thompfon und einigen Varianten diefer, die vielleicht weniger allgemein gekannten Inftrumente von Moreau Wolf (Frankreich) und von Corradi.

Unter dem Namen Divulfeur retrograde hat Dr. Moreau Wolf ein Inftrument conftruiren laffen, welches dem alten Wattmann'ichen Dilatator etwas ähnlich ift. Eine dünne Röhre ift in ihrer vorderen Hälfte durch fechs Längeneinfchnitte gefpalten, und beherbergt einen geknöpten Stab. So lange das Knöpfchen vorgefchoben bleibt, hat die Röhre allüberall den gleichen Durchmeffer, fo wie aber das Knöpfchen zurückgefchraubt wird, drängt es fich in das Innere der Röhre, und treibt die fechs Röhrenbranchen federnd auseinander, welche ihrerfeits die Strictur einreifsen follen. Das W a t tmann'fche Inftrument hat eine Röhre mit zwei Branchen, und der geknöpfte Stab wird zurückgezogen. Beim Morea u'fchen find fechs Branchen und der Stab wird zurückgefchraubtDiefs der wefentliche Unterfchied.

Dr. Corradi's Dilatatore a corona ift eine Metallfonde, welche an ihrem Ende, quafi als Conductor, eine Reihe beweglich mit einander verbundener und im Durchmeffer allmälig abfallender Metallkügelchen (rofenkranzähnlich) auffitzen hat. Die eminente Beweglichkeit diefes konifchen Gliedertheiles foll die Einführung in die Strictur, wenn ftärkere Deviation vorhanden ift, aufserordentlich erleichtern. Eine Reihe von Röhren verfchiedenen Kalibers, welche fcheidenartig fich über den Conductor fchieben laffen, follen die weitere Dilatation ermöglichen.

Die Idee zu diefem Inftrumente ift wohl dem Oesophagus dilatator von Trouffeau entlehnt worden, den wir, obwohl nicht neu, dennoch im betrefien. den Capitel anfithren wollen, um diefen Ausfpruch zu begründen.

Zur Entfernung fremder Körper aus der Harnröhre hat M at hi e u (Frankreich) eine Zange conftruirt, welche vor den bis jetzt gebräuchlichen, namentlich vor der Pitha'fchen, einen grofsen Vorzug hat. Sie läfst fich nämlich in jeder Tiefe der Harnröhre anftandslos öffnen, was bei den bis jetzt tublichen Zangen aus dem Grunde nicht der Fall fein konnte, weil fie nach Scheerenart conftruirt waren und das Oeffinen der Zange ganz unmöglich wird, fobald man diefelbe in einer Tiefe von mehr als zwei Zoll einführt. Bei der M a th i eu'fchen Zange ift das Oeffnen der Blätter gleich möglich, ob man nun knapp hinter dem Orificium oder am Bulbus urethræ zu arbeiten hat. Das Schlofs ift zwei Centimeter hinter dem Zangenende angebracht, und die Blätter öffnen fich durch Gleiten der Branchen übereinander und durch Hebeldruck.

Zum Durchtrennen von Proftatatumoren hat Mércier (Frankreich) ein Inftrument anfertigen laffen, welches einem kleinen Steinzertrümmerer der Form nach ähnlich conftruirt ift. Man foll zwifchen den Branchen - eine wird in die Blafe gebracht, während die andere vor der Proftata bleibt - den Tumor faffen und es durch ein verftecktes, von der männlichen zur weiblichen Branche fich bewegendes Mefferchen durchfchneiden. In Paris foll ein Chirurg mit dem 
Inftrumente an fich felbft diefe unangenehme Operation eigenhändig ausgeführt haben.

Medicamenten. und A etzmittel-Träger für die Harnröhre. Um medicamentöfe Stoffe an einem beftimmten Punkte der Harnröhre - gewöhnlich am proftatifchen Theile - wirken zu laffen, find Inftrumente von Ditt el (Oefterreich) und Garreau (Frankreich) angegeben worden. Beide find einander fehr ahnlich, und beftehen aus einem vorne offenen Katheter, in dem fich ein Mandrin, der vorne einen dickeren Knopf trägt, bewegt. Der Katheter wird bis zur erkrankten Partie vorgefchoben, und der Mandrin entfernt. In die Lichtung des Katheters bringt man nun das mit Butyrum de Cacao - in Stäbchenform gebrachte Medicament und fchiebt es fofort mit dem Mandrin in die Harnröhre, worauf der Katheter wieder entfernt wird.

Eine Modification des Lalle m an t'fchen Aetzmittel-Trägers hat M a thi e u conftruirt. Das Inftrument befteht aus einem kleinen filbernen Troge der mit einem Mandrin verbunden, aus dem vorne abgeftutzten Katheter vorgetrieben werden kann. Es unterfcheidet fich von dem Lalle mant'fchen und den übrigen bisher bekannten und ähnlich gebauten Inftrumenten durch den Umftand, dafs der Trog im Katheder gedreht werden kann, und man fomit entweder im Kreife herum ätzen oder beliebige Punkte der Harnröhre intenfiver zu treffen vermag. Es führt den Namen: Porte caustique courbe à chaine rotative.

Steinzertrümmerung. Zur bequemen Ausführung der Steinzer trümmerung, welche wohl vielfach von der Lage des Patienten abhängig if, hat Réliquet (Frankreich) ein Geftell erfonnen, welches leicht transportirbar und leicht überall - auf jedem Bett und jedem Tifch - anwendbar ift. Es ftellt eine der Form der hinteren Kreuz- und Beckengegend eines Erwachfenen ent. fprechend geformte fattelähnliche Platte dar, welche auf einem feften Geftelle ruht. und der man durch Schraubenwirkung zweierlei Bewegungen mit grofser Leichtigkeit und Rafchheit geben kann.

Die Platte läfst fich einerfeits heben und fenken, und ferner nach rechts oder links beliebig fchief ftellen. Wenn auch der Patiént auf der Platte ruht, vermag der Operateur felbft, mit einer Hand leicht die Stellungen zu ändern, ja er kann fogar durch rafche Drehung eine fo plötzliche Stellungsänderung erzielen, dafs das Becken eine Erfchuitterung erfährt, und dadurch der Stein zwifchen die Branchen des früher eingeführten und geöffneten Steinzertrümmerers getrieben werden kann. Wenn wir auch hievon keinen befonderen Vortheil erwarten, fo können wir doch die Zweckmäfsigkeit diefes Apparates nicht leugnen, da jeder Chirurg die Erfahrung gemacht haben dürfte, dafs die Beckenftellung des Kranken bei der Steinzertrümmerung von der gröfsten Bedeutung ift, und es fehr erwünfcht ift, ohne Deplacirung des Kranken diefelbe beliebig ändern zu können.

An Steinzertrimmerungs-Inftrumenten ift mehreres Neue geliefert worden, und zwar fowohl beztiglich der Branchen als auch bezüglich des Schloffes. $\mathrm{R}$ eliquet hat klein gefenfterte weibliche und ftark gezähnte männliche Branchen angegeben. Die Zähne der letzteren paffen genau in die Fenfter der erfteren. Es hat diefe Einrichtung den grofsen Vortheil, dafs Steinfragmente unmöglich zwifchen den Branchen verbleiben und das Schliefsen des Inftrumentes hindern können. Die kleinen Fenfter laffen der weiblichen Branche mehr Feftigkeit, als der bisher iibliche grofse Ausfchnitt. Die fcharfen Zähne zerdrücken leichter den Stein und die Fragmente müffen, weil durch die Fenfter getrieben, viel kleiner ausfallen. Eine andere Vorrichtung um das Steckenbleiben der Fragmente beim Ramaffeur zu verhindern, ift durch die fogenannte Bague glifiante gegeben worden: eine breite Metallfeder, welche die weibliche Branche des Ramaffeur ausfegt, bevor die männliche fchliefst. Eine dritte Modification ift der Brife piérre a languétte mobile von Mathieu. Am Ende der weiblichen Branche ift mittelft eines Charniergelenkes ein dünnes, bis zum Buge reichendes, planes Metallplättchen angebracht, welches bei geöfinetem Inftumente vorhangartig die Aushöhlung der 
weiblichen Branche deckt und erft beim Schliefsen durch die männliche Branche in die Aushöhlung hinein gedrückt wird. Beim Wiederöffinen fchnellt die Metall. zunge durch die eigene Elafticität aus ihrer Zwinge wieder hervor und ftellt fich in ihre natürliche Lage zurück. Begreiflicherweife werden dadurch auch alle gefafsten und zerdriickten Steinfragmente herausgefchleudert und der jederzeit genaue Verfchlufs des Inftrumentes gefichert.

A m uff a t (Frankreich) hat unter demNamen lithoclaft a mouvements latéraux ein Steinzertrümmerungs-Inftrument angegeben, bei dem das vesicale Ende der männlichen Branche gewiffe feitliche Bewegungen zum Auffuchen von Steinreften auszuführen vermag, während für gewöhnlich diefe Branche durch einen Sperrkegel fixirt gehalten wird.

An Schlofsvorrichtungen fanden wir neben dem alten Ecron brifé mit Drehfcheibe von Léroy d'Etiolles und dem Pignon von Charrière die neueren, viel zweckmäfsigeren und bequemeren Einrichtungen zum Oeffnen und Schliefsen der gebrochenen Schraube, und zwar:

a) Die Druckfchieber.Vorrichtung von Thompfon (England). Das Vorfchieben des Knopfes fchliefst die Schraube, das Zurtickfchieben öffnet fie.

b) Die Umlegbalken-Vorrichtung von Colli n (brifepièrre à bascule). Vor- und Rticklegen des kleinen Balkens fehliefst und öffnet die Schraube ähnlich dem Thompfor'fchen Mechanismus.

c) Die Hebelvorrichtung von Déformeaux (Frankreich). An der unteren Seite der Trommel ragt ein Hebelarm vor. Schliefst man das Inftrument. welches man ja beim Operiren an der Trommel hält, fefter in die Hand, was unwill. kürlich der Fall ift, wenn man das Gefühl bekommt, den Stein gefafst zu haben, fo drückt man nothwendigerweife auch den Hebelarm und fchliefst die Schraube; ein Nachlaffen des Druckes genügt, um letztere wieder zu öffnen. Für geübte Operateure wie der Erfinder mag die Einrichtung fehr zweckmäffig fein, weniger geübte dagegen, oder Operateure, die nit Inftrumenten anderer Syfteme umzugehen gewohnt find, dürften wenigftens im Anfange die Schraube oft unzeitig fchliefsen.

Erwähnenswerth ift endlich der von Collin erdachte und mit bewunderns. werther technifcher Vollkommenheit ausgeführte Brife piérre portant une fcie fur fon bec male. Der gefafste Stein wird durch eine ftarke Kettenfäge ähnlich wie durch ein $\mathrm{He}$ in e'fches Ofteotom nach und nach durchfägt.

Zum Auspumpen der zertrümmerten Steinfragmente hat $\mathrm{Ma}$ a fonne uve (Frankreich) ein finnreiches Inftrument erdacht. Die Procedur des Auspumpens der Fragmente ift bei gut functionirender Blafe nicht abfolut nothwendig, die Frag. monte, wenn hinlänglich klein, gehen bekanntermafsen nach und nach mit dem Urin ab, bei etwas paretifcher Blafe jedoch geht der Urin allein ab und der Detritus verbleibt. Für folche Fälle ift das Auspumpen nach der Lithotripfie unumgänglich nothwendig, denn das Ausräumen mit dem Ramaffeur ift eine ebenfo inhumane als gefährliche Procedur, da hiebei die Urethral-Schleimhaut vielfach verletzt und zerriffen wird. Das $\mathrm{M}$ a i s o n n e u v e'fche Inftrument befteht aus einem weiten Katheter mit grofsem Fenfter, einer Pumpe und einem dazwifchen eingefchaltenen Glasrecipienten, der einerfeits das Ende des Katheters und anderfeits das Anfatzrohr der Pumpe aufnimmt. Der Katheter ragt frei in den Raum des Recipienten bis etwa zu deffen Mitte hinein.

Die Pumpe aspirirt mit einiger Gewalt Blafenfluffigkeit in den Recipienten und treibt fie unmittelbar darauf dahin zurïck. Durch die zurückgetriebene Flüftigkeit wird der ganze Blafeninhalt aufgewirbelt, und das zweite Einpumpen wird fchon Fliiffigkeit und Detritus in den Recipienten einfaugen. Hier angelangt finkt der Detritus vermöge der gröfseren Schwere zu Boden und die Flüfigkeit allein wird zurückgetrieben. So wird nun fortgepumpt bis der Recipient vie! Detritus am Boden zeigt.

Chwat (Rufsland) hat eine Vorrichtung zu gleichen Zwecken erfonnen, welche der von Dittel angegebenen faft analog ift. Ein dicker Katheter hat am 
Veficalende eine fchräge und fehr weite Offinung (Fenfter), die beim Einführen des Inftrumentes durch einen Obturator mittelft Mandrin gedeckt wird. An der Handhabe des Katheters befindet fich ein rechtwinklig abgehendes mit dem Katheter communicirendes Rohr, welches mit dem Schlauch eines Irrigators verbunden wird. Aus diefem fliefst das Waffer ohne Unterbrechung in die Blafe, fobald der Operateur die axiale Katheteröffnung mit dem Finger verfchliefst, und es entleert fich, Steinfragmente mitnehmend, aus der Blafe, fobald der Kautfchuk. fchlauch gefchloffen und der Finger von der Kathetermündung entfernt wird. Dittel's Inftrument hat bekanntlich einen Verfchlufshahn, der den ftopfenden Finge: erfetzt. Endlich hat L e it e r (Oefterreich) einen Katheter à double courant verfertigt, deffen Einfpritzcanal eng und deffen Abflufsrohr fehr weit ift; eine Nachahmung des Reliquet'fchen Inftrumentes, nur mit dem einzigen Unterfchiede, dafs letzteres nur eine kurze Abflufsröhre, die nur wenige Zoll tief in die Harnröhre reicht, befitzt, während beim Leiter'fchen Katheter $\mathrm{Zu}$ - und Abflufsrohr die gleiche Länge befitzen. Die Idee und das Wefen des Apparates find jedoch bei beiden ganz identifch.

Zum Zertrümmern von in der Harnröhre fteckenden, gröfseren Fragmenten hat $\mathrm{Re}$ li que t einen brifepiérre uréthrale erdacht, welcherin derForm den feinerzeit von Segalas und Nélaton angegebenen etwas ähnlich ift. Die weibliche Branche ift eine ftellbare Curétte mit der das Fragment gefafst wird. Die männliche Branche fchliefst hierauf. und zerftückelt das Fragment mittelft eines vierblätterigen kleinen Perforativftückes, welches in ihr verborgen ift, und durch eine Schraube getrieben wird.

Mathieu hat zum Zertrümmern von Steinfragmenten in der Harnröhre ein Inftrument conftruirt, welches aus zwei in einander fteckenden Röhren und einem durch die Lichtung des inneren laufenden Perforativmandrin befteht. Jedes der Rohre ift zu einem[kleinen, aber feften hakenförmigen, ftumpfen Ende ausgezogen. Je nachdem man nun die innere Röhre um die halbe Axe dreht, ftellen fich beide Hacken entweder parallel einer hinter den andern, oder aber fie opponiren einander. Im gefchloffenen Zuftande, id est bei parallel geftellten Haken führt man das Inftrument bis zum, und wo möglich über das Fragment, opponirt fodann durch Drehen die Haken und fucht das Fragment zwifchen beiden wie durch eine Zwinge zu faffen. Wenn diefs gelungen, zerdrückt man es mittelit des Perforativmandrins.

Steinfchnit. Aufser den verfchiedenartigft geformten Leitfonden und Meffern find jene Apparate zu erwähnen, welche, obzwar fehr alt, dennoch in neuerer Zeit wieder aufgefucht wurden, und welche ungeübten Händen dazu ver. helfen follen, beim Perinealfchnitte wirklich die Harnröhre zu treffen und zu öffnen. Sie beftehen im Allgemeinen in troisquartähnlichen gefurchten Wegweifern, welche ohne Hinzuthun des Operateurs zur Leitfonde fuhren und ihm den Weg angeben follen, den er mit dem Meffer zu durchwandern hat. Die Apparate haben zwei verfchiedene Typen, entweder wird der Wegweifer von der Leibfonde aus durch das Mittelfleifch durchgeftochen, alfo von innen nach aufsen, oder er wird von aufsen durch das Mittelfleifch zur Leitfonde gebohrt, fomit von aufsen nach innen. Ein Mufter der erften Art ift derApparat von Mércier. Die Leitfonde ift faft bis zum Buge katheterförmig gehöhlt, und bekommt erft im Schnabeltheile die untere Hohlrinne. Sie beherbergt in ihrem Innern eine gefurchte Pfeilfonde, welche, fobald die Leitfonde regelrecht eingefürt wurde, herausgeftochen wird, und am Mittelfleifche zum Vorfcheine kommt. Das nun in die Rinne der Pfeil. fonde eingefetzte Meffer wird einfach hineingefchoben, es gelangt mit Sicherheit in die Furche der Leitfonde und trennt die Harnröhre.

$\mathrm{Smith}$ in Baltimore hat ein Inftrument der zweiten Kategorie angegeben. Bei diefem artikulirt die Pfeilfonde mit einer gewöhnlichen Leitfonde knapp unter dem Griff. Ift die Leitfonde in die Blafe gebracht, fo bohrt der Operateur die Pfeilfonde von aufsen her in das Mittelfleifch, bis fie die Rinne der Leitfonde erreicht, fetzt fodann das Meffer in die Rinne der Pfeilfonde an und fchiebt es hinein. 
Ein diefem ganz identifches Inftrument, angeblich von $\mathrm{K} l$ ein, findet man in alten chirurgifehen Rüftkammern.

Zur mechanifchen Dilatation des Blafenhalfes von der Perinealwunde aus hat Dolbe a u (Frankreich) ein nach allen Seiten hin gleichmäfsig wirkendes Dilatatorium angegeben. Es hat Aehnlichkeit mit einer Hand mit aneinandergelegten Fingerfpitzen. An ein kleines Plateau find circa 8 oder 1o allmälig fich zufpitzende Metallzungen mittelft Charnieren verbunden. Ein Kautfchukband hält alle Zungen mit ihren Spitzen convergirend an einander, die zufammen etwa die Dicke einer Bleifeder haben dürften. So wird das Inftrument durch die Perinealwunde in den Blafenhals hineinzwängt, und nun drängt man mittelft einer Schraube einen kleinen Stempel zwifchen die Metallzungen hinein, welche auf diefe Weife beliebig ftark auseinandergetrieben werden.

Alle anderen Dilatatorien, die ausgeftellt wurden, find Varianten des alten Pajola.

Lithoklaften will ich im Allgemeinen alle jene Inftrumente nennen, welche den $Z$ weck haben, nach gemachtem Blafenfchnitte den etwa zur Extraction zu grofsen Stein in der Blafe in Stücke zu brechen. Alle diefe Inftrumente werden demnach von der gefetzten Blafenfchnitt-Wunde aus eingeführt und unterfcheide ich fie infoferne von den Lithotriptoren. In der neueren Zeit, wo man den Schnitt felten bis in den Blafenhals hin ausdehnt, fondern wo man nur den membranöfen und einen Theil des proftatifchen Abfchnittes der Urethra durchtrennt, und den letzten oder hinterften Theil des proftatifchen Theiles fammt dem Blafenhalfe ftumpf erweitert, find auch die Lithoklaften häufiger zur Anwendung gekommen, als diefs in einer früheren Zeit der Fall war, wo man den Schnitt bis in die Blafe fortfetzte.

Néla to $\mathrm{n}$ hat zwei Arten von Lithoklaften angegeben, feine ténétte a préffion ftellt eine ftarke mit Levret'f chem Schlofs - damit man jeden Arm ifolirt einfuhren könne - verfehene Zange dar, deren Branchen in je zwei ftarke, gabelförmig divergirende, fcharf geränderte und fpitze Ausläufer endigen, und deren Griffe durch einen Schrauben-Querbalken mit grofser Kraft fich nähern laffen, um den gefafsten Stein zu zerdrücken.

Für gröfsere und härtere Steine dient fein Forceps brise-pièrre, eine ftarke, ebenfalls mit Schrauben-Querbalken ausgeftattete Zange, die einen axial gleichfalls durch Schraubenwirkung fich bewegenden Bohrftab mit kurzem und fcharfem Dreizack trägt. Der gefafste Stein wird theils durch Druck der Zangenarme, theils durch die fprengende Wirkung des Bohrers zerftückelt. Modificationen diefer Steinzerdrücker gibt es mehrere.

Maifonneuve hat folgenden Lithoklaft erdacht. Ein gerader etwa ring fingerdicker, ausgehöhlter Metalliftab endigt mit einem fchwach löffelförmig gewölb. ten, innen rauhen und zu einem Viertelkreis-Bogen gekrümmten Schnabel. Er imitirt die weibliche Branche eines Lithotriptors. In der Cilindrifchen Aushöhlung des geraden Theiles der Branche bewegen fich zwei concentrifch ineinandergefchachtelte, ftarke Metallftäbe. Der äufsere ift hohl und hat im ganzen Umkreife des vorderen Endes fägeförmige Zähne; der innere ift maffiv und endigt mit einer vierkantigen Spitze und ausgehöhlten Flächen (bajonnetartig). Bei der Anwendung führt man zuerft die weibliche Branche ifolirt an der Leitung des Fingers in die Blafe ein und umfafst damit den Stein. Hierauf fchiebt man die in einander gefchachtelten Stäbe bis zum Steine vor, und klemmt ihn damit ein unter Zuhilfenahme einer Schraube. Das Perforativftück, welches durch Schraubenwindung im hohlen Cylinder fich bewegt und beim Einführen darinnen verborgen war, wird nun vor und in den Stein eingefchraubt. Man bohrt mit Leichtigkeit das Perforativftück tiefer und tiefer ein und bricht damit in den meiften Fällen den Stein. Sollte diefs der Härte des Steines wegen nicht erfolgen, fo hört man mit dem Schrauben des Perforativftiickes auf, und beginnt den Cylinder gleichfalls durch Schraubenwirkung vorzudrängen. Da nun der Cylinder einen gröfseren Durch. 
meffer befitzt als das Perforativftück, fo tritt die Wirkung des Keiles ein und der Stein wird hiedurch gefprengt. Der Bug der weiblichen Branche mufs aber aus. nehmend gut und ftark gebaut fein, denn er mufs, falls der Stein beträchtlich hart ift, oft einen enormen Druck aushalten.

Ueber Steinzangen ift wenig Neues $z u$ berichten; dafs die eine fchärfer gezahnt, die zweite mehr flachgekrimmte Branchen und die dritte ein verfchieb. bares Schlofs behufs grörserer Parallelftellung hat, find längft bekannte Modificationen.

Entfernungfrem der Körper aus der Blafe. Frankreich zeichnet fich in der Varietät genial erdachter Inftrumente diefer Kategorie aus. Es würde wohl zu weit führen, alle die hieher gehörigen Objecte zu befchreiben. Es genüge zu erwähnen, dafs zwei Ideen dabei vertreten find. Nach der einen bezweckt man den fremden Körper - der meiftens ftabförmig ift - mit dem Inftrumente zu faffen. ihn, falls er quer gefafst wurde, axial mit dem Inftrumente zu ftellen und fo zu entfernen, nach der anderen will man den quer gefafsten Fremdkörper entweder, falls er weich ift, biegen und doppelt zufammengelegt extrahiren, oder, falls er hart und fpröde wäre, zerbrechen. Die Inftrumente befitzen zur Erreichung der ge. dachten $Z$ wecke die verfchiedenartigften Mechanismen.

Zum Blafenftich hat Dittel eine einfache Einlagecanüle aus weichem Kautfchuk angegeben, die an ein Stativ befeftigt ift, welches feinerfeits an der Symphyfe feftgegurtet wird. Das obere Ende der Canẗle hängt mit einem doppel fchenkeligen Rohre zufámmen, an deffen zweitem Schenkel ein Abflufsfchlauch feftgemacht wird und heberartig wirkt. Diefer Apparat kommt nattirlich erft zur Anwendung, wenn die Stichwunde granulirt und die Gefahren der Urininfiltration voriber find. Er erfetzt alfo die Fleurant'fche Doppelcanüle durchaus nicht und ift blofs beftimmt, dem Kranken das ftete Liegen im Bette zu erfparen und die Blafe weniger zu reizen.

Unter dem Namen D y n a mo meter vefical hat Mallez (Frankreich) ein Inftrument angegeben, deffen Zweck ift, die Kraft des Harnftrahles bei atonifchen Zuftänden der Blafe zu prïfen. Ein Sperrhahn-Katheter hat zu diefem Behufe ein kleines Anfatzftïck, welches im Innern eine bewegliche Platte an einen federnden Stift verbunden birgt, der den Zeiger eines Kraftmeffers bewegt. Die Scheibe des Kraftmeffers hat eine Scala mit der Eintheilung nach Grammen. Bei geöffnetem Hahn drïckt natïrlich die Flüfligkeitsfäule mittelft der Platte auf den Stift und diefer weift durch den Zeiger den Druck in Grammen aus.

\section{Weibliche Sexualorgane.}

S pecula. Nebft den altbekannten Vaginalfpiegeln fanden wir den neuen fo vorziiglichen Scheidenfpiegel von $\mathrm{Cusco}$ (Frankreich), Speculum a bec de canard. Beim Oeffnen divergiren deffen vorderes und hinteres entenfchnabelförmiges Blatt blofs an ihrem freien Ende, während die vorderen, mit einander durch einen Ring verbundenen Endtheile keine Durchmeffervergröfserung eingehen. Hiedurch wird der Scheideneingang, als der empfindlichfte Theil, nicht gezerrt und das durch Schraubenwirkung oder Hebeldruck (zwei Varianten) erweiterte Speculum dilatirt ad maximum den Scheidegrund, ftellt den Muttermund ohne weiteres Zuthun ein, und fixirt fich derart, dafs er vom Operateur nicht mehr gehalten zu werden braucht. Durch die Erweiterung und Anfpannung des Scheidengewolbes wird auch der Uterus tiefer herabgezogen und zugänglicher gemacht. Spéculum trivalve échancre von Démouy (Frankreich) nennt fich ein dreiblat tiger Scheidenfpiegel, deffen eine Branche an beiden Enden je einen tiefen und weiten Ausfchnitt befitzt. Er foll das Touchiren mit den Fingern erlauben, ohne hiezu das Entfernen des Spiegels nothwendig zu machen. 
Unter den fpatelförmigen Scheidenfpiegeln nehmen die von Sims angegebenen den erften Platz ein. Sie find wie bekannt löffelförmig. Collin und Mathieu haben daran zwei bewegliche Parallelftäbe angebracht, welche die Länge und Krümmung der Spatel befitzen. Aufgeftellt drängen fie die Seitenwände der Vagina auseinander, fpannen dadurch die obere Wand derfelben und treiben fie auch in die Höhe. Es wird dadurch zu den nöthigen Manipulationen bei Fifteloperationen mehr Platz gewonnen.

Zur Erweiterung des Muttermundes und des Gebärmutter-Halfes fanden wir aufser den Einlagfäben für Laminaria und Prefsfchwamm, den Dilatateur utérin von $\mathrm{P}$ a j ot (Frankreich). Zwei dïnne, in ihrer Mitte artikulirende und in ein hölzerner Handhabe vereinigte Metallftäbe tragen an ihren Enden je ein doppelt knieförmig gebogenes und lang auslaufendes, kleines unả gehöhltes Speculumblatt. Eine Schraube am Handgriffe erlaubt die Entfernung der Blätter von einander. Das Inftrument wirkt ähnlich einem zweiblätterigen Ohrfpiegel und erweitert den Mutterhals nach Bedarf.

Zur Hyfterotomie waren nebft den artikulirten Meffern von Sims mehrere Modelle des Hyfterotome cachè ausgeftellt, die im Mechanismus dem Oefophagotome von Trélat ganz analog conftruirt find und in einem Tempo die doppelte Incifion des Muttermundes erlauben, von Greenholg u. A.

Um dem Muttermunde Blut zu entziehen haben Collin und Mathieu ein Inftrument erdacht, welches einem blutigen Schröpfkopfe ähnlich wirken foll. Der Scarifateur ift ein runder Schröpfftock, der an einem längeren Stiele befeftigt ift und einen Hebel zum Losdrücken der Klingen befitzt. Der gläferne Schröpfkopf ift durch einen langen Glascylinder imitirt, welcher oben offen, unten gefchloffen ift. Die Metall-Verfchlufsplatte verlängert fich trichterartig zu einem Rohre, das mit einem Sperrhahne verfehen ift und mit einem Kautfchukfchlauche verbunden werden kann.

Nach gemachter Scarification wird der Muttermund im Glascylinder aufgenommen und nun wird mittelft einer Saugpumpe, die man mit dem Kautfchukrohr in Verbindung bringt, im Cylinder der luftverdïnnte Raum erzeugt.

Diefer Apparat wirkt jedenfalls viel intenfiver als Blutigel oder einfache Scarificationen. Dafs man durch alleinige Benïtzung des Glascylinders auch den trockenen Schröpfkopf imitiren könne, ift wohl klar, anders ftellt fich freilich die Sache, wenn man dabei die Nützlichkeitsfrage in Betracht zieht.

Injectionsapparate für die Gebärmutter-Höhle haben wir zwei gefun. den. Die kleine Spritze mit Uterinrohr von B raun (Oefterreich) und den Injecteur intra uterin von Blatin (Frankreich). Letzteres ift ein langes Uterinrohr an deffen Ende ein kleiner Kautfchukballon angebracht ift, ähnlich dem Pulverbläfer für den Kehlkopf.

Zur Abtragung der portio vaginalis uteri hat Collin eine Doppelguillotine conftruirt. Zwei gekrümmte und ihre Concavität einander zukehrende, fcharf gefchliffene Mefferklingen find an ihren oberen Enden mit einander verbunden, während jedes der unteren Enden mit den Branchen einer fcheerenartig gebauten Zange artikuliret.

Oeffnet man die Zange, fo entfernen fich die Meffer von einander und bilden einen nach Belieben weiteren oder engeren Bogen. In diefen wird der Mutterhals gefafst, und durch Schliefsen der Zange concentrifch abgetragen. Der Operateur ift im Stande das zu entfernende Stück der portio vaginalis genan abzumeffen, und kommt nie in die fatale Lage mehr wegzunehmen, als er eigentlich gewollt hatte.

Was die Mächtigkeit der Guillotine anbelangt, fo kann man mit dem Inftrument ein fechsfach zufammengelegtes, dickes Tuch oder Lederftück anftandslos und fcharf durchfchneiden.

Cauterifation des Muttermundes. Hiezu hat Nélaton feinen wohl allgemein bekannten Gasbrenner, und einen Vaginalfpiegel mit Doppelwandung, Zu- und Abflufsrohr angegeben. Bei der Cauterifation wird durch den Wandraum 
des Spiegels mittelft der Rohre ein continuirlicher Strahl kalten Waffers durchgeleitet, damit die Vaginalwandungen und deren Umgebung durch die Glühhitze der Gasflamme nicht leiden.

Uterusträger. An Peffarien fanden wir neu die Hebelpeffarien von Aluminium von $\mathrm{H}$ o d g e (England) und einen Peffarienträger von Si m s (Amerika), welcher dazu dient, das Peffarium richtig einzulegen: ein etwas gekrümmter Metallftab mit einer Aushöhlung an der Spitze und einem Haken am Körper. Zwifchen beiden wird das Peffarium der Länge nach gefafst und gehalten. Uterus. träger, die am Becken befeftigt werden, und vom Mittelfleifche aus in die Scheide hineinragen, hat $\mathrm{S}_{\mathrm{p}} \mathrm{i} 11 \mathrm{~m}$ ann (Amerika) ausgeftellt.

Ein gekrümmter Stab trägt einen oder zwei übereinander ftehende, horizontale, luftpolfterartig gebaute, gehöhlte Scheiben, welche von fchwachen Spiralfedern getragen werden. Die Elafticität und das Schwungvermögen diefer Hyfterophoren ift bedeutend, namentlich bei jenen Apparaten, die zwei Scheiben und demnach zwei Federfpiralen befitzen. Der Muttermund wird in die Aushöhlung der Scheibe gebracht, und der Uterus fomit fchwebend getragen.

Diefe Art Hyfterophoren haben zweifellos einen bedeutenden Vortheil vor den ftarren, da fie beim Gehen die Bewegungen des Uterus nicht auf brüske Weife hemmen, und demzufolge auch beffer und leichter vertragen werden. Es mag der Unterfchied beiläufig der fein, wie zwifchen einem federlofen Bauernwagen und einer gut federnden Sänfte.

Polypen des Uterus. Zum Faffen der Uteruspolypen ift von Robert (Frankreich) eine Zange conftruirt worden, welche mit fcharfen Spitzen das Neu gebilde zu faffen vermag. Jedoch fpringen die Spitzen erft im Momente des Faffens vor, fo dafs der Operateur bei der Handhabung fich nicht verletzen und die glatte Zange auch über das Neugebilde bis zu deffen Halfe unaufgehalten gleiten kann. Das Vorfpringen der Spitzen wird im nöthigen Momente mittelft Schubern bewerkftelligt, die an der Aufsenfeite jedes Zangenarmes laufen.

Ein ähnlich conftruirtes, und dasfelbe bezweckendes Inftrument hat auch Richet (Frankreich), angegeben. Zum ficheren und richtigeren Faffen von Neo. plasmen, deren Infectionsgrenzen nicht in einer und derfelben Ebene liegen, hat Greenhalgh (England) eine Pince a branches gliffantes ausgeftellt, bei der eine Branche im Schloffe verfchoben werden kann, nach vor- oder rückwärts, ohne ihr Faffungsvermögen im geringften zu alteriren. Die Zange ift im Uebrigen der Mufe a ux'fchen analog gebaut.

Zurkünftlichen Befruchtung finden wir den Fécondateur artificiel von Pajot (Frankreich). Ein etwa kielfederftarker Glascylinder ift in zwei Halbcylinder zerlegbar, welche auf einander fich verfchieben laffen. Zieht man den einen etwas zurück, fo bleibt der rinnenförmige Theil des anderen Halbcylinders prominent. Mit diefem fchöpft man nun wie mit einem Löffelchen im hinteren Vaginalgewölbe etwas von dort unmittelbar früher deponirtem Sperma virile auf, fchliefst den Cylinder, führt ihn fofort in die Uterushöhle ein, und prefst alldort den Inhalt durch Stempeldruck wieder aus.

Retrouterinal- Abfceffe. Zur Entleerung diefer hat Monat (Frank. reich) ein wohl unnöthiges Inftrument conftruiren laffen. Ein langer Troicart beherbergt in feiner Cannüle zwei Mefferklingen, welche durch eine Schraube zum Vorfpringen gebracht werden können. Die Troicartcannüle bedeckt den Stachel und erft beim Anlegen und Drücken wird der Stachel, indem die Cannüle etwas zurücktritt (Federwirkung), prominent, durchbohrt das Hindernifs, und wird gleich wiedervon der Cannüle umfafst, fobald diefes überwunden ift. Die ftumpfe Cannüle wird nun weiter vorgefchoben, und ift fie genügend tief, fo läfst man die Meffer vortreten und fchneidet im Zurïckziehen.

Veficovaginal. Fifteln. Befondere Einftellungsapparate haben wir nicht zu verzeichnen, dagegen müfen wir ein gut ausgedachtes Verfahren von Corradi erwähnen, welches die Auffrifchung der Fiftelränder betrifft. Dafs das 
Refultat der Operation von der exacten und correcten Auffrifchung fehr viel abhängt, und dafs diefer Act der Operation zu den fchwierigften gehört, ift woh! bekannt. Corra di erleichtert fich diefe Aufgabe folgendermafsen: Breitgedrückte. gekrümmte Heftnadeln ohne Oehrwerden von einem zum anderen Wundwinke der Fiftel in kurzen $Z$ wifchenräumen - möglichft nahe bei einander - durch beide Fiftelränder je doppelt durchgeftochen, fo dafs fie von jedem einen beliebig breiten und tiefen Saum umfaffen. Ift die Fiftel ihrer ganzen Länge nach derart mit Nadeln befpickt, fo fchneidet man mit einer eigens hiezu conftruirten Scheere. welche der Fläche nach gekrümmte Blätter hat, die Nadeln mit einem Schlage heraus. Um diefs ficherer und bequemer ausführen zu können, befitzt die Scheere an ihrer concaven Seite ein im gleichen Sinne gekrümmtes drittes, jedoch ftumpfes Blatt, welches in der Axe der Scheere gegen die Schneideblätter bewegt werden kann. Es dient zur Fixirung der Nadeln. Mit dem Herausfchneiden der Nadeln hat man natürlicher Weife auch die Fiftel in ihrem ganzen Umkreife wund gemacht.

Fiftelmeffer, Haken und Pinzetten der verfchiedenften Form, Nadelhalter und Näh-Werkzeuge aller Art find ausgeftellt worden. Es würde ohne Zeichnung fchwer möglich fein, über alle zu berichten; ich will nur das Näh.Werkzeug von Leroy d'Etiolles (Frankreich) anführen, welches die Nadel in einem Kreis. bogen bewegt und zum Nähen in der Tiefe fehr praktifch fein dürfte.

Ovariotomie. An Troicart's fanden wir nebft dem einfachen Hohl. troicart von Spencer Wells (England) und dem Stacheltroicart von Robert jene, welche Vorrichtungen befitzen um die Cyftenwand zu fixiren, und fowoh! deren Abrutfchen von der Troicartcannüle, als auch das Danebenfliefsen des Cyfteninhaltes zu verhindern, und zwar:

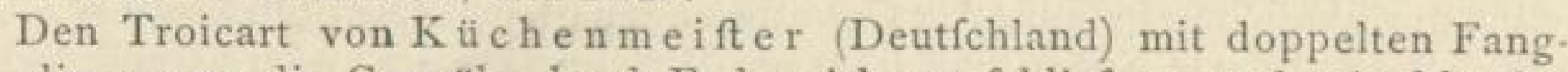
armen, die gegen die Cannüle durch Federwirkung fchliefsen, und mit fcharfen Spitzen verfehen find.

Den Troicart von $\mathrm{Collin}$ mit rafch fteigender Schneckenwindung und Schraubplatte. Nachdem er eingeftochen worden, dreht man den Troicart um die eigene Axe und windet die Cyftenwand rafch bis zur oberften breiten Schneckenwindung, allwo angelangt, fie zwifchen diefer und der Schraubplatte feftgeklemmt wird.

Den Troicart von $\mathrm{Pan}$ as (Frankreich) mit Stellfedern und Schubplatte. Aus der Troicartcannüle treten, nachdem es eingeftochen wurde, aus vier kleinen Fenftern vier Metallblätter hervor. Die Cyften wand wird zwifchen diefen und der Schubpla'te feftgeklemmt.

Den Troicart von Mathie u mit Teller und Luftballen. Vor der Abflufs. röhre trägt der Troicart eine tellerförmige Platte und unmittelbar vor diefer einen kleinen Kautfchukballon der leicht aufgeblafen werden kann und in diefem Zuftande fich knapp an den Teller anlegt. Bei der Anwendung wird der Troicart bis zum Teller in die Cyfte eingeftochen und hierauf rafch der Ballon aufgeblafen. Diefer klepmmt nun zwifchen fich und dem Teller die Cyftenwand ein.

Zum Faffen der Cyftenwände erwähnen wir die fehr brauchbare Plattenzange von Nélaton. Zwei runde, fcharf gerinnte und mit fechs fcharfen und durch. greifenden Spitzen - eine Platte trägt die ftark vorfpringenden Spitzen, die andere entfprechende Löcher - verfehene Zangen geftatten das fichere Faffen und Halten der Cyftenwand. An Klemmen fanden wir nebft der urfprünglichen Klemme von $\mathrm{S}$ pencer Wells und mehrfachen Modification derfelben, auch die Ecrafeur Kettenklemme. Ferner erwähnen wir als zur Ovariotomie gehörend die pince à amorcéllement, und die pince à cauterifation, beide von $\mathrm{P} e ́ a n$ (Frankreich). Erftere dient zum langfamen Zerdrïcken oder Zerbeifsen fefter Adhäfionen, um die Blutung zu vermeiden, letztere zur Application des Glüheifens an blutenden Stellen, wobei fie die Aufgabe hat, die zu cauterifirende Partie ficher zu halten und die Umgebung vor der Glühhitze zu fchützen. 


\section{Geburtshilfe.}

Geburtszangen waren gewifs reich vertreten. Wir fanden alle möglichen Varianten, felbft den Léniceps von Mat te i und deffen Modification von Ham on de Fresnay.

Neu und befonders intereffant find jedoch die zwei Forcipes à traction continuelle von Chaffagny (Frankreich) und Rouffel (Schweiz). Der in diefen Inftrumenten vertretene gemeinfame Gedanke der beiden Erfinder ift, die Entwicklung des Kindes nicht der Armeskraft und der Gefchicklichkeit des Operateurs zu überlaffen, fondern diefelbe einem continuirlich wirkenden, mechanifchen Zuge, welcher vom Operateur blofs geregelt wird, zu übertragen. Die Erfinder meinen, ihre Methode fuhre fchneller zum Ziele, wirke fchonender auf Mutter und Kind als das gewöhnliche Verfahren, und fie fetze auch den minder gewandten Geburts. helfer in die angenehme Lage, mit ficherem Erfolge und grofser Bequemlichkeit feines Amtes zu walten; ja fie geftatte die Exerese auch in jenen Fällen von bedeutenden Beckenverengerungen, wo bisher zu anderen Gewaltmitteln gegriffen werden mufste,

Die Componenten der Apparate find: Eine Geburtszange, eine Spange, die an einem feften Punkte am Körper der Kreifenden angelegt wird, und einer Schraube nebft Schnur, welche den conftant wirkenden Zug ausüben.

Chaffagny's Apparat ift der ältere und möge daher zuerft befprochen werden. Die Geburtszange hat nicht gekreuzte, fondern parallele Arme, welche ftatt dem Schloffe durch einen Querfab vereinigt werden, und an den Handhaben eine Fixirfchraube tragen. Die Krümmung und der Bau der Kopftheile der Zange find denen gewöhnlicher, gefenfterter Geburtszangen gleich. Die Stützftange ift ziemlich lang, hat gepolfterte Enden und trägt am Mittelpunkte eine gerade und rechtwinkelig, nach rückwärts abgehende Schraube, an der durch eine Handwelle ein kleiner Cylinder hinauf und herunter bewegt werden kann. welcher centralwärts einen Haken auffitzen hat. Diefe Stiitzftange wird der Kreifenden in der Geburtslage an den oberen Epiphyfen beider Unterfchenkel knapp unter der Patella angelegt; die Kniee bilden fonach bei $\mathrm{Chaffagny}$ die feften Punkte, welche die Traction auszuhalten haben. Der Zug felbft wird durch eine Schnur bewerkftelligt, welche einerfeits um beide Fenfter der Geburtszange gefchlungen, und anderfeits am Haken des Schraubencylinders feftgemacht werden. Die Schnitre müffen fo hoch oben eingreifen, denn hätten fie am Ende der Handhaben ihren Angriffspunkt, fo würde trotz der parallelen Arme der Kindesfchädel gequetfcht werden können.

Rouffel hat eine gewöhnliche, gefenfterte Geburtszange mit gekreuzten Branchen und eine Stützftange, welche dem Gefä́se der Kreifenden angepafst wird, und ftatt der langen Schraube eine kleine Schraubwelle mit Sperrvorrichtung trägt. Auch hier wird die Schnur um die Zangenfenfter herumgelegt und an der Welle befeftigt. Eine kleine Dynamometer-Vorrichtung gibt auch von der jeweilig angewandten Zugkraft genaue Kunde, ift aber infoferne überflitflig, als die Gröfse der Zugkraft ja nicht früher beftimmbar ift. Beffere Auskunft gibt jedenfalls die Welle oder Schraube nach der Kraft, mit der fie bewegt werden kann. So wie faft allgemein in der Chirurgie gibt auch hier das Gefühl des Operateurs den beften Dynamoter ab.

Der wefentliche Unterfchied beider Apparate ift demnach die Verfchiedenheit der Stütz- oder Angriffspunkte der Kraft; Chaffagny hat die Kniee, Rouffel die Sitzknorren dazu gewählt. Offenbar find letztere ftabiler als erftere, deren Stellung durch jede Bewegung der Kreifenden geändert werden kann. Ift der Apparat angelegt, fo foll man ohne Rückficht auf Wehen oder Wehenpaufen die Schraube wirken laffen, bis der. Widerftand grofs wird. Nun wird paufirt bis der in der Bewegung der Schraube gefühlte Widerftand fich verringert hat, worauf neuerdings bis zür Erreichung des früheren Widerftandes fortgefchraubt wird, 
So wird nun bis zum Durchfchneiden des Kopfes aus den Schamtheilen fortgefahren. Mögen die Geburtshelfer vom Fach ibber den. Werth der Traction continuélle ein Urtheil fprechen.

$\mathrm{K}$ e phalotribe fanden wir auch reichlich vertreten und kamen die von Braun, D ubois, Depaul, Valétte de Lyon u. A. m. zur Ausftellung, ferner der Kranioklaste von Simpfon (England), der Transforateur von $\mathrm{Hub}$ bert de Louva n (Frankreich), der Braun'fche Haken und der Embryotome und der Couteau embryotome von Jaquemier (Frankreich).

Von Forceps scie fanden wir zwei Exemplare, den einfachen von van $\mathrm{Huve}$, und den doppelten von Collin.

Das Inftrument von van $\mathrm{Huvel}$ ftellt einen gefenfterten Forceps dar. An der Innenfläche des einen Fenfterbalkens jedes Zangenarmes läuft eine Hohl rinne, welche eine Kettenfäge nebft einem Conductor aufnimmt. Bei gefchloffenen Armen geht' die Kettenfäge an einem Conductor längs der Rinne des Fenfterbalkens eines Zangenarmes hinauf, tritt dann aus der Rinne heraus, fetzt quer über den Innenraum des Forceps zum anderen Zangenarme hinüber und läuft hier angelangt, im zweiten Conductor längs der Hohlrinne des Fenfterbalkens diefes zweiten Zangenarmes wieder herab. An den Aufsenenden hat die Kettenfäge je einen kleinen Querbalken als Handhabe. Bei der Anwendung geht die Wirkung der Kettenfäge von unten nach oben, das heifst, vom Schloffe zur Abrundung der Zangenbranchen, und ift ihre Bewegung eine doppelte, einmal quer von einer Branche zur anderen, wodurch fie fagend auf den gefafsten Kindeskopf wirkt, und zweitens vertical von unten nach oben, was durch die Conductoren mittelft Schraube erreicht wird. Hiedurch vermag die Säge den Kindesfchädel vom Scheitel bis zur Bafis nach und nach entzwei zu trennen. Beim Forceps à double scie von Collin - einem Meifterwerke inftrumentaler Technik - ift der Mechanismus dem fo eben befchriebenen im Ganzen wohl ähnlich, nur find hier beide Fenfterbalken jeder Zangenbranche gehöhlt, und zwei Kettenfägen bewegen fich darin zu gleicher Zeit, und treffen am Ende der Hohlrinnen zufammen. Mit diefem Inftrumente fägt man demnach vom Kindesfchädel ein dreieckiges Stück heraus, deffen Bafis dem Scheitel, deffen Spitze dem Schädelgrunde entfpricht.

Vom rein inftrumentalen Standpunkte wäre noch zu erwähnen, dafs van $\mathrm{H}$ uvel feine Kettenfäge an der Hinterfeite des.Schloffes austreten läfst, während Colli in beide Sägen an der Vorderfeite der Griffe hat, ein Umftand, welcher das Sägen etwas erleichtern dürfte.

Endlich hat Mathieu die Idee der Van Huvel'fchen forceps fcie mit einem Kephalotribe vereinigt. Die Zangenbranchen find fchmal, nicht gefenftert und ftark gehöhlt, die Ränder fcharf. Die Kettenfäge bewegt fich in der Mitte der Aushöhlung, und die Handhaben des Forceps find unten wie alle Kephalotribe mit einer Schraubftock-Winde verfehen. Mit diefem Inftrumente kann man den Schädel des Kindes entzweifägen und die Hälften gleich zerdrüicken und auseinanderdrängen.

\section{Varia.}

Transfufion des Blutes. Zur Transfufion defibrinirten Blutes ift aufser verfchiedenen Glasfpritzen von Marti n u. A. der durch Luftdruck wirkende Apparat von Belin a zu erwähnen. Er befteht aus einem 150 Gramm haltenden Glascylinder von etwa 5 Centimeter Durchmeffer, welcher unten zu einer kielfeder. dicken offenen Spitze ausgezogen if, und feitlich knapp unter der Verfchlufsplatte ein rechtwinkelig abftehendes, kurzes Rohr trägt, welches durch einen Kautfchuk. ftoppel verfchliefsbar ift.

In diefen Cylinder wird das defibrinirte Blut eingefullt. Die Cylinderfpitze kommt mit einem Kautfchuckfchlauche in Verbindung, welcher die zur Einfuhrung in die Vene beftimmte Cannüle trägt. Das Blut wird aus dem Cylinder dadurch 
getrieben, dafs man durch das obere Rohr, nach Abnahme des Stoppels mittelft eines dafelbft eingepafsten doppelten Kautfchukballons Luft eintreibt. Diefe fam. melt fich zwifchen Blut und Verfchlufsplatte an, und ift fie genügend verdichtet, fo treibt fie allmälig das Blut aus dem Cylinder durch den Kautfchuckfchlauch in die Vene ein. Um den Lufteintritt in die Vene vor dem Beginne der Transfufion zu verhiiten, ift die Einfatzcannüle troicartähnlich gebaut, und zweifchenklig.

Der axiale Schenkel nimmt den Troicartfachel auf, der ftumpfwinklig angefetzte den Kautfchuckfchlauch des Cilinders. Vor der Anfetzung des Schlauches zieht man den Stachel foweit zurück, bis etwas Blut durch den Schlauchfchenkel aus der Vene herausrinnt. Hiedurch wird fämmtliche Luft aus der Cannüle herausgetrieben, zu gleicher Zeit läfst man durch den Schlauch etwas Blutflüffigkeit aus dem Recipienten ausrinnen, unmittelbar bevor man Schlauch und Cannüle mitfammen verbindet. Der Apparat fpielt, wie ich mich wiederholt zu überzeugen Geleheit hatte, vorzüglich, nur habe ich den Stachel des Troicarts durch einen vorne ftumpfen Stab erfetzen laffen, da ich es vorziehe, die Eröffnung der Venenwand mit der Scheere vorzunehmen. Noch wäre der Mantelüberzug für den Recipienten zu erwähnen, der die Beftimmung hat, jede Abkühlung des Blutes während der Transfufion zu verhüten. Er wird über den Recipienten gezogen, fobald diefer aus dem Wafferbade genommen wird, und ift an beiden Seiten der Länge nach gefpalten, damit man die Vorgänge innerhalb des Recipienten beobachten könne.

Ein leicht zu handhabender Apparat zur Transfufion ift von M a th i e u angegeben worden. Er befteht aus einem Glascylinder, welcher nach unten fpritzenformig gefchloffen ift, und oben einen weiten, mit einer Klappe und Ventilvorrichtung verfehenen Trichter trägt. Innerhalb des Cylinders bewegt fich mittelft einer gezähnten Pumpenftange ein genau fchliefsender Stempel. Ein Zahnrad fungirt als Motor. Die Pumpenftange ift ihrer ganzen Länge nach gehöhlt, und verbindet fich am Aufsenende mit einem Kautfchukfchlauche welcher die Einfatzcannüle trägt.

Das defibrinirte Blut wird durch den Trichter in den Cylinderraum gebracht, und hierauf, nach Entfernung der Luft mittelft Stempeldruck durch die Pumpenftange in den Kautfchuckfchlauch und weiter in die Vene getrieben.

Zur Transfufion nicht defibrinirten Blutes hat Dr. Rouffel aus Genf folgenden neuen Apparat angegeben. Ein kleiner Doppelrecipient aus Metall hat die Beftimmung an die Ellbogen-Beuge des Individuums aufgefetzt zu werden, der das Blut gibt. Er ift der Form nach ähnlich einem ovalen Glasfturze und beherbergt in feinem Innern zwei, von einander vollftändig getrennte Räume. Der kleinere Innenraum ift cylinderförmig und trägt eine Aderlafs-Lanzette an einem Stabe, welcher aus dem Dache des Recipienten herausragt, und einen Knopf trägt. Der Aderlafs wird im gegebenen Momente durch Herunterdrücken des Knopfes fchnepperartig gemacht. Mit dem Innenraume hängen zwei Kautfchuckfchläuche in Verbindung. Einer trägt am Ende einen Metallring als Befchwerer und foll unter Waffer geftellt werden, wir wollen ihn $a$ nennen, der andere $b$ erweitert fich in feinem Verlaufe zu einem kleinen Handballon, der als Pumpe dient, ift gegen fein Ende zu durch eine eingefchaltete kurze Glasröhre unterbrochen, und trägt die Einfatzcannüle. Der äufsere gröfsere Raum, zwifchen dem eben befchriebenen und der Recipientenwand gelegen, ift ebenfalls mit einem Kautfchuckballon in Verbindung, der den Zweck hat, die Luft dafelbft zu verdünnen, wodurch der ganze Apparat in der Ellbogen-Beuge des Blutfpenders durch Luftdruck feftgehalten wird. Hiezu ift deffen Rand der Form der Ellbogen-Beuge entfprechend, etwas wellenförmig gebaut, abgerundet und trägt zwei kleine Marken, welche mit der Richtung des Verlaufes der blutfpendenden Vene gerichtet fein müffen, damit die verborgene Lanzette diefe auch mit Sicherheit treffen könne.

Der Gebrauch diefes Apparates ift folgender:

Man prefst den Kautfchuckballon des Aufsenraumes zufammen, drückt den Recipienten mit Rückficht auf die Markenrichtung in die Ellbogen-Beuge, und läfst nun den Ballon aus; indem er fich wieder auszudehnen ftrebt, verdünnt er die 
Luft im Aufsenraume und der Recipient wird durch den äufseren Luftdruck in feiner Lage unverrückbar feftgehalten. Da der cylindrifche Innenraum mit feinem Rand das gleiche Niveau mit jenem des Recipienten einhält, und fomit der Haut der Ellbogen-Beuge knapp und genau anliegt, bleibt diefer von der Luftverdünnung ausgefchloffen. Nun wird die Luft aus diefem Innenraume und dem Kautfchukfchlauche dadurch ausgetrieben, dafs mittelft des im Abfchlufsrohre $b$ eingefchalteten Handballons laues Waffer durch die Röhre $a$ in den Innenraum und die Röhre $b$ eingefogen wird, bis es durch die Einfatzcannüle herausfpritzt. Ift fomit alle Luft forgfam ausgetrieben, fo drückt man auf den Knopf der Lanzettenftange und macht den Aderlafs. Durch fortgefetztes Pumpen treibt man das Waffer vollends aus, und Blut rückt nach. Rafch wird nun die Einfatzcannüle in die Vene eingebunden, oder auf eine zweite früher eingebundene Cannüle angefetzt, aus der man im felben Momente die Luft, durch Austretenlaffen einiger Tropfen Blutes ebenfalls austreibt. Es wird nun fort und fort gepumpt, bis die Transfufion beendigt ift, und hiedurch nicht defibrinirtes Blut von der Vene eines Individuums direct in jene eines zweiten getrieben. Die Menge des transfundirten Blutes wird aus der Anzahl der Zufammendrückungen des Pumpballons gemeffen, indem man früher leicht eruiren kann, wie viel Fluiffigkeit die einmalige Action der Pumpe austreibt Damit der Apparat nicht verfage, mufs er ausnehmend genau conftruirt fein, und namentlich mufs die Treibftange der Lanzette luftdicht der Dachöffinung des Recipienten anpaffen, damit nicht auf diefem Wege Luft in den Apparat während der Action gelange.

Da der Apparat neu ift, und mir fowohl als Anderen darüber jede Erfahrung abgeht, enthalte ich mich jeder kritifchen Beleuchtung, wofür es a priori viele Anhaltspunkte gehen dürfte. Rouffel foll damit in zwei Fällen die Transfufion mit glücklichem Erfolge ausgeführt haben.

Moncoq (Frankreich) hat zur directen Transfufion nicht defibrinirten Blutes einen Apparat erfonnen, welcher einer Klyfopompe nicht unähnlich ift. Man denke fich eine gläferne Klyfopompe mit zwei, mit Klappen verfehenen Abflufs röhren, an denen mittelft Kautfchukfchläuchen je eine Troicartcannüle hängt. Eine Cannüle kommt in die Vene des Blutfpenders, die zweite nach Austreibung der Luft in die Vene des zu Transfundirenden und die Klyfopompe faugt zuerft das Blut ein und treibt es dann wieder aus.

Inftrumentezur Blutftillung. An Pincetten, welche Vorrichtungen befitzen, um den Ligaturfaden über die Pincettenfpitze zu fchieben und die Fingernägel des Affiftenten zu erfetzen, find mehrere Varianten ausgeftellt worden. Doch nihil novi sub sole könnte man bei deren Betrachtung ausrufen, die alten Rüftkammer-Pincetten von Förfter, Paland, Blömer u. A. erfcheinen eben in frifcherer Adjuftirung und in zierlicherer Form. Neu, doch nicht befonders zweckmäfsig und auch gar nicht nothwendig, ift ein Apparat von Collin zur Unterbindung fehr kleiner Arterienäfte, die mit der Pincette fchwerer ifolirt zu faffen find. Bekanntlich hilft man fich in folchen Fällen dadurch, dafs man eben etwas mehr Nachbargewebe mitfafst und dann den ganzen Kegel unterbindet. Ganz dasfelbe leiftet der Collin'fche Apparat. Ein kleiner, konifch zulaufender Cylinder, einer kleinen konifchen Trepankrone nicht unähnlich, birgt einen feinen centrifch verlaufenden Stab, der an feinem Ende zwei divergirende kleine Häk. chen auffitzen hat. Eine Feder drückt den Stab vor und dreht ihn zugleich ein paar Mal um die Axe; vorgelaffen fchnellt der Stab von felbft zurück. Der Cylinder wird der blutenden Stelle aufgefetzt und nun der Stab vorgedrückt. Er fafst das Gewebe, dreht es um die Axe, und fpannt den Kegel durch fein Zurück. fchnellen. Ein Ligaturfaden wird nun längs des konifchen Cylinders zum Kegel geleitet und letzterer unterbunden.

Afpirateure find Apparate, welche, wenn auch nicht neu, doch erft in der neueren Zeit in der operativen Chirurgie eine grofse und früherkaum geahnte Verbreitung gefunden haben. Man wendet fie bekanntlich zu diagnoftifchen oder 
zu therapeutifchen Zwecken an. Die Apparate, nach dem Syfteme der Pumpen conftruirt, beftehen im Allgemeinen aus einem feinen Troicart und einem damit verbundenen Pumpwerke. Bei ihrer Anwendung wird der luftvefdünnte Raum entweder während der Action felbft nach und nach durch Retraction des Pumpenftengels erzeugt, oder die Luftverdïnnung wird fchon vor der Action vollends bewerkftelligt. In diefer Verfchiedenheit beruhen eben die Varianten der Afpirateure. Wenn auch nicht wefentlich, fo ift diefe Verfehiedenheit für den Chirurgen doch infoferne wichtig, als er mit den Apparaten letzterer Art mit gröfserer Bequemlichkeit operirt, und während der Operation feine Hände und feine Aufmerkfamkeit beffer verwenden kann als mit dem Ziehen des Stempels.

Apparate erfter Art ftellen Glasfpritzen mit Schliefshähnen dar, an denen man mit oder ohne Einfchaltung von Kautfchukröhrchen feine fchneidende Troicartcannülen befeftigt, die an Stärke des Kalibers und an Länge vielfach variirend, den Stichcannülen der Pravaz'fchen Injectionsfpritzen ähnlich gebaut find.

Apparate letzter Art find von Dieulafoy und Potain (Frankreich) ausgedacht worden. Der Unterfchied beider ift wefentlich der, dafs bei Die ula foy die ausgepumpte Flüffigkeit in den Spritzenraum felbft eingefogen wird, wogegen bei Potain der luftverdünnte Raum nicht in der Spritze felbft, fondern in einer dazwifchen eingefchalteten Flafche hergeftellt wird, und demzufolge die Flüfig. keit auch nur in diefe ftrömt. Die gröfsere Einfachheit und Billigkeit, die leichtere Reinigung und Confervirung des Apparates geben dem Potain'fchen Inftrumente für die Praxis den Vorzug; D i e u la fo y hingegen hat die Priorität der Idee und das unbeftreitbare Verdienft dem Afpirationsverfahren Bahn gebrochen zu haben.

Wir wollen die Apparate felbft näher beleuchten. Von Die u la fo y waren drei Varianten ausgeftellt:

Der A f pir a t e u r a e n u o che, das erfte und urfprüngliche Inftrument. Es befteht aus Stichcantile, Kautfchukrohr und dem Afpirateur: eine Glaspumpe von 45 bis 50 Grammes Inhalt mit zwei Sperrhähnen an den beiden Ausflufsrohren, von denen eines in der Axe, das andere rechtwinkelig zur Axe des Inftrumentes fteht. Die Pumpftange hat unmittelbar hinter dem Stempel einen Ausfchnitt encoche), welcher nach Zurückziehung des Stempels durch eine Drehung nach rechts in einen am Schlufsdeckel der Pumpe befindlichen Vorfprung eingepafst werden kann, wodurch der Stempel am Schlufsdeckel fixirt wird. Beim Gebrauche fperrt man zuerft beide Hähne ab, zieht hierauf den Stempel zurïck, und befeftigt ihn in der zurückgezogenen Lage auf die früher angedeutete Art. Der Pumpenraum wird dadurch luftverdünnt. Ift nun die Stichcannüle in die Flüffigkeit enthaltende Körperhöhle eingedrungen, fo braucht man blofs den Hahn jener Abflufsröhre, mit der die Cannüle verbunden wurde, zu öffnen, um die Flüffigkeit fofort in den Spritzenraum zu bekommen. Ift diefer vollgefüllt, fo fperrt man den Hahn wieder $\mathrm{ab}$ und öffnet jenen der anderen Abflufsröhre, befreit den Stempel durch Drehen nach links von feiner befeftigten Lage, und entleert durch ihn die Fliiffigkeit. Nun kann man wie früher den luftverdünnten Raum wieder herftellen und das Auspumpen beliebig fortfetzen. Dafs man mit diefem Apparate nach dem Auspumpen ohne jede Unterbrechung auch Flüffigkeiten in die entleerte Höhle einfpritzen und wieder einpumpen könne, ift wohl klar.

A f pirateur a créma illère unterfcheidet fich vom früheren durch feine Gröfse, indem der Pumpenraum 150 Gramm Flüffigkeit zu faffen vermag. Die gezähnte Pumpenftange wird nicht unmittelbar durch die Hand, fondern durch ein Zahnrad mittelft eines Schlüffels, ähnlich wie bei einer Klyfopompe bewegt, und die Fixirung des Stempels an jedem beliebigen Punkte durch einen Stift beforgt. Die Pumpe ift in etwas fchiefer Stellung an ein hölzernes Poftament befeftigt, wodurch das Halten des Inftrumentes während der Operation vermieden wird. 
Double afpirate ur. Diefer Apparat ftellt zweifenkrecht neben einander ftehende Afpirateure a crémaillère dar, die an einer feften Unterlage fo nahe neben einander befeftigt find, dafs ein Zahnrad beide Pumpftangen in Bewegung fetzen kann. Diefes Bewegen der Pumpftangen erfolgt in entgegengefetztem Sinne. infoferne als beim Drehen des Zahnrades gleichzeitig eine Pumpftange hinauf und die zweite hinunter bewegt wird. Hiedurch faugt die eine Pumpe, während die andere gleichzeitig die früher aufgefogene Flüfigkeit austreibt. Vier Klappen vermitteln den richtigen Gang diefes pneumatifchen Apparates. Hähne und Fixirftift fehlen natürlich an den Pumpen, dagegen ift die Stichcannüle mit einem Schliefshahne verfehen. Mit diefem Apparate erleidet das Auspumpen keine Unterbrechung, was bei den zwei frïher erwähnten Modellen ftets der Fall fein mufs, nur wäre er kaum in die Gruppe jener Apparate zu zählen, bei denen das Vacuum vor der Operation bewerkftelligt wird, fondern gehört mehr in die erfte Gruppe, bei denen das Vacuum während der Operation erzeugt wird.

Der Afpirateur von Pota in befteht aus einer beliebigen Flafche, die mit einem genau und gut paffenden Kautfchukftoppel verfchloffen wird. Eine Metall. röhre durchbohrt den Stoppel und theilt fich aufserhalb des letzteren in zwei Arme, die mit Hähnen verfehen find. Ein Arm verbindet fich mittelft eines Kautfchukfchlauches mit einem feinen Stacheltroicart, der andere ebenfalls mittelft eines Kautfchukrohres mit einer Pumpe. Bei geöffnetem Pumpenhahne wird zuerft die Luft aus der Flafche gepumpt und in diefe ftrömt die Flüffigkeit fobald der Troicarthahn geöffnet wird. Die Menge der ohne Unterbrechung der Operation zu entleerenden Flüffigkeit variirt nach dem Inhaltsquocienten der gewählten Flafche, wefshalb auch diefer Afpirateur zum Unterfchiede des Dieulafoy'fchen der Afpirateur a vide variable genannt wird. Die Vorzüge des Potain'. fchen Afpirateur haben wir fchon erwähnt, fein Nachtheil im Vergleich zu Dieulafoy liegt darin, dafs man damit wohl auspumpen, aber nicht zugleich auch einfpritzen kann.

Modificationen diefer Afpirateure namentlich des D i e u la fo y'fchen Afpirateur à encoche find vielfach vorgenommen worden, ebenfo eine des Potain'fchen von $\mathrm{C}$ hwat, ob mit Nutzen bleibt fehr in Frage, defshalb glaube ich auch alle diefe Varianten mit Stillfchweigen übergehen $z u$ dürfen, denn das Princip bleibt fich doch bei allen gleich.

A quapunctur nennt man ein Verfahren, welches darin befteht, mittelft eines kräftig getriebenen haardünnen Wafferftrahles die Haut punktförmig zu durchlöchern. Der Zweck ift die Hervorbringung eines Reizes, und findet es Anwendung bei Neuralgien, Paresen, kurz bei Leiden, bei denen eine ftärkere fogenannte Revulfion der Haut gewünfcht wird Der von Mathieu conftruirte Apparat befteht aus einer Druckpumpe mit langer Hebelftange, welche das Waffer unter ungeheuerem Drucke in ein langes und dünnes Zinnrohr treibt, das gleich einem Schlauche bewegt werden kann und welches mit einer oder zwei haarfeinen Oeffnungen endigt. Neuerer Zeit hat Mathieu den Apparat infoferne modificirt, als er ftatt der einfachen eine Doppelpumpe angebracht hat, welche durch eine einzige Hebelftange bewegt wird.

Mundfpiegel. Das grofse Arfenal von Apparaten zur gewaltfamen Eröffnung der Mundhöhle wurde durch ein neues Inftrument bereichert, welches feiner Conftruction und leichten Handhabung wegen Erwähnung verdient. Es befteht aus zwei nach vorne zu fehr dünn endenden, horizontal ftehenden Metall. fpateln, von denen im Ruhezuftande die eine um einige Linien hinter der anderen zurückfteht. Das einfache, wie gefagt, vorne fehr dïnne Blatt wird bei der Anwen. dung langfam und allmälig zwifchen den gefchloffenen Zahnreihen gefchoben. Drïckt man nun die zwei fenkrecht abftehenden Handhaben des Inftrumentes zufammen, fo wird zuerft das rückftehende Blatt bis zum Niveau des zuerft eingedrungenen nachgefchoben, und hierauf erft entfernen fich beide parallel von einander. Die Gewalt, die man anzuwenden vermag, ift eine beträchtliche und die 
Einführung ift ziemlich leicht. Der Nachtheil des ingeniös erdachten Apparates mag aber wohl darin beftehen, dafs er die Schneidezähne als Angriffspunkt der Kraft nimmt und diefe hiedurch leicht Schaden nehmen können. Auch bedarf es damit einer gröfseren Kraftentfaltung, als wenn man den Angriffspunkt näher dem Winkel des Unterkiefers verlegt.

Tonfill o t ome. Zur blutigen Abtragung hypertrophirter Mandeln finden wir mehrere Varietäten von guillotineartig wirkenden Inftrumenten. Aufser den bekannten Apparaten von Fahnenftock, Charrière und Mathie u und deren Modificationen, hat N yrop (Dänemark) zwei neuere Varietäten ausgeftellt, und zwar: Ein Charrière'fches Modell, wobei ftatt der Gabel zwei von der Seite eingreifende Doppelhaken angebracht find. Statt demnach die abzutragende Tonfille aufzufpiefsen, wird diefelbe unmittelbar vor der Abtragung wie durch eine Mufeux'fche Hakenzange von beiden Seiten her gefafst. Eine zweite Variante ift der Tonfillotom von Morell Machenfis aus London. Das Inftrument, ähnlich der alten Guillotine zur Abfchneidung der Uvola, befteht aus einer breiten, vorne oval gefenfterten Metallplatte, beftimmt, die Tonfille aufzunehmen. In den falzartig eingekerbten Rändern der Platte fpielt ein gleich breites, vorne fcharf gefchliffenes Meffer, tiber welchem noch eine Gabel zum Faffen und Vorziehen der Mandel verfchiebbar angebracht ift. Mit diefem Apparate wird demnach die Tonfille von vor- nach rückwärts durchtrennt, während die übrigen Inftrumente diefs durch die entgegengefetzte Bewegung vollführen. Ein befonderer Vortheil ift diefem Inftrumente nicht abzufehen.

Zur Stillung der Haemorrhagie nach vollführter Operation hat Ricord (Frankreich) einen Compréffeur des amygdales conftruiren laffen, nach der Idee des Signoroni'fchen Tourniquets. Zwei auf langen und mäfsig gekrümmten Stäben befeftigte Metallpelotten bilden die Componenten des Apparates. Die kleinere Pelotte wird intrabuccal auf die blutende Tonfille angepafst, die gröfsere zweite Pelotte findet aufsen am Halfe ihren Angriffspunkt. Verbindet man nun die Tragftäbe miteinander und läfst die an letztere angebrachte Schraube wirken, fo ift man im Stande, die Pelotten beliebig zu nähern und hiedurch die Compreffion auszuführen.

O efophagusinftrumente. Zur Entfernung fremder Körper aus dem Oefophagus find zwei neue Zangenmodelle ausgeftellt worden, das eine, von C o $11 \mathrm{in}$, hat das Princip der Mathieu'fchen Urethralzange, das zweite, von Mathie u, hat eine Länge von etwa 52 Centimeter und befteht aus einer etwa 20 Centimeter langen Zange, deren etwas gekrümmte Branchen je eine Kettenreihe von vier beweglich miteinander verbundenen fchmalen Metallgliedern tragen. Je zwei der acht Kettenglieder find in ihrer Mitte gekreuzt und artikuliren dafelbft durch eine Schlofsvorrichtung. Oeffnet man die Zangengriffe, fo divergiren die Kettenglieder fcheerenartig mit ihren Enden aus einander, indem fie fich in ihren Kreuzungspunkten bewegen, fchliefst man fie, fo nähern fie fich. Das Ganze erinnert unwill. kürlich an jene Soldatenfpiele der Kinder, welche das Aufftellen von breiten oder fchmalen Colonnen ermöglichen. Die M a thi e u' $f$ che Zange ift fehr handfam und ihrer Biegfamkeit wegen leicht in die Schlundröhre einzuführen. Die Branchen (die oberften zwei Gliederketten find hiezu löffelförmig gehöhlt und abgerundet) faffen mit fehr grofser Kraft und halten ficher, da ja der Druck der Hand durch die vielen einzelnen Hebelarme natürlich auch verftärkt werden mufs.

Silveftri (Italien) hat ein Inftrument zur Entfernung von tief in der Schlundröhre fteckenden Fremdkörpern anfertigen laffen, welches er pinzetta efofago-thoracica nennt. Eine bewegliche und entfprechend lange Röhre birgt ein durch Vorfchieben fich öffnendes Zängelchen, welches den Fremdkörper faffen foll. Damit man nicht aber zugleich die Oefophagus-Schleimhaut mitfaffe, wird über dem Zängelchen, aber am unteren Ende der Röhre, ein Schwammftück oder ein aufzublafendes Kautf́chukbeutelchen befeftigt und hiemit die Oefophaguswände knapp ïber dem Fremdkörper auseinandergehalten. 
Von Oefophagotomen finden wir ebenfalls zwei Varianten, den Oefophagotom von Maifonneuve, welchem die Idee feines Urethrotoms zu Grunde liegt, und jenen von Trélat (Frankreich). Eine Metallfonde, die fich konifch zufpitzt und der Krümmung des Schlundes entfprechend gebaut ift, hat 8 Centimeter vor ihrem Ende eine platte olivenförmige Ausbauchung auffitzen. Diefe foll, nachdem die Spitze der Sonde durch die Strictur gewandert ift, an letzterer fich anftemmen. Vor diefer Ausbauchung, alfo der Spitze zu, find zwei fchmale Biftouriklingen verborgen, welche im gegebenen Momente durch Drehen eines, der Handhabe auffitzenden Knopfes zum Vorfpringen gebracht werden. Eine kleine Scala zeigt, ähnlich wie beim Dupuytren'fchen Cyftotome double den Grad, bis zu welchem die Klingen vorfpringen und wird die doppelte Durchfchneidung der Strictur im Zuriick. ziehen des montirten Inftrumentes bewerkftelligt.

Aehnlich diefem ift der Oefophagotom von Reibard (Frankreich). Die Ausbauchung ift nur näher der Sondenfpitze, und die Klingen fpringen aus ihr. Er trennt alfo auch von oben nach unten.

Zur allmäligen Erweiterung von Oefophaguftricturen fanden wir, nebft den bekannten, mit Blei gefüllten Sonden, den Rofenkranzdilatator von Trouffea u. Das Inftrument befteht aus einer Fifchbein-Sonde, an deren Ende eine Reihe von drei oder vier immer kleineren Elfenbein-Oliven ficher befeftigt ift. Die kleinfte Olive geftattet, wenn fie einmal durchgedrungen ift, das Nachfolgen der gröfseren.

Réophore cefophagien nennt fich ein Inftrument, welches dazu dient, um elektrifche Ströme auf die Schlundröhre einwirken zu laffen. Es ift ähnlich einer Oesophagusbougie, aus Kautfchuk gefertigt, und führt zwei ifolirte Kupferdrähte, welche am Ende der Sonde in einen kupfernen Knopf endigen. Man kann diefen Réophore natürlich ebenfo gut auch für andere canalförmige Cavitäten benützen.

Nafenpolypen. Zur Erkenntnifs und blutigen Entfernung von Nafenpolypen hat Duplay (Frankreich) ein speculum bivalve pour les narines erdacht. Es hat den Mechanismus eines zweiblätterigen Ohrfpiegels, nur find keine Handhaben dabei, fondern das Oeffnen und Schliefsen erfolgt durch directen Druck auf die Blätter, und wird durch eine Schraube gefichert, auch find die Blätter etwas länger, breiter und löffelförmig gebaut.

Mit diefem Spiegel kann man Nafenpolypen, die nicht zu weit nach rückwärts implantirt find, ziemlich deutlich fehen und diefelben mittelft einer Zange entfernen, ohne im Dunklen erft viel fuchen zu müffen. gels total.

Tiefliegende Polypen entziehen fich natürlich der Einwirkung des Spie-

Zur Entfernung von Nafen-Rachenpolypen finden wir die Clamp scie von Péa u, eine zum Faffen des Polypen entfprechend gebaute fefte Zange, an deren Branchen eine grobgezahnte Säge durch Auf- und Niederlegen einer Hebelftange zum Spielen gebracht werden kann. Sie foll den Polypen weniger abfägen, als fozufagen abbeifsen, und hiedurch die Blutung verhindern. Es ift hiemit das Péanfche Princip des amorcéllement auch auf die Nafen-Rachenpolypen angewendet.

Ohrinftrumente. Aufser einer Anzahl Varianten in Beleuchtungs. apparaten und Inftrumenten zur Entfernung von Polypen und Fremdkörpern aus dem äufseren Gehörgange, finden wir einen uns praktifch fcheinenden Trepan für das Trommelfell. Es ift bekannt, wie fchnell künflich im Trommelfell gefetzte Oeffnungen verwachfen und wie viel Mühe der Arzt öfter hat, um den zu frühen Verfchlufs derfelben hintanzuhalten. Bonnafont und Mathieu haben ein Inftrument erfonnen, deffen Bezeichnung den Zweck und die Wirkung dentlich genug erklären: Trepan de la membrane du Trimpan laissant un oeillet en aluminium. Das Inftrument hat Aehnlichkeit mit dem Augentrepan von Wecker, nur dafs er in die Trepanationsöffnung eine kleine Oefe aus Aluminium zurückläfst, welche durch ein dünnes Seidenfädchen zur beliebigen Zeit herausgezogen werden kann. Rein and Son (England) hat Schallcondenfatoren für Schwerhörige in allen Varietäten ausgeftellt. 


\section{Inftrumente für Operationen an Knochen.}

Abgefehen von den Perioftablöfern von Ollier, Langenbeck, Verneuil, und den fcharfen Löffeln zum Evidement des os von Sédillot, den Meifeln von Laugier Vanzetti etc. fanden wir einen Knochenbohrer neuer Conftruction, der nach L a u gi e r's Angabe von Ma th i e u zuerft verfertigt wurde.

Es beruht auf dem Principe der Bewegung durch Ineinandergreifen zweier Zahnräder. An einer feften Handhabe find zwei gezähnte rechtwinkelig zu einan. der geftellte Metallräder angebracht; ein in der Axe der Handhabe gelegenes, welches durch eine kleine Welle in Rotation gebracht werden kann, bewegt durch Eingreifen der Zähne ein zweites, gleichfalls gezähntes Rad, welches horizontal am Ende der Handhabe angebracht ift. Diefes letztere nun bewegt den Bohrer. Namentlich zur Anlegung der Knochennaht ift diefes Inftrument fehr brauchbar. La u gie r hat auch ftatt des Bohrers eine kleine Trepankrone fubftituirt, um im Knochen zu beliebigen Zwecken gröfsere Bohrlöcher anlegen zu können. Collin hat denfelben Mechanismus auch für gewöhnliche Trepankronen zur Ausführung gebracht.

An Amputations-Bogenfägen fanden wir mehrere Varianten in Bezug auf die Art und Weife des Spannens, welche aber fchon bekannt fein dürften.

Verrenkungen. Zur Einrichtung veralteter Luxationen der grofsen Gelenke haben Mathieu und Robert (Frankreich) einen Apparat erfonnen, womit der Chirurg im Stande ift ohne jede Kraftanftrengung und mit Vermeidung zahlreicher Affiftenz die Einrenkung vorzunehmen. In den meiften Parifer Hofpitälern find damit erfolgreiche Verfuche vorgenommen worden und Verrenkungen, welche zwifchen 32 und 120 Tage alt waren, mit Kraftentfaltungen von 90 bis 210 Kilo reponirt worden. Der Apparat fetzt fich aus folgenden Theilen zufammen Aus einer ftarken, viereckigen, gezähnten Eifenftange, welche an dem einen Ende einen drehbahren gepolfterten Krückenkopf trägt und zur Contraextenfion dient

und aus einer ebenfalls viereckigen, eifernen Scheide, welche die Stange in fich aufnimmt und die Extenfion bewirken foll. $\mathrm{Zu}$ diefem $\mathrm{Zwecke}$ hat fie einen breiten Doppelgurt, welcher die einzurenkende Extremität ficher umfafst und fixirt, ein Zahnrad mit Schneckenfeder und Kurbel und endlich eine Sperrfeder, die in die Zähne der Stange eingreift und fich im gegebenen Momente durch Hebeldruck mit Leichtigkeit öflnen läfst. Am Zahnrad ift zugleich ein Kraftmeffer angebracht, das in jedem Momente die durch die Umdrehungen erzielte Zugkraft in Kilo abzulefen geftattet. Bei der Anwendung wird die Krücke der gezähnten Stange an einem feften Punkte des Körpers centralwärts vom luxirten Gelenke angepafst - alfo in die Ellbogen-Beuge, Achfelhöhle oder Schenkelfalte. refp. Sitzbein, je nachdem die Verrenkung das Ellbogen-, Schulter-oder das Hüftgelenk betrifft - hierauf wird der Fixirgurt am Vorder-Oberarme oder Oberfchenkel feitgefchnallt und nun die Kurbel in Bewegung gefetzt. Erachtet der Operateur die Extenfion als genügend, fo öffnet er die Sperrfeder, annulirt dadurch fofort die Zuggewalt und ift nun im Stande mit der Extremität zur Vollendung der Einrichtung alle jene rotatorifchen oder anderweitigen Bewegungen auszufuhren, die er nothwendig glaubt.

Für die Einrichtung von Luxationen im Schulter-oder Hüftgelenke haben Robert und Collin den Krückenkopf durch einen breiten gepolfterten Ring erfetzt, welcher allerdings den Schultergürtel und die Beckenfeite beffer und ficherer ungreift und dadurch die Contraextenfion wirkfamer geftaltet, für das Elibogen-Gelenk jedoch nicht anwendbar ift.

Diefer Apparat bildet jedenfalls einen Erfatz für den bisher üblich gewefenen Flafchenzug. 
Für Einrichtung frifcher Verrenkung ift bekanntlich von Dr. Anger die Extenfion mit Kautfchukröhren als Erfatz der vielen Gehilfen empfohlen worden

Collin und Mathieu haben zur Ausübung des nöthigen Zuges eine kleinere Abart der foeben befchriebenen Extenfionsmafchine conftruirt.

Eine Metallfcheide, in welcher fich mittelft eines Zahnrades eine gezähnte Stange bewegen kann und eine Hebel-Sperrfeder, welche im Momente den aus. geübten Zug ftoppen kann, bilden die Hauptcomponenten des Apparates. Metall. fcheide fowohl als Stange endigen mit je einem Haken; erfterer dient zur Befeftigung der Kautfchukröhren, letzterer zur Fixirung an irgend einem feften Punkte der Aufsenwelt. Als Erfatz des Kautfchuks hat Mathi e u eine doppelte Spiralfeder-Vorrichtung (deux réfforts à boudin) conftruirt.

Dem Apparate kann zur Meffung der angewandten Kraft auch ein Dynamometer eingefchaltet werden.

Die Charrière'fche Zange zur Reduction von Fingerluxation if auch neuerer Zeit zweckmäfsig verändert worden. Bekanntlich hatten in der urfprüng. lichen Zange die Branchen die Form von grofsen zweizackigen Gabeln, deren Fenfter durch ftraff gefpannten, ftarken Gurtenftoff und Korkholzfcheiben aus. gefüllt waren. DerGurtenftoff umgab fcheidenartig jede Gabel. Der verrenkte Finger wurde von den zwei Couliffen erfafst und gehalten. Bei längerem Gebrauche dehnt fich aber der Stoff und die Zange wird unbrauchbar. Hierauf modificirte man das Inftrument. Man befeftigte an der Gabel je einen breiten Lederftreifen; beide kreuzten fich gegenfeitig, und bildeten eine Doppelfchlinge. Durch Schliefsen der Handgriffe wurde diefe verengert und fafste den dazwifchengelegten Finger mit gröfserer Kraft und Sicherheit. In neuefter Zeit wurde endlich eine dritte Modification erfonnen. Die eine der ziemlich fchmalen Branchen ift maffiv, die zweite gefenftert. Eine einfache, breite Lederfchlinge läuft durch das Fenfter der letzteren und ift am Rücktheile der maffiven Branche feftgemacht. Die Verkleinerung der Schlinge gefchieht ebenfalls durch Schliefsen der Hand. griffe, wodurch die Branchen zur Divergenz gebracht werden. Eine Sperrvorrichtung fichert vollends den Schlufs.

Zur Behandlung von Knochenbrüchen hat Mulatier-Silvent (Frankreich) Bonnet'fche Drahthofen und Drahtfchienen verfchiedener Form ausgeftellt; fchon mit Gyps beftreute Gacebinden, die in Blechbüchfen verpackt, namentlich im Felde, zur rafchen Anlegung von Gypsverbänden fehr praktifch fein follen fahen wir in der deutfchen Abtheilung bei Schorer aus Lübeck. Wir können diefer Idee durchaus nicht das Wort reden, da bekanntermafsen der Gyps, wenn noch fo luftdicht verpackt, dennoch in relativ kurzer Zeit alle jene Eigenfchaften verliert, welche ihn zu Verbänden geeignet machen.

In der ruffifchen Abtheilung dagegen fanden wir etwas viel Praktifcheres. nämlich einen fehr einfachen, hölzernen Apparat, um Binden mit grofser Rafch heit durch Gypspulver zu ziehen und aufzurollen.

Apparate zur Zimmergymnaftik hat $\mathrm{Paz}$ (Frankreich) ausgeftellt. Etwas Compendiöferes, Praktifchereres und Eleganteres läfst fich kaum denken. Auch Amerika hat ähnliche Apparate, jedoch in viel einfacherer Form zur Anfchauung gebracht.

Krankenftühle zum Schieben oder Selbftrollen fanden wir in vorzïglichen Exemplaren bei Ward (England), Lipowsky und Tifcher aus Heidelberg.

Ein Krankenbett, welches ohne Verrücken des Kranken das Reichen des Leibftuhles geftattet, und welches auch das Aufliegen der Kreuzgegend erfchweren dürfte, fanden wir in der dänifchen Abtheilung bei Hanfen. Es ift ungemein einfach conftruirt, fo dafs es von Jedermann auf den erften Blick bedient werden kann, und ift auch, was wir als Hauptpointe auffellen, in Folge feiner Einfachheit leicht herftellbar und fehr billig. Krankenhäufern und Privat-Heilanftalten möge es warm empfohlen fein. Ein ähnliches Bild fanden wir auch in der deutfchen Abtheilung, ausgeftellt von Gnant (Württemberg). 
Sehr zweckmäfsigen Operationstifchen und Geburtsfeffeln begegneten wir in der franzöfifchen, deutfchen, italienifchen (C a valli, tragbares Geburtsbett) und öfterreichifchen Abtheilung. Als den beftmontirten und praktifcheften Operations. tifch möchten wir den von $\mathrm{Paz}$ bezeichnen.

Grouffin (Frankreich) ftellte eine mit dem Wachsthum des Kindes verlängerbare Kinderwiege aus. Kinderwagen fanden wir bei Mathieu u. A. Sitzbäder mit elaftifchem Sitz, Frauenbidets mit Scheidenrohr und Klyfopompe. vorrichtung, Zimmerdouchen verfchiedenfter Form begrüfsten wir als Fortfchritt der Körperhygiene; bemerkenswerth war uns ferner ein fehr zweckmäfsiger. wenn auch etwas complicirter und daher fchwer zu bedienender Apparat zu ZimmerDampfbädern für den ganzen Körper, den Charles (Frankreich) ausgeftellt hat. Dampfbäder für einzelne Körperregionen, untere oder obere Extremitäten, fehr einfacher Conftruction, hat R a smuffen (Dänemark) conftruirt.

Endlich fahen wir vom greifen $\mathrm{C}$ harrière eine ganze Ausftellung von fehr praktifchen und finnreich erdachten Apparaten zur Rettung von Menfchenleben in Feuers- und Waffergefahr. Rettungskäften mit den verfchiedenften Inftrumenten zum Oeffnen des Mundes (L a b o r d e t t e's Kehlkopf-Spiegel. Schlundfonden. Inftrumente zur Laryngotomie, Medicamente etc.); ferner äufserft compendiöfe Strickleitern, Fixirhaken und andere Utenfilien, für deren ausgezeichnete Verwendbarkeit uns fchon der Name des Ausftellers die befte Bürgfchaft gibt.

\section{Bandagen.}

Bruchbänder. Von Nabel-Bruchbändern find zwei fehr zweckmäfsige Neuerungen ausgeftellt worden. Die eine von D olbe a u (Frankreich), die zweite von Rasmuffen (Dänemark). Beide haben den Zweck, das Verrücken der Pelotte bei den verfchiedenen Körperftellungen zu verhindern.

Das Nabel-Bruchband von Dolbeau. Die Pelotte trägt eine lang. geftreckte (I8 Centimeter lange), horizontale, fehr elaftifche und doch fefte Metallfeder, an deren Enden zwei Kautfchukrohre angebracht find, welche auf dem Rücken des Bruchkranken zufammengebunden werden. Die Elafticität der Metallfeder drückt die Pelotte an die Bruchpforte und das elaftifche Kautfchukrohr hält die Bandage unverrïckt, da dasfelbe bei jeder Stellung und Bewegung des Körpers knapp angefchmiegt bleibt.

Das Nabel-Bruchband von Ras muffen ift etwas fchwerer zu befchreiben.

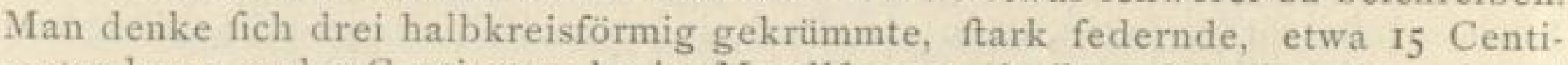
meter lange und 2 Centimeter breite Metallipangen in ihren Mittelpunkten derart gegenfeitig verbunden, dafs die fechs freien Enden in gleichmäfsigen Abftänden von einander in einer Ebene zu ftehen kommen und einen halbkugelförmigen Raum umfaffen. In der allen gemeinfchaftlichen Axe fteht, der Concavität der Halbkugel entfprechend, die Pelotte. An der convexen Seite ift eine abftehend gekrümmte vierte Metallfeder befeftigt, die den Bauchgurt trägt. Es ift klar, dafs der durch diefe Bandage ausgetibte doppelte Federdruck ein ebenfo fefter als conftant wirkender fein mufs; auch für die Vermeidung des Verfchiebens ift hin. länglich geforgt, indem die fechs Spangenenden krabbenartig die Nabelgegend umfaffen und eine Dislocation kaum erlauben.

An Schenkel-und Leiften-Bruchbändern haben Spill mann (New-Orleans), Salt (England) und R a smuffen ebenfalls Neuerungen angebracht, welche das Tragen der fo läftigen Schenkelriemen überflüffig machen. Die Beckenfeder ift ganz dem Umfange des Beckens entfprechend gekrümmt und trägt nicht an ihren Vorderenden die Pelotte, fondern diefe wird bei $\mathrm{R}$ asmuffen von einer fenkrecht nach abwärts ftehenden Spange, bei Spillmann von zwei, ein Dreieck bildenden Spangen getragen. Die Beckenfeder fchmiegt fich genau dem Becken an, und da fie von deffen Horizonte nirgends abweicht, wird fie auch bei Bewegungen keine 
Verfchiebung eingehen, da die Darmbein-Teller und die Trochanteren diefs nicht geftatten.

Die erforderliche Stellung der Pelotte wird bei Rasmuffen und Salt durch eine ftarke Stellfchraube mit Feder, bei S pill $\mathrm{m}$ an $\mathrm{n}$ durch andere mecha. nifche Vorrichtungen erzielt, die fich ohne Beigabe einer Zeichnung nicht gemein verftändlich befchreiben laffen.

Weiters müffen wir, was Verbände und orthopädifche Apparate betrifft. noch folgende Neuerungen und Modificationen erwähnen:

Der Extenfionsapparat von Ta y lor (Amerika) für Entzündungen im Hüftgelenke, welcher bei continuirlich fortdauernder Wirkung dem Kranken das Verlaffen des Bettes geftattet. Er befteht aus einem feften Beckenringe mit gepolftertem Schenkelgurte. Vom metallenen Beckenringe geht entfprechend der Aufsenfeite der Extremität eine lange, gehöhlte Stahlfpange bis etwa zur Mitte des Unterfchenkels. In der Höhlung diefer bewegt fich ein ftarker Metallftab, der unten rechtwinkelig gebogen endet. Durch eine Schraube kann man beliebig den Metallftab in der Scheide der oberen Spange verfchieben. Bei der Anwendung wird an der kranken Extremität zuerft mit Heftplafter-Streifen nach C rosb y'icher Art der Zug angebracht, deffen Auslaufbänder am gebogenen Endtheile der unteren Spange befeftigt werden. Pafst der Beckenring genau und unverrückbar, fo braucht man blofs die untere Metallfpange in divergirender Richtung von der oberen zu fchrauben, um eine beliebig ftarke conftante Extenfion auszuüben.

Streckapparate für Kniegelenks-Contracturen waren in vielfachen Varietäten vertreten. Da die älteren Apparate mit Lagerbret, welche den Kranken zur conftanten Bettruhe in der Rückenlage verdammen, kaum mehr in Gebrauch kommen, beftehen die neueren Apparate aus einem Oberfchenkel- und einem Unterfchenkel-Stücke und wird die Streckkraft an der Verbindung beider ange. bracht. Die Verfchiedenheiten beruhen nun in den Varianten, wie diefe vermittelt wird. Wir haben deren drei notirt, und zwar: a) die Streckung wird durch die Hände des Operateurs bewerkftelligt und der Apparat hat nur den Zweck, die gewonnene Befferung zu erhalten; b) die Streckung erfolgt durch Schraubendruck. der feitlich oder rückwärts eingreift; c) die Streckung erfolgt durch elaftifchen Zug. $Z$ u diefem $Z$ wecke haben beide oberen und unteren Seitenfchienen, einige Centimeter von ihrer gegenfeitigen Verbindung, zwei lothrecht nach aufwärts ftrebende Metallbälkchen von etwa 6 Centimeter Höhe. Die Enden der Bälkchen, die bei der Anlegung des Apparates in der palhognomonifchen Stellung der Extremität entfprechend dem Beugungswinkel divergiren, werden durch dünne, mehrreihige Kautfchukröhrchen verbunden, die angefpannt, nach und nach die Convergenz der Bälkchen und fonach die Streckung vermitteln.

$\mathrm{Zu}$ weit würde es führen, wollten wir alle Apparate für Klumpfufs, Spitz. fufs etc. befchreiben, die von Collin, Nyrop, Rasmuffen, Windler, Walter, Schlecht u. A. m. ausgeftellt wurden.

An Miedern für Wirbelfäule-Krankheiten konnten wir-folgende verfchiedene Typen unterfcheiden.

St ützmieder. Gefchloffene. Becken und Thorax umfaffende Mieder mit eingelegten oder aufsen aufliegenden Stahlfchienen, mit ringförmiger Beckenftütze und Achfelgürtel.

Offene Mieder mit ringförmiger oder gebrochener Beckenftütze und Achfelkrücken.

Gefchloffene, der Rückenform genau abmodellirte Miederküraffe aus geprefstem, fiebartig durchlöchertem Leder (Collin und Mathieu), die nach Gypsabdrücken geformt werden. Aehnliche Küraffe in entfprechender Form werden auch zur Imobilifirung erkrankter Gelenke an den Extremitäten verwendet, ferner auch bei Caries vertebrarum colli cravattenartig zum Tragen des Kopfes.

Streckmieder. Gefchloffene Mieder mit ganzer Beckenftütze, Achfelgürtel und einfachen oder doppelten, glatten oder pelottirten Gurtenzügen, welche 
entweder an der Innenfeite der Mieder angebracht find oder an deffen Aufsenfeite verlaufen.

Offene Mieder mit ganzer oder gebrochener Beckenftütze, Achfelkrücken und breiten, abftehend gekrümmten, ftark federnden Stahlbändern, welche vom Rückenftabe ausgehen und die der Convexität der fkoliotifchen Krümmung entfprechende Thoraxfeite umklammern follen. (N y rop.)

Offene Mieder mit ganzer Beckenftütze, Achfelkrucken, beweglichem Rückenftabe und Gummifchnür.Zug. (Collin.)

Offene Mieder mit verfchiebbaren Becken- und Achfelhöhlen-Stützen. Das Mieder wird der pathognomonifchen Lage entfprechend angelegt und die allgemeine Geraderichtung durch Schraubenwirkung erzielt. (S chlecht.)

Offene und gefchloffene Mieder mit Zügen oder Metallplatten, die durch Schraubenvorrichtung geregelt werden.

Offene Mieder mit gebrochener Beckenftütze, doppeltem Rückenftab, der bis zur Halswirbel-Säule reicht, keine Achfelkrücken, fondern Ledergurten, die tornifterartig die Schultern umfaffen. Der Zug wird durch Metallplatten ausgetibt, die den Thorax feitlich umfaffen. Die Metallplatten find mit Spangen verbunden, welche die Rückenftäbe kreuzen und allhier mit Zähnen eingreifen (à cremaillère). Natürlich mufs dabei die Krümmung früher durch die Hände des Operateurs möglichft ausgeglichen werden, worauf erft die Metallplatten anzupaffen find. Für Kyphofen oder Lordofen find die Rückenftäbe entfprechend der Ver. krümmung gebrochen und allhier mit Stellfchrauben verfehen. (T a ylor.)

Apparate zur Behandlung des Schiefhalfes, bei denen durch Schrauben in jeder Richtung auf den Kopf eingewirkt werden kann und die in technifcher Beziehung das gröfste Lob verdienen, haben Collin und Mathie u ausgeftellt.

Erwähnenswerth ift endlich noch ein Apparat, welcher die Brauchbarkeit des Vorderarmes und der Hand bei fchlotteriger Verbindung nach Refection im Ellbogen-Gelenke vermittelt. Collin erzielte diefs durch Compreffion des zweiköpfigen Armmuskels mittelft einer Platte von geprefstem Leder, die durch eine Schraube ftellbar ift.

Künftliche Gliedmafsen kamen fehr zahlreich zur Ausftellung und haben fich diefsbetreffs England (Gra y), Frankreich, Italien, Schweiz (We ber-Moos), Deutfchland und Oefterreich hervorragend betheiligt. Das Materiale, woraus die künftlichen oberen oder unteren Gliedmafsen gefertigt, waren Holz, Leder und Hartgummi. Die Bewegung der Gelenke wurde durch Kautfchukftränge oder Darmfaiten vermittelt. Das Gewicht wurde auf das allergeringfte reducirt, fo dafs Oberfchenkel-Piecen im Ganzen drei Pfund wogen. Einen neuen Mechanismus in der Imitation der Sprunggelenks-Bewegung bei küntlichen Beinen hat W e b e rMoos erdacht. Ich konnte darüber nur fo viel erfahren - es wird eben geheim gehalten - dafs es in einer gefchickten Combination zweier Kautfchukcylinder mit einem höchft einfach conftruirten Kettengelenke befteht.

Inftrumentef ï $\mathrm{r}$ An thropologie. Inftrumentenmacher L. Mathieu aus Paris hatte eine grofse Anzahl diefsbezüglicher Apparate ausgeftellt. Es dürfte wohl die vollftändigfte Sammlung fein, die bis jetzt exiftirt. Ich werde im Folgenden blofs die Namen und die Verwendung der intereffanteren Apparate anführen, denn detaillirtere Befchreibung würde zu viel Raum in Anfpruch nehmen.

Le goniométre focial von B roca. Zur Meffung des Gefichtswinkeis,

L'équérre fléxible auriculaire von Broca. Winkelmafs zur Beftimmung der Interauricular-Linie.

Le profilométre von Sauvage. Modificirt.

L'anthropométre. Zur Höhenbeftimmung jeglichen Körpertheiles.

Le compas d'épaiffeur mit Millimeter-Theilung, und le compas d'épaiffeur micrométrique mit Viertelmillimeter-Theilung. millimeter-Scala

Le compas gliffiere. Die Taften bewegen fich parallel zu einander. Halb. 
L'endométre. Zur Beftimmung des intracraniellen Durchmeffers ohne Eröffnung des Schädels. Das Inftrument wird durch das Hinterhaupts-Loch eingeführt.

Le pachymetre. Zur Beftimmung der Dicke der Knochenwandungen.

L'orbitoftat a crémaillere. Zur Beftimmung der Sehaxen.

Le craniophore de Topinard. Zur richtigen Schädelftellung behufs Mefuration.

Le craniographe et le ftéréographe de Broca. Zwei Apparate zur Zeichnung der Schädelcontouren in geometrifcher Projection.

L'endographe de Broca. Zur Zeichnung der intracraniellen Conturen ohne Eröffnung des Schädels.

Le céphalométre d'A u telme.

Le goniométre de Jacquart.

Le goniométre facial de Broca.

Le goniométre pariétal de Quatrefages.

Le goniométre occipital à arc.

Le goniométre occipital rectangulaire.

Le goniométre auriculaire.

Le rhinométre. Zur Beftimmung der Höhe der Nafenhöhlen.

Le crochet sphéuoidal et la fonde optique. Zur Beftimmung des Virchow'fchen Keilbein-Winkels ohne Scheiteleröffnung.

Le cranioscop de B roca, der durch das Hinterhaupts-Loch eingeführt wird.

Nebftdem fanden fich noch Inftrumente von Charles B ell, Piérre C a m per, Leach, Barclay, Morton, Burk, Mantegazza u. A.

\section{Zahn-Heilkunde.}

Künftliche Zähne und Gebiffe von vorzüglichem Materiale und exquifiter Schönheit hatten Amerika (S. White, H. Ju fti und Allen) und England (A fh) ausgeftellt. Die franzöfifchen Zähne (Devillemur) hingegen find untergeordnet an Qualität, dafür aber viel billiger im Preife, fie differiren durch ihre faturirtere Farbe. In der amerikanifchen Abtheilung waren fowohl die gewöhnlichen Stiftzähne als auch Wurzelzähne zu fehen; die Letzteren für Gebiffe aus continuous gum, einer porzellanähnlichen Maffe, welche die Farbe und das Aus. fehen des Zahnfleifches täufchend imitirt. Neu, aber von fehr geringem praktifchem Werthe find die Piècen mit Zähnen unregelmäfsiger Stellung, und Piecen mit künftlichen Zähnen, welche der gröfseren Täufchung wegen Goldplomben tragen White, Jufti, Allen).

Berghammer (Oefterreich) hatte Gebiffe zur Anfchauung gebracht welche, obwohl aus continuous gum gefertigt, dennoch Gaumenplatten aus Vulcanit tragen. Bisher wurden, wie bekannt, die Zahnfleifch-Zähne ftets mit Metallplatten - gewöhnlich Platin - verbunden. Der Erfatz diefer Metallplatten durch Vulcanit, welches der fchon fertigen Piece nachträglich aufvulcanifirt wird, ift jedenfalls eine Neuerung, welche das Gebifs etwas weniger fchwer machen dürfte.

Gebiffe von Celluloid Bafe als Erfatz des Vulcanits kamen nur vereinzelt zur Anfchauung. Der Celluloid ift eigentlich nie recht in der Praxis verwendet worden, weil diefe amerikanifche Erfindung vor Allem den Nachtheil eines permanenten Kampfergeruches hat. Nebftem verziehen fich die Platten leicht beim tragen, und ein derartiges Gebifs wird in kurzer Zeit unbrauchbar.

Ebenfo unpraktifch und längft verworfen find die ihrer Leichtigkeit wegen empfohlenen Gebiffe aus Aluminium, da das Metall unter der Einwirkung der Mundfluffigkeiten fich fehr leicht zerfetzt. Sa uer (Berlin) und Berghammer hatten Aluminiumgebiffe ausgeftellt. 
Als Neuerungen an Inftrumenten und Behelfen zu Plombirungen glauben wir Nachfolgendes anführen zu müffen:

Stahlplättchen (S. White) als Zwifchenlagen, wenn der żu füllende Zahn ftarke Defecte an feinen Seitenflächen zeigt und der Nachbarzahn noch vorhanden ift. Die fraglichen Plättchen zwifchen den Zähnen eingepafst, erfetzen die fehlende Wand während der Dauer des Plombirens, ermöglichen die rafche und präcife Ausführung desfelben und werden nach Beendigung der Plombe wieder entfernt,

Green's Electric Burring Eugine (S. White). Unter diefem Namen finden wir zwei Apparate, eine Bohrmafchine und eine Goldplomb.Dicht. mafchine, welche beide durch Electricität mit grofser Rafchheit und Kraft getrieben werden. Die Bohrmafchine, der natürlich eine rotirende Bewegung mitgetheilt wird, ift zur Aufnahme beliebiger Zahnbohrer eingerichtet, kann aber nur für Zahnhöhlen dienen, welche an der Aufsenfläche der Zähne gelegen find. Bei feitlichen Höhlen ift das Inftrument entweder gar nicht oder nur fehr oberflächlich anwendbar. Die Dichtmafchine hat eine fenkrechte ftofsende Bewegung, und kann gleichfalls Stopfer beliebiger Form aufnehmen. Ob diefer Apparat beffer und zweckdienlicher fei als der bisher gebräuchliche einfache und der automatifche Hammer, diefs kann wohl nur der Verfuch lehren, die Bohrmafchine dürfte jedoch nur in fehr geübten Händen ganz unfchädlich fein.

Zahnärztliche Inftrumente, als Zangen, Bohrer, Stopfer etc. fämmtlich vernickelt, find von $\mathrm{S}$. White und $\mathrm{A}$ fh vielfach neu und in verbefferter Form ausgeftellt worden, insbefondere in der äufseren Ausftattung und grofsen Auswahl übertreffen fie die der Parifer Ausftellung. Wir heben befonders als neu hervor die Zahnnerven-Inftrumente ven $\mathrm{P}$ almer und Arrington.

Operation'st ühle für Zahnärzte fanden wirbei S. White, O. C. White, Afh und in der deutfchen Abtheilung. Die amerikanifchen Stühle haben die Novität, die Kugelgelenke durch zweckmäfsigere Mechanismen erfetzt zu haben. Sie geftatten alle nur immer denkbaren Stellungen und find fehr leicht und mit geringer Kraftanftrengung ftellbar.

F iill mate riale. Neu ift S. White's Goldpräparat "The globe gold foil“. Benzow aus Stockholm brachte Mufter von Metalllegirungen zu Amalgamplomben, deren Werth aus der blofsen Betrachtung nicht entnehmbar ift.

Vulcanifirapparate mit felbftregulirbarem Sicherheitsventil waren von Friefe \& Rohrfchneider in Magdeburg und Joung in Stuttgart ausgeftellt worden, erftere haben den Apparat mit einer Centralfchraube verfehen, wodurch die Bedienung des Apparates wohl erleichtert werden mag.

\title{
DIE OCULISTISCHEN INSTRUMENTE.
}

\author{
Bericht von \\ DR. HANS ADLER, \\ ordinirender Augenarst des $k$. k. Krankenhaufes Wieden in Wien.
}

„Die eigenthümliche Befchaffenheit des Auges begünftigt die Anwendung phyfikalifcher Unterfuchungsmethoden fowohl für die functionellen, wie für die anatomifchen Störungen des lebenden Organs. Die Augen-Heilkunde hat auch wohl eben defshalb, weil fie der wiffenfchaftlichen Methode die günftigften Anhaltspunkte darbietet, befonders viele ausgezeichnete Forfcher angezogen und fich fchnell zu ihrer jetzigen Stellung entwickelt, in der fie den ubrigen Zweigen 
der Medicin etwa ebenfo als leuchtendes Beifpiel der Leiftungsfähigkeit der echten Methode vorangeht, wie es lange Zeit die Aftronomie den übrigen Naturwiffenfchaften that."

Die Phyfik, zur Unterfuchung des Auges dienftbar gemacht, förderte in den beiden letzten Decennien einen grofsen, bis dahin unbekannten Inftrumentenapparat zu Tage, der heute in der Hand des praktifchen Augenarztes bereits zum unentbehrlichen Werkzeuge geworden und ftetig in Zunahme begriffen ift.

Die Wichtigkeit diefes Theiles des oculiftifchen Apparates erhellt aus dem oben citirten Ausfpruche des berühmten Phyfiologen Helmholtz, dem die Augenheilkunde die Begründung der naturwiffenfchaftlichen Unterfuchungsmethode und die Erfindung der wichtigften Inftrumente verdankt.

Wir erwähnen als hieher gehörig die vielen Modificationen von Augenfpiegeln, Ophthalmometern, Tonometern, Augen-Spiegelbildern, ans Auge aufzufetzenden Mikrofkopen, Augenloupen, Probebrillen, Photometern, Optometern, Perimetern, Farbenfcalen, Sehproben u. f. w.

In diefem Apparatencomplexe, deffen Entwicklung mit dem Fortfchreiten der Wiffenfchaft Hand in Hand geht, der auch de facto in den letzten Jahren eine wefentliche Bereicherung erfahren, mufste naturgemäfs der Fortfchritt gefucht werden, deffen Darftellung wir auf einer Weltausftellung vor Allem erwarten foll. ten; doch hat uns leider die diefsjährige Weltausftellung in diefer Richtung nichts Erwähnenswerthes geboten, indem diefe Apparate überhaupt keine oder nur mangelhafte Vertretung fanden.*

Wir müffen uns daher vorzüglich nur mit jener Gruppe ophthalmologifcher Inftrumente befchäftigen, welche der chirurgifch-technifchen Fertigkeit des Augenarztes dienen und von denen in den Ausftellungskäften der chirurgifchen Inftrumentenfabrikanten Vieles und manches Neue hierorts $\mathrm{zu}$ fehen ift.

Bei der ziemlich fcharfen Abgrenzung des oculiftifchen Operationsgebietes, dem kleinen, zarten Bau der erforderlichen Inftrumente ift die Vereinigung der nothwendigften Augeninftrumente in einem Etui auch heutzutage noch möglich; ja wir fahen auch auf diefer Ausftellung häufig Firmen nur durch ein einziges Etui recht gut vertreten.

Ift es für den praktifchen Arzt und felbft für den beginnenden Ophtalmo. logen nun einerfeits auch fehr bequem, die wichtigften technifchen Werkzeuge in compendiöfer Form fich anfchaffen und aufbewahren zu können, fo erfordert der Titel: „Augenetui“, um nicht prätenfiös zu erfcheinen, eine forgfältige, auf das Verftändnifs eines fehr gewiegten Fachmannes gegründete Auswahl des wirklich Brauchbaren und Nothwendigen aus der übergrofsen Anzahl der exiftirenden Augeninftrumente.

Kliniken und Specialiften werden fich ihren Apparat nach eigenem Bedürfniffe erweitern können, das "Augenetui“ aber im obigen Sinne, darf, foll es anders den Käufer zu Dank verpflichten, nur vielfach praktifch Bewährtes enthalten.

Der Berichterftatter des k. k. öfterreichifchen Centralcomités der Parifer Weltausftellung 1867 (officieller Ausftellungsbericht I. Lieferung, S. 67) fcheint, wie uberhaupt von den Augeninftrumenten, unter denen er "Neues nicht findet", auch von der Einrichtung des "Augenetuis" nicht fehr erbaut gewefen zu fein.

Uns fcheint, dafs in der althergebrachten Zufammenftellung desfelben fich dermalen eine gründliche Reform wenigftens anbahne. Eine grofse Maffe von nach der Kante gebogenen Scheeren, Doppelhaken, Augenfpiefsen, namentlich aber jene übergrofse Anzahl verfchieden gekrümmter, oft unheimlich breiter Staarnadeln ift verfchwunden; dafür finden wir überall Weber's Thränenfack-Meffer, Bowman's

* Die Subfellien, deren Einrichtung für den Augenarzt in den letzten Jahren Wich tigkeit gewonnen, werden als einer anderenA btheilungsgruppe angehörig, in dem entfprechenden Berichte Erwähnung finden müfen. 
Sonden und vor Allem das v. Gräfe'fche Schmalmeffer, feine Cyftotome und Löffel.

Uns erfcheint-diefe Purganz vom alten Ballafte fehr gefund und vortheilhaft, wir begrüfsen diefe Thatfache als einen wefentlichen Fortfchritt, namentlich infoferne wir darin den glorreichen Sieg der Extractionsmethode gegenüber der Niederlage der Reclinationsmethode auf allen Linien erkennen; fpeciell berührt uns die allgemeine Anerkennung des fchönen Vermächtniffes des unfterblichen Gräfe freudig.

Doch dünkt uns, dafs diefe Revolution manchmal zu weit geführt, vorzïglich nach Betrachtung eines fonft fehr gut componirten grofsen Etuis, in dem wir Gräfe's Schmalmeffer in Io, fage zehn Exemplaren, das ehrwürdige Beer'fche Lappenmeffer überhaupt gar nicht vorfanden.

In diefer Zeit der Gährung, des Kampfes der verfchiedenften Extractions. methoden darf der einzelne Augenarzt felbft zu Nutz und Frommen derWiffenfchaft für feine Perfon verwerfen, was er nurmag; die Herren Inftrumentenmacher follen aber dem "Augenetui* den Boden der Neutralität wenigftens auf Kriegsdauer zu bewahren trachten und nicht, wie fpeciell in diefem Falle, durch vorfchnelles Abwerfen eines durch viele Decennien nicht grundlos als Souverän anerkannten, verdienftvollen, jedenfalls noch heute verwendbaren Inftrumentes einer jüngeren ärztlichen Generation die intereffante Gelegenheit benehmen, durch Selbft. fchauen und Selbftprüfen fich ein eigenes Urtheil zu verfchaffen.

Ein Etui war durch den Preis (500o Francs) auffallend, vielleicht auch durch die fehr hübfchen, aber unpraktifchen, viereckigen Perlmuttergriffe.

Wir fahen auch auf diefer Ausftellung fogenannte Augeninftrumente, die fo koloffal in ihren Maffen, fo plump in ihrer Mache waren, dafs wir uns unwillkürlich fragen mufsten, ob diefe Erzeugniffe nicht nach Angabe eines die AugenHeilkunde am gröfseren Säugethiere praktizirenden Thierarztes gefertigt worden.

Diefe Erfcheinung rührt wohl daher, dafs faft alle chirurgifchen Inftrumenten- und Bandagenmacher auch Augeninftrumente felbft erzeugen, ein alter Ufus, von dem abgegangen zu fein, fo Mancher im Intereffe feines eigenen Renommés nicht bereuen wird; es wäre Vielen beffer, ohne eigene Mühe die als gut anerkannten Inftrumente jenes Collegen in den Verkehr fetzen, der aus der Verfertigung, von Augeninftrumenten mehr oder weniger eine Specialität gemacht hat.

Dafs das Princip der Arbeitstheilung ein richtiges, dafs die fpecialiftifche Eintheilung des Gefchäftsbetriebes keine fchädliche Maxime, zeigt der Erfolg der drei erften Wiener Firmen nach jeder Richtung. Die mehr weniger bei jeder derfelben hervortretende, fpecialiftifche Richtung hat nicht nur jedem einzelnen befriedigende materielle Vortheile, fondern auch die gleiche auszeichnende Beurtheilung der Jury verfchafft.

Eine derfelben hat wenig exponirt, die zweite es ganz correct unterlaffen, oculiftifche Inftrumente überhaupt auszuftellen.

Und fo reftirt eigentlich nur Thürriegel als erwähnenswerth, deffen Fabricate als die fchönften unter den öfterreichifchen, fich durch gute Ausftattung bei relativ billigem Preife hervorthun.

England und Amerika brachten keine, Deutfchland relativ nicht viele Augeninftrumente zur Ausftellung.

Reichhaltiger war Italien (vorzüglich durch Lollini), Rufsland, Dänemark (durch Nyrop) vertreten. zu fuchen.

Der Glanzpunkt unferer Gruppe war in der franzöfifchen Abtheilung

Die beiden Parifer Häufer Mathie und Collin überragen weitaus an Mannigfaltigkeit, Glanz, und Schönheit der ausgeftellten oculiftifchen Inftrumente ihre fämmtlichen Concurrenten. Die neuen Erfcheinungen in diefer 
Branche, zu deren detaillirter Befchreibung wir jetzt übergehen wollen, verdanken wir zum gröfsten Theile diefen beiden letztgenannten Firmen.

Von den zur Entfernung der Katarakta dienenden Inftrumenten find erwähnenswerth die von Thürriegel exponirten, die Eduard v. Jäger zur Vollführung des "Hohlfchnittes, " feiner neuen Extractionsmethode, erfand. Diefe find:

Ein St a a rmeffer, dreieckförmig, dem Beer'fchen ähnlich, nurfchmảler, Länge 35 , Breite $5 \frac{1}{2}$ bis $61 / 2$ Millimeter, der ftumpfe Rücken legt fich in die Wundwinkel, die er verfchliefst. Die Flächen des Meffers find cylinderartig gekrümmt, die vordere concav, die hintere convex.

Das Häkchen ift in feinem Halfe rechtwinkelig nach abwärts gebogen; diefer 7 Millimeter lange Theil leicht concav gekrümmt, trägt eine feine, nadelförmige Spitze.

Die Spatel (am Griffende des vorigen Inftrumentes angebracht) deren Halsende leicht aufwärts gebogen, ift $3 \frac{1}{2}$ Millimeter hoch und 8 Millimeter breit und hat eine vordere fchwach concav ausgehöhlte Fläche.

Die Sonde zur Ausleitung des Staares aus Silberdraht, ift nach ihrer flachen Seite unter einem Radius von 8 Millimeter gekrümmt; am anderen Ende des Griffes ift

Ein gewöhnlicher D av i elf cher Löffel angebracht.

Die Löffel zur Entfernung der Corticalis find oval, mäfsig concav, fehr dünn, 4 Millimeter breit, 6 Millimeter lang und zum Halfe fenkrecht nach abwärts geftellt.

Nach der Bauart der Inftrumente braucht man als ambitexter Operateur; zweierlei Meffer, Häkchen, S patel, Löffel, dagegen nur eine Sonde einen Davielfchen Löffel.

Die Vortheile der Methode follen fein: Lineare Wunde, Erhaltung des Kammerwaffers bis zur Vollendung des Schnittes, leichter Austritt des Staares.

Die Schwierigkeit des Hohlfchnittes ift das Aufgeben des Druckes auf die Schneide wie beim Lappenfchnitt.

Die Pince cystitome von Wecker, eine Irispinzette, deren beide Branchen je einen fchneidenden Triangel zur Eröffnung der Vorderkapfel tragen; es foll diefes Inftrument die Vortheile der zwei in dem Namen enthaltenen Inftru. mente vereinen.

Ferner die Pinc e cyft itome von Loren ço und von Meyer. der eben befchriebenen fehr ähnlich.

Der häufigeren Ausführung und der wachfenden Anzahl der Indicationen zur Ausführung der Iridectomie entfprechen die ftets erneuerten Verfuche zur Verbefferung der hiezu benöthigten Inftrumente. Wir finden :

Lanzen von Warlomont nach Art der Weber'fchen Extractions. meffer gekrümmt, von verfchiedener Breite (2, 3,4 und 5 Millimeter).

Hieher ift auch das Gräf e'fche $\mathrm{Schmalmeffer} z u$ zählen, das in verkürzter Form von manchen Operateuren mit Vorliebe verwendet wird, namentlich wo man bei enger Vorkammer ein breites Colobom anftrebt.

$\mathrm{Sch}$ erk liefs ein $\mathrm{Schmalmeffer}$ conftruiren, welches 6 Linien lang, fomit eigentlich die Spitzenhälfte des Gräfe'fchen Meffers ift. Das Mefferchen fetzt fich in einen platten, 8 Linien langen Stiel fort, der mit ihm etwa einen rechten Winkel bildet, dann wieder horicontal abgebogen unmittelbar in ein der Klinge paralleles Heft fich fortfetzt. Mit diefer Modification ift es leichter Hinderniffe, welche vorfpringende Orbitalränder oder Nafenwurzel machen, zu überwinden. Man bedarf, um von und gegen fich fchneiden zu können, zweierlei Mefferchen.

Von Irispinzette $\mathrm{n}$ fanden wir eine übergrofse Anzahl, unter den verfchiedenften Winkeln abgebogene, mit Häckchen und Riffen an der Spitze oder der Kante verfehene oder ohne folche. Bei der fo häufig entftehenden 
Schwierigkeit, Exfudatfchwarten etc. zu entfernen, wird eine gröfsere Auswahl von Pinzetten dem Praktiker von Nutzen fein können; da wir nicht in der Lage waren, den jedesmaligen Erfinder der Modificationen zu eruiren, viele derfelben auch fehr geringfügig, entfällt hier deren detaillirte Befchreibuug.

Sehr erwähnenswerth erfcheint uns dagegen die fchon mehrfeitig verwendete Irispinzette von $\mathrm{Liebreich}$, die (wie der Erfinder fagt) mit Benützung eines neuen, bis jetzt in der Chirurgie noch nicht in Verwendung gekommenen mechanifchen Principes conftruirt ift:

„Die Branchen der Pinzette drehen fich, ohne fich von einander zu entfernen, um eine Längsaxe, einen Draht, der in der Mitte des Inft rumentes angebracht ift." Die Haken derfelben, befinden fich am convexen Rande der Branchen an deren Ende. Das fchreibfederartig gehaltene Inftrument kann leicht mit drei Fingern dirigirt und auch durch eine fehr kleine Cornealwunde eingeführt werden, da der in der Wunde eingeführte Theil faft vollkommen gefchloffen bleibt. Das Inftrument braucht nicht, wie alle anderen Irispinzetten radial eingeführt zu werden. Iridodefe,

Es eignet fich auch zur Extraction von Kapfelftaaren, zur Corelyfe und

Zwei Formen find hievon im Gebrauche, eine gewöhnliche und eine mit nach abwärts gerichteten Haken.

Dann die $\mathrm{Nadel}$ inzette von $\mathrm{Heymann}$. Zur Pupillenbildung in ftarren Membranen modificirte Heymann eine Fifcher'fche Pincette, indem er eine Branche um einige Millimeter verlängerte und nadelförmig zufpitzte. Eine folche Nadel kann ohne Verletzung der Wundränder durch jede lineare Wunde eingeführt, die ftarre Membram mit der verlängerten Branche durchftochen und durch Schlufs der Pinzette eine Partie derfelben gefafst werden.

Von neueren Irisf che ren fahen wir:

Die Pince-Cifeaux (Mathieu ftellte eine ähnliche fchon auf der Parifer Weltausftellung aus) von We cker modificirt. Im Namen liegt fchon die Bedeutung diefes Inftrumentes, welches geeignet ift, Scheerenfchnitte in der vorderen Augenkammer auszuführen und zugleich die abgefchnittene Partie auszuziehen.

Eine Scheere von Dowe11, von Collin verbeffert, deren Branchen wie die einer "Pinzette" gebaut find, felbe können durch den Druck zweier Finger aufserordentlich leicht in Thätigkeit gefetzt werden; diefelbe foll zu Operationen hinter der Cornea verwendbar fein.

Endlich eine neue feine Scheere von Liebreich zur Excifion der Iris hinter der Cornea.

Von Lidhaltern heben wir unter der grofsen Anzahl der verfchiedenften Modificationen hervor:

Das Ophthalmoftat von M Noyes aus zwei Armen beftehend, die durch ein an dem Schläfentheil angebrachtes Schraubengewinde in verfchiedene Entfernung gebracht werden können.

Den Lidhalter von Partridge. Ein viereckiger Stab fteht mit einem Drahte in fefter Verbindung, der das obere Augenlid hält; ein zweiter Draht, der fich mit einer Schraubenvorrichtung an dem Stabe feftftellen läfst, fixirt das untere Lid. Für jedes Auge ift ein befonderes Inftrument erforderlich.

Ein ähnlicher Lidhalter wurde von Paul Schrötter angegeben.

Auch die Fixationspinzette hat Veränderungen erfahren, davon fanden wir:

Eine "Pinzette mit doppelter Fixhtion" von Monoyer. Zur Immobilifirung des Augapfels - den Mittelpunkt als unbeweglich angenommen - bedarf es noch der Fixirung zweier Punkte feiner Oberfläche. Monoyer liefs daher feine Fixationspinzette doppelarmig auslaufen; jede Branche endigt in zwei Arme. Es fei hier erwähnt, dafs Ed. v. Jäger fchon früher ein zweiarmiges Fixationsinftrument (das auch in mehreren Etuis vorhanden war) conftruirte, fowie 
dafs Juft die Monoyer'fche Pinzeite fchon wieder verbefferte, infoferne, als er den Abftand der Branchen, der bei Monoyer 13 Millimeter betrug, auf 8 Millimeter reducirte (wir fanden auch folche von II und 9 Millimeter vorräthig); diefe letztere Pinzette ift daher auch zum Druck auf den unteren Linfenrand geeignet, was z. B. bei der Weber'fchen Extractionsmethode erforderlich.

Ganz neu ift die Anwendung des Trepans fürs A uge; wir fahen:

Einen Augentrepan von Bowman, einem Sattler-Locheifen ähnlich, hat er eine Hemmung, um verfchieden tief eindringen zu können; das Ganze wird durch eine Feder in Bewegung gefetzt und kann leicht durch Daumen und Zeigefinger einer Hand dirigirt werden.

Ferner:

Einen A ugentrepan von Wecker, von Mathieu nach Art des künftlichen Blutegels gebaut: auch hier wird die locheifenförmige Krone, deren Durchmeffer zwifchen I bis 5 Millimeter beträgt, durch eine Feder in Bewegung gefetzt. Der fchneidende Theil fitzt in einem foliden Auffatze, der fich genau der Form der Cornea oder Sclera adaptiren kann; fo kann man zuerft das Inftrument auffetzen, die zu trepanirende Stelle genau auswählen und dann erft, um zu fchneiden die Feder fpielen laffen.

Ein Verfahren, wenn auch im Alterthum bereits geübt, fo doch von Wecker erft neuerlich wieder bekannt gemacht, hat zum Zwecke, die Hornhaut mit Farbftoffen (namentlich chinefifcher Touche) zu färben. Zur Tätowirung verwendete Wecker anfangs feine Tätowirungsnadel, eine breite Staarnadel, mit einer bis an die Spitze gehenden Rinne zur Aufnahme des flüfigen Farbftoffes. Jetzt conftruirte er hiezu ein eigenes In ft $r$ u m en t p o u $\mathrm{rt}$ a t o un a ge, eine Vereinigung von 4 bis 5 Nadeln, welche gleichzeitig eindringen, nachdem man früher auf die Hornhaut den Farbftoff mittelft feiner S p a tule pour t a t o u$\mathrm{n}$ ag e, einem eigens geformten, kleinen, filbernen Löffel aufgetragen.

Ferner fanden wir gleichfalls von Wecker conftruirt: das Nevrotome caché und die Spatule conductrice, welche zwei Inftrumente es ermög. lichen, ein Mefferchen gefchützt bis zum Sehnerven in der Orbita vorzufchieben, um dafelbft die "Scheide des Optikus anzufchneiden". Bei Neuritis optica follen hievon fehr gute Erfolge zu erwarten fein.

Neu find auch die Verfuche, medicamentöfe Flüffigkeiten im zerftäubten $\mathrm{Zuftande}$ ans Auge" zu bringen; mehrere Oculiften wollen hiemit fchöne therapeutifche Erfolge erzielt haben.

Ein hiezu verwendbares, nach dem Syfteme des Siegle'fchen Inhalationsapparates gebautes Inftrument ift der hier ausgeftellte Fumigateur de Laurenco ; da zwei Zerftäuber am Apparate (der zur Fixation der Stirne einen breiten Metallknopf trägt) angebracht, können gleichzeitig beide Augen behandelt werden.

Liebreich conftruirte zu gleichem Zwecke einen Pulverifate ur.

Noch find ferner zu erwähnen:

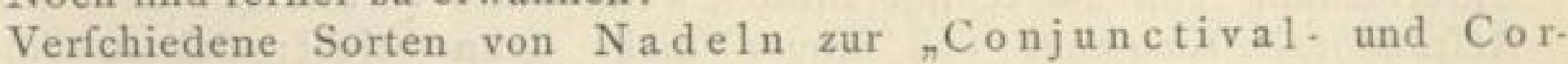
nealfutur".

Unter vielen $\mathrm{Nadelhaltern}$ nennen wir die neu conftruirten nach Sands und nach Collin.

Von den exponirten Thränenfack. Operationsinftrumenten find erwähnenswerth:

Ein Couteau boutonné à double tranchant von Wecker.

Eine Cannule à mandrin pour injections ducanal nafal eben. falls von Wecker angegeben.

Kleine Nägel aus Aluminium von Noy ces.

Ein fehr hübfches, kleines Etui für Thränenfack-Operationen von Mathi e u zufammengeftellt. 
Schliefslich miffen wir noch hervorheben: Ein kleines, fehr nett gearbeitetes E tu i,das nachv. Jäger's Angabe von Thü r ri e gel gefertigt - sit venia verbo „zurkle ineren A u gen chirurgi e "vollkommen ausreicht. Trotz feiner I2 Inftrumente (fremde Körpernadel, Lanzenmeffer, fpitzer und ftumpfer Haken, Spitzund Skalpellbiftouri, Cilien und Hakenpinzette, Löffel nach Daviel und Pinzette mit gerifftem Ende, Fifchbein-Sonde, gerade feine Scheere) ift es ein fehr leicht portatives Tafchenetui.

Die künftlichen A ugen waren ziemlich zahlreich vertreten, wir nennen hier die Sammlungen von:

Kofta \& Harburg (Hamburg), Paul Greiner (Hamburg), Louis Genotte (Belgien), endlich eine kleine Collection fehr billiger Fabricate von Dr. Desjardins de Morainville (à Stück r2 Francs).

Die anerkannten Meifter der Prothefe der "Familie Boiffoneau angehörig, lieferten prachtvolle, äufserft täufchend hergeftellte Kunftaugen in den mannigfaltigften Formen.

Befonders hervorzuheben ift die neue Modification à double echan. crure, welche jede Reizung beim Gebrauch verhindern foll.

A. P. Boiffonneau ftellte ferner unter dem Titel: „Pathologie oculaire" eine Sammlung von 24 Emailaugen (pathologifche Vorgänge am Auge darftellend) mit Wachslider - Einfaffung aus. Als Fabricate wegen der Schwierigkeit der Herftellung beachtenswerth, find wir uns über den Zweck folcher Verfuche nicht klar.

Sollen fie vielleicht die klinifche Beobachtung erfetzen? Sie werden diefs ebenfo wenig vermögen, wie Talrich's: "A ugen und Liderkrankungen" (roo Wachspräparate zum Preife von rooo Francs), denen wir gleichfalls in der franzöfifchen Abtheilung begegneten.

Das Oeil artificiel de Perrin mit 12 verfchiedenen auf Kupferfchalen gemachten Augenhintergriinden ift zur Uebung für Anfänger in der Kunft der Augenfpiegel-Unterfuchung beftimmt.

Auch beim Ophthalmofkopiren ift die Uebung am Menfchenauge felbft eigentlich durch Nichts zu erfetzen und befitzen wir in dem von Mohr (Würzburg I870) conftruirten „Ophthalmophantome" fchon einen viel vollkommneren Apparat, der nicht nur die Uebung in der Augenfpiegel-Unterfuchuug überhaupt, fondern auch zum Zwecke der Beftimmung der Refractionsanomalien ermöglicht.

Zudem geftattet der Mohr'fche Apparat die Verwendung von Ed. v. Jäg er's Augenfpiegel-Bildern* und ftellt fomit ein „phyfiologifches und pathologifches Material künftlich zu Verfügung, wie es uns keine, felbft nicht die gröfste Augenklinik gleichzeitig bieten kann."

Von Augenfpiegeln fanden wir nicht viel und nichts nennenswerthes Neues. Aber mit wirklicher Befriedigung haben wir zu conftatiren, dafs die Unterfuchung ,im aufrechten Bilde“, wenn auch vorerft nur zum Zwecke der Refractionsbeftimmung, fich immer mehr Bahn bricht; faft an fämmtlichen neueren exponirten Augenfpiegeln fanden wir die fogenannte Rekoff'fche Scheibe, welche die Verwendung des Augenfpiegels als Optometer fo fehr erleichtert, angebracht.

* Sein unter dem Titel: „B eiträge zur Pathologie des A uges" nunmehr voll. endeter, aus 77 Bildern beftehender, gröfserer und fein aus 128 Spiegelbildern zufammengefetzter "Handat la s" (von deffen Verwendung oben die Rede) waren durch die k. k. Staatsdruckerei in Wien ausgeftellt. Obwohl einer anderen Gruppe angehörig konnten wir nicht umhin, an diefer Stelle diefer ausgezeichneten Augenfpiegel-Bilder zu erwähnen, die mit dem Verftändniffe des Forfchers ausgewählt, mit einem Fleifse und einer Porträtwahrheit hergeftellt find, die die Arbeit v. Jä g e r's zu einer bisher unerreichten Leiftung macht. 
Von fonftigen optifchen Inftumenten $z u$ augenärztlichen Zwecken fanden wir bei F. Fritfch (Wien) ein neues Ophthalmometer nach Woinow's Angabe gefertigt. Als befonders zweckmäfsig daran müffen wir hervorheben, dafs das Licht einer fixen Lampenflamme von drei ebenen Glas. fpiegelchen reflectirt wird, die an einer um eine horizontale Axe drehbaren Stange angebracht find.

Sonft fanden wir felbft bei $\mathrm{Nachet}$ (Paris) nur von der Parifer Aus. ftellung bekanntes.

Zweckmäfsig arrangirte B rille n käft en fanden wir vorzüglich bei Mathieu und $\mathrm{Nachet}$. F. Fritfeh exponirte in reicher Auswahl nach v. Arlt's Angabe, praktifch ausgezeichnet bewährte Zufammenftellungen.

Ein fehr finnreiches, nettes Brill eng eft ell mit drei Räderchen zum Rollen der Probegläfer enthielt Mathie u's Kaften; F. Fritf ch verwendet in feinem von Biermann angegebenen Prismenbrillen.Geftelle, für viereckige, um ihr Centrum drehbare Prismen, Klammern, auch enthält fein Brillenkaften einen fehr verwendbaren kleinen Apparat mit ftenopäifchen Löchern zu optometrifchen Beftimmungen.

Auch die diefsjährige Weltausftellung brachte uns der fo vielfach erwünfchten Uniformität des Brillenkaftens und feiner Gläfer nicht näher.

Vielleicht fehen wir eheftens die Noumerotagefrage beendet; dann hätten fich die Oculiften über die Brillenfcala im Probekaften geeint und fchleifen erft die optifchen Inftitute ihre Gläfer nach einem gemeinfchaftlichen Mafse, fo bringt uns die nächfte Weltausftellung die internationalen Brillengläfer im internationalen Brillenkaften!

\title{
DIE INSTRUMENTE
}

\section{FÜR LARYNGOSKOPIE UND RHINOSKOPIE.}

\author{
Bericht von \\ DR. L. SCHRÖTTER, \\ Vorfand der Klinik für Halskrankheiten an der Wiener Univerfität etc.
}

In meinem Berichte über Laryngofkopie und Rhinofkopie für die additionelle Ausftellung der Gefchichte der Gewerbe und Erfindungen, welcher bereits ein halbes Jahr vor Eröffnung der Weltausftellung gefchrieben war, fage ich, dafs, ,was auch immer für werthvolle Entdeckungen im Auslande gemacht. wurden, doch unfer Vaterland in der Pflege der neuen Lehre (Laryngofkopie) obenan ftand." Und in der That hat die Weltausftellung in wahrhaft glänzender Weife die Richtigkeit diefes Ausfpruches bewahrheitet. Denn was von anderen Ländern in diefem Fache geboten wurde, war meift fo wenig originell und im Vergleiche mit dem Inftrumenten-Apparate für die übrigen medicinifchen Disciplinen fo geringfügig, dafs es kaum Erwähnung verdient. Einige Fabrikanten haben allerdings nicht felbfttändig in ihrem Lande ausgeftellt, fondern nur eine mehr minder vollftändige Sammlung für die Ausftellung der in Gruppe XIV von Dr. Schrötter zufammengeftellten „Gefchichte der Laryngofkopie“ eingefchickt, was aber nur auf Veranlaffung der betreffenden Aerzte gefchah.

Es ift zu bedauern, dafs F rankreich, deffen Inftrumentenmacher einen fo hervorragenden Platz einnehmen, aus diefem Zweige der Medicin nur einzelne wenige Inftrumente ausgeftellt hatte. 
Von Beleuchtungsapparaten ift aufser einem kleinen portativen Linfen-Apparate von $\mathrm{R}$ aoul $\mathrm{M}$ athieu und einem anderen von Colin Nichts zu erwähnen; und auch diefe haben vor ähnlichen anderer Autoren keinerlei wefentliche Vortheile. Neu war ein Inftrument von Colin, um mit Gewalt den Mund eines Patienten zu öffnen, bei welchem eine, in eine feine Kante auslaufende, fchiefe Ebene aus Stahl mittelft Hebelwirkung zwifchen die Zähne hineingetrieben wird. Das Inftrument geftattet grofse Kraftentfaltung, ift aber wegen des verwendeten Materiales fehr unangenehm.

Mat hi e u brachte einen gedeckten Aetzmittel-Träger von Fauvel, bei dem durch eine losgelaffene Feder das Aetzmittel plötzlich an die betreffende Stelle angedriickt wird, worin eben kein erheblicher Vortheil erblickt werden kann.

Einiges Auffehen erregte der bei Mathieu ausgeftellte Pinfel von Dr. Krishaber in Paris, deffen Dimenfionen in ganz erftaunlicher Weife über alles Nothwendige hinausgehen.

Von elektrifchen Inftrumenten ift nur bei Mathieu der fchon bekannte Réophor von Fauvel zu finden. In Galvanokauftik bieten die Franzofen nichts Neues. Co $l$ in ftellte zwei guillotineartig wirkende Polypotome aus, die beide fehr finnreich conftruirt find, aber mit allen ähnlichen Inftrumenten die Complicirtheit und fchwere Einfihrbarkeit theilen, ohne weitere Vortheile zu bieten.

Unter den Zerftäubungs. Apparaten verdient der von Mathieu conftruirte Erwähnung, der fich durch Erzielung einer gröberen, feineren und feinften Zerftäubung auszeichnet.

Das Rhin ofk op von Dr. Baxt und das von Colin, beide in der Ausftellung von Robert \& Colin, welche den Zweck haben, den Spiegel und die Vorrich. tung zum Heben des weichen Gaumens und der Uvula in einer Hand zu vereinigen, find beide finnreich erdacht, leiden aber an den Fehlern ähnlicher, fchon von Czermak und Störk angegebener, und feither nicht weiter in Gebrauch kommender Inftrumente.

Sehr nett ift eine kleine, gegliederte Pincette von Colin, um aus der Cannüle nach gemach ter Tracheotomie Croupmembranen etc. zu entfernen.

Ebenfo ift ein von demfelben Inftrumentenmacher angegebenes Dilatatorium mit drei Branchen, um nach Entfernung der Cannüle die Wundöffnung offen zu erhalten, recht zweckmäfsig.

Anhangsweife feien noch zwei Inftrumente für den $\mathrm{O}$ efo ph a g u s erwähnt: das Eine von Mathie u nach Art jener Scheeren, wie fie die Kinder zum Aufftellen der Soldaten verwenden, verlängerbar gebaut, dient zur Entfernung fremder Körper aus dem Oefophagus. Da das Inftrument bedeutend verlängert werden kann und relativ wenig Breite befitzt, erfcheint es fehr praktifch. Das zweite Inftrument von $\mathrm{C}$ olin, dem Uréthrotome caché nachgebaut, geftattet durch fehr finnreiche Vorrichtung genau abzulefen, wie weit die anfänglich verdeckten Meffer in die Oefophagus-Strictur eingefchnitten haben und gewährt daher, wenn man überhaupt ein folches Inftrument anwenden will, einige Sicherheit.

In Italien fanden fich nur in der Ausftellung von Baldinelli aus Mailand einige Neuigkeiten : Ein Beleuchtungs-Apparat von Dr. L a b u s in Mailand, bei dem mittelft eines grofsen, am Stative befeftigten Reflectors in zweckmäfsiger, aber gleich complicirter Weife, wie bei allen ähnlichen Apparaten, Licht in die Mundhöhle geworfen wird. Ein Beleuchtungs-Apparat von Dr. Ch r ift o for is, wo eine an einer Stirnbinde befindliche planconvexe Linfe den Zweck hat, einfaches Tageslicht (jedenfalls nicht in ausreichender Weife) in den Mund zu werfen; endlich ein kleines Tafchen-Laryngoskop von Baldinelli. Inftrumentenmacher L oll in i aus Bologna ftellte in einer grofsen Sammlung chirurgifcher Inftrumente ein ungemein elegant gearbeitetes Etui nach Bruns aus.

In Dänemark fand fich nur bei Profeffor Nyrop ein kleines, fehr correct gearbeitetes Etui mit einigen Inftrumenten nach Bruns und Wintrich. 
Sehr auffallen mufs es, dafs Deutfchland, in dem fo hervorragende Laryngofkopiker leben, in keiner regeren Weife hervortrat und nichts Neues bot. Nur zwei Dinge erregten unfer Intereffe: es war diefs erftens die in der Mafchinenhalle ausgeftellte dynamo-elektrifche Lichtmafchine von Siemens \& Halske in Berlin, die natülich in diefem koloffalen Mafsftabe nicht für uns zu brauchen ift, es aber wohl der Mühe werth wäre, Verfuche anzuregen, ob fich nicht in kleinerem Mafsftabe eine folche Lichtquelle für unfere Zwecke ausnützen liefse. Der zweite Apparat war der von Dr. Ste in in Frankfurt am Main in Gruppe XIV ausgeftellte Heliopictor. Die gewonnenen laryngofkopifchen Bilder find in der That recht befriedigend, es muifste aber erft ein praktifcher Verfuch zeigen, ob das Verfahren in' der That fo einfach ift, und behält fich Referent eine fpecielle Prïfung des Gegenftandes vor.

Aufserdem ftellten Louis B l u m b e r g in Berlin, Friedrich Hell e $\mathrm{r}$ in Nürn. berg einige wenige Inftrumente nach den bekannten Formen von Bruns, Lewin und Tobold - H ell er aufserdem eine Dubofque'fche Lampe - aus. Auch H. Wind. le $\mathrm{r}$ in Berlin brachte hier nur ein Paar bekannte Inftrumente und foll von diefen noch in Schrötter's Ausftellung gefprochen werden.

In Ungarn hat Peter Fif cher aus Peft eine fchön gearbeitete Sammlung chirurgifcher Inftrumente geliefert, namentlich eine grofse Anzahl verfchiedener Modificationen des Tonfillotomes; in laryngofkopifchen Inftrumenten aber nur einige Polypeninftrumente nach dem Mufter der Störk'fchen Guillotine.

$\mathrm{R} u f s$ land ftellte in der Ausftellung feines Kriegsminifteriums doch auch ein kleines Tafchenetui für Laryngofkopie, Reflector mit Stirnbinde und einen Aetzftab aus.

Wie fchon erwähnt, hat am reichften $\mathrm{O}$ eft e r r e i c h in unferem Fache exponirt. J. M a ng aus Prag und J. So be l aus Graz ftellten wohl nur ältere Inftrumente in der bekannten Form und in nur wenigen Exemplaren aus; fie find aber recht gut gearbeitet. Es mufs Wunder nehmen, dafs J. Leiter aus Wien, dem das fchöne Verdienft gebührt, Inftrumente für die Laryngofkopie zuerft in grofsem Mafsftabe fabricirt, ja geradezu diefen Induftriezweig in Auffchwung gebracht und manche nennenswerthe Neuerung eingeführt zu haben, fich diefes Mal nur auf die Vorführung der bekannten Inftrumente, und auch nicht in reichlicher Auswahl, befchränkt hat. Auch J. Thürrieg1, der eine Reihe von Jahren unter Türck's fpecieller Anleitung arbeitete, brachte nur Weniges und nichts Neues. Heinrich $\mathrm{R}$ e in er aus Wien ftellte in feiner Ausftellung zwei fehr fchön gearbeitete Etuis mit Inftrumenten, wie fie Schrötter und Störk gebrauchen, aus. Die "Gefchichte der Laryngofkopie“ von Dr. Schrötter und H. Reiner, welche ihren Platz beffer in der Ausftellung des Unterrichts-Departements oder in der additionellen Ausftellung gefunden hätte, aus manchen Gründen aber hier eingereiht wurde, gab einen vollftändigen Ueberblick über den Stand des Faches, von den erften Tagen feiner Entftehung bis zur heutigen fo fchön entwickelten Höhe.

$\mathrm{Schrötter} \mathrm{wandte} \mathrm{fich} \mathrm{nämlich} \mathrm{mündlich} \mathrm{und} \mathrm{fchriftlich} \mathrm{an} \mathrm{jene} \mathrm{Aerzte,}$ die fich mit Kehlkopf-Krankheiten befonders befchäftigen, mit dem Anfuchen, Inftrumente ihrer Erfindung, namentlich die hiftorifche Entwicklung des Faches beleuchtende, feiner Ausftellung zuzuwenden.

Mackenzie in London (Inftumentenmacher Mayer \& Meltzer), Bruns in Tubingen (Inftrumentenmacher Beuerle \& Albrecht), Tobold und L e w in in Berlin (Inftrumentenmacher Windler und J. Thamm), So m m e rbrodt in Breslau, Rauchfufs in Petersburg. Störk und Fieber in Wien entfprachen dem Wunfche, und fandten mehr minder reichhaltige Sammlungen ihrer Inftrumente im Originale ein. - Eine fehr grofse Anzahl von Inftrumenten wurde von Heinrich Reiner in Wien, theils nach feinen eigenen Kenntniffen, theils nach den von Schrötter angegebenen Zeichnungen und Erklärungen ausgeführt; ein Theil 
ift Schrötter's Privateigenthum; ein anderer Theil endlich ift Eigenthum der Klinik für Laryngofkopie an der Wiener Univerfität. *

Es verfteht fich von felbft, dafs nicht alle erdenklichen Inftrumente aus geftellt wurden, fondern von jeder Gruppe nur die wichtigften, die den Gegen. ftand am beften zu erläutern im Stande waren, oder anderweitig ein höheres Intereffe erregen.

Zuerft kamen die verfchiedenen Beleuchtungsapparate, wie fie von Türck, Czermak, Störk, Lewin, Tobold, Bruns, Krishaber, Fauvel, Moura-Bourouillou, Rauchfuss angegeben wurden; die finnreiche, aber complicirte Lampe zum Höherund Tieferftellen mittelft des verfchiebbaren Parallelogrammes von Mackenzie; die einfache Petroleumlampe nach Schrötter, von Ditmar in Wien ausgefuihrt, die fich durch die grofsen Dimenfionen des Rundbrenners ( $15^{\prime \prime \prime}$ Durchmeffer) auszeichnet und ein ganz vorzügliches Licht gibt; der Prismen-Apparat von B os e in Berlin; endlich die verfchiedenen, theils im Munde (Czermak), theils mittelft Stirnbinde zu befeftigenden Reflectoren, den ohne Weiteres einfachften und zweckmäfsigften Apparaten. Hierauf folgten die verfchiedenen Formen der Kehl. kopf-Spiegel, unter denen fich noch Originale der zuerft von Türck angegebenen befanden. Wohlthuend unterfcheidet fich die einfache Form des runden Wiener Spiegels, mit dem man, nebenbei gefagt, Alles zu leiften vermag, von den complicirten, unpraktifchen, oft geradezu nur in Spielerei ausartenden Angaben Anderer.

Nun folgten die wenigen Apparate, um vergröfserte Spiegelbilder zu erhal. ten, darunter der erfte von Primarius Werthe im in Wien angegebene. Neu ift die Form der Anwendung der einfachen Biconvexlinfe von Dr. W eil in Heidelberg. die aber in ihrer Leiftung nicht fo weit geht als die alte Türck'fche Perfpectiveloupe. Es ift richtig, dafs diefe bei Weitem complicirter und in ihrer Anwendung Anfangs geradezu mühevoll ift. Durch von $\mathrm{S} c h \mathrm{röt} t \mathrm{e}$ angegebene Verbefferungen find diefe Nachtheile aber bedeutend vermindert. Diefer hat nämlich das Geftell des Türck'fchen Beleuchtungsapparates fo eingerichtet, dafs es am Stuhle des Unter. fuchenden felbft befeftigt werden kann, und anderfeits zur Einftellung des Fernrohres, ftatt des kaum je ruhig zu bewirkenden Verriickens mit der Hand eine kleine mit der linken Hand zu dirigirende Schraube angebracht. In diefer Weife gelingt es leicht, einer grofsen Anzahl von Zuhörern das grofse, oft überrafchend fchöne Bild zu zeigen.

Unter den Apparaten zur Befeitigung einer zu grofsen Zungenwölbung befindet fich nichts Neues.

Die jetzt folgenden Vorrichtungen zum Aufheben einer zu ftark liegenden Epiglottis find meift bekannt. Neu ift nur eine kleine, federnde, an einem Faden befindliche, von Dr. Glasgow (in St. Louis) angegebene Klemme, welche fich aber nur fehr fchwer fo einrichten läfst, dafs fie eben hält und anderfeits wieder nicht zu feft drückt. Der entfprechend gebogene elaftifche Katheter nach Schrötter oder allenfalls das von ihm angegebene Inftrument zum Durchführen eines Fadens durch die Epiglottis find, wie fich vergleichsweife leicht zeigt, jedenfalls das Einfachfte.

Die Vorrichtungen, um pulverförmige Subftanzen in den Larynx zu bringen oder Flüfigkeiten in denfelben zu träufeln, folgten in hiftorifcher Aufeinanderfolge, ohne wefentlich Neues zu bieten.

Unter den verfchiedenen Formen der A etzmittelträger zeichnet fich neben dem finnreichen Störk'fchen, der alte Türck'fche, von Schrötter modi. ficirte, durch feine Einfachheit, bei gleicher Leifungsfähigkeit mit allen Uebrigen,

* Diese wurde im März 1870 im k. k. allg. Krankenhaufe errichtet und mit $x 6$ Betten ( 8 Männer, 8 Weiber) verfehen. So viel mir bekannt ift, gibt es nur eine zweite änliche Anftalt. unter Mackenzie's Leitung in London, 1863 errichtet; gibt es nur eine zweite ahnliche Anftalttorium. So kurz das Beftehen der Wiener Anftalt ift, hat doch die Zahl der Zuhörer und der hilfefuchenden Kranken in foleher Weifer Antalt in, hat doch die Zahl der Zuhorer und der drückender Weife als zu klein erweifen. 
aus. Denn dort, wo z. B. Bruns zu einem Hefte zehnerlei Anfatzenden für Aetzungen an verfchiedenen Stellen des Kehlkopfs bedarf, genügt das Eine Schrötter'fche Inftrument, welches, weil es biegfam und der eigentliche Aetzftab drehbar ift. Aetzungen an allen möglichen Localitäten geftattet. So fchön die Deckungsröhre bei dem Inftrumente von Bruns auch gearbeitet ift, fo ift fie doch um ein Bedeu. tendes complicirter, daher fchwerer rein zu halten und theurer.

Nun folgt die grofse und am weiteften ausgebildete Reihe von Inftrumenten zur Unterfuchung und Entfernung von Neubildungen und fremden Körpern aus dem Schlunde und dem Kehlkopfe. Es würde zu weit führen, wollte man diefe alle aufzählen; es foll hier nur auf folgende Punkte aufmerkfam gemacht werden: Am zweckmäfsigften müffen offenbar jene Inftrumente erfcheinen, die bei gleicher Sicherheit in der Handhabung die gröfste Anwendung in Bezug auf Verfchiedenheit des Sitzes der Gefchwulft und auf Gröfsenverhältniffe des betreffenden Individuums geftatten, und bei alledem einfacher und billiger find als andere. Allen diefen Anforderungen genügen die Inftrumente der Wiener Schule, wie fie zuerft von Türck angegeben und gegenwärtig von $\mathrm{H}$. R e in e $\mathrm{r}$ in ausgezeichneter Weife, mit wefentlichen Modificationen von S chrötter ausgeführt werden. Diefe Inftrumente haben nämlich alle einen nicht zu kleinen und fich darum bequem in die Hand legenden Griff, eine mit doppelter Krümmung verfehene Röhre, in welcher der zu deckende eigentliche Operationstheil mittelft einfachen Knopfes verfchoben wird. Die eine der erwähnten Krümmungen, die in horizontaler Ebene angebracht ift und fich nach rückwärts befindet, hat den grofsen Vortheil, dafs dadurch die Hand des Operateurs von der Mundöffnung des Kranken wegkommt, und das Licht gut einfallen kann. Die zweite am vorderen Ende des Inftrumentes in verticaler Ebene angebrachte Krümmung hat den Zweck, da diefer Theil biegfam ift, das Inftrument dem Baue verfchiedener Individuen nach Gröfse etc. accommodiren zu können. Der Vortheil kann nicht einfacher gefchildert werden, als wenn ich fage, dafs dort, wo Schrötter ein einziges solches Inftrument nothwendig hat, Mackenzie in London deren achtzehn, Fauvel in Paris deren nicht viel weniger brauchen, die aber alle von Stahl und fomit vollkommen unbiegfam find. Die doppelte Krümmung der Wiener Inftrumente ift allerdings für das Unterbringen in Etuis unbequem, das Auseinandernehmen derfelben und Einbringen anderer Blätter durch Einfchrauben nach Türck mühfam und zeitraubend; durch die Verbefferungen von Schrötter jedoch find alle diefe Nachtheile vollkommen überwunden. Denn es wird das Auseinandernehmen der Inftru. mente und Einpaffen neuer Blätter durch eine einfache fägeförmige Zähnung beider Endtheile in ebenfo ficherer als fchneller Weife beforgt. Eine andere, ganz wefentliche Verbefferung ift die von H. Reiner angegebene finnreiche Methode, mittelft welcher die Drehung des Endtheiles der Inftrumente bewirkt werden kann. Schon Mackenzie hat eine Pincette angegeben, bei welcher bei einfacher Krümmung (Endkrümmung in verticaler Ebene, Inftrument von Stahl) die Drehung der Pincettenbranchen durch eine von $\mathrm{M}$ a y e r \& $\mathrm{M}$ elt $\mathrm{z}$ e rungemein fchön gearbeitete in der Deckungsröhre befindliche Kette bewirkt wird. Bei Reiner aber wird bei doppelter Krïmmung des Inftumentes dasfelbe in viel einfacherer Weife dadurch erreicht, dafs der-drehbare Stab, an welchem die Pincettenbranchen angebracht find, fich nach vorne verjüngt und von der Verjüngungsftelle bis zur eigentlichen Pincette hin, ein an den genannten Stellen angelötheter feiner Draht fpiralig herumgewunden ift. Es verfteht fich von felbft, dafs diefe finnreiche Idee für alle ähnlichen Inftrumente verwerthet werden kann.

Es mufs befonders betont werden, dafs es gar keinem Zweifel unterliegt, dafs fich diefelbe Operation in gleich gelungener Weife mit ganz verfchiedenen Inftrumenten ausführen läfst, dafs jeder Erfinder Lieblingsinftrumente haben wird, und zwar ganz berechtigt, indem er eben mit denfelben Operationen aus.

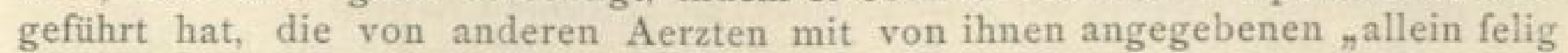
machenden" vollführt wurden. Es ift daher eine principielle Beurtheilung der 
Inftrumente kaum möglich. Bei den meiften Operationen im Kehlkopfe handelt es fich darum, das Inftrument durch die Mund- und Rachenhöhle gedeckt in den Larynx einzuführen und es erft, wenn es an der richtigen Stelle angelangt ift, für die betreffende Wirkung: Schneiden, Aetzen, Kneipen etc. zu entfalten. - So zieht es z. B. der Eine vor, die Deckung in der Weife zu beforgen, dafs das eigentliche Inftrument fix ift, zur Deckung aber über dasfelbe eine Röhre gezogen wird, während es der Andere für zweckmäfsig hält, wenn in einer fixen Röhre das Inftrument vor- und zurïckgefchoben werden kann. Der Eine wieder will nur das Vorfchieben durch eigene Handbewegung beforgen, während das Zurïckfchieben durch eine beim Vorfchieben comprimirte Feder gefchieht. Der Andere endlich, und das ift mein Standpunkt, will das Vor-und Rückfchieben vollkommen in feiner Macht, alfo von jeder Feder-, Hebel- etc. Wirkung vollftändig unabhängig haben. Mit Beweifen läfst fich hier nicht ankämpfen, indem der Betreffende eben antwortet, es liege ihm das Inftrument nach feiner Angabe beffer in der Hand etc.

Scheerenartige Inftrumente fanden fich bei Rauchfufs und Bruns und in Zeichnung nach Merkelvor; fie haben fich theils wegen complicirten Baues, theils wegen gröfserer Raumentfaltung, theils wegen Unficherheit nicht als zweck. mäfsig erwiefen.

Guillotineartige Inftrumente lagen in reicher Auswahl vor. Die älteften, (ich betone: die älteften) von $\mathrm{M}$ a thie u fchon $\mathrm{r} 858$ und $\mathrm{I} 86 \mathrm{r}$ angegebenen; folche von $\mathrm{T}$ ü rck (in befonders grofser Zahl), Bruns und Störk, endlich das fchönfte von H. R e in e r. Diefes ungemein elegant gearbeitete Inftrument ift nämlich die vollkommenfte, nur höher ausgebildete Nachahmung der Tonfillenguillotine und hat folgende grofse Vortheile: Es ift erftens biegfam; zweitens wird die Gabel, die den Tumor fixirt, felbftfändig vorgefchoben (gegen $\mathrm{M}$ a t $\mathrm{h}$ i e u) und drittens ift die ganze Guillotine fo drehbar, dafs das e in e Inftrument für alle möglichen Fälle angewendet werden kann. Wenn alfo die Guillotine mit Berüickfichtigung ihrer Complicirtheit uberhaupt angezeigt ift, fo ift diefe Form jedenfalls die vollkommenfte.

Schlingenfchnürer fanden fich ebenfalls ín grofser Anzahl nach Bruns, Lewin, Gibb, Störk, Schrötter, Sommerbrodt vor, ohne dafs das eine oder andere diefer Inftrumente einen wefentlichen Vortheil darbieten würde.

Hieran fchliefsen fich die galvanocauftifchen, wohl entbehrlichften Inftrumente in der ganzen Laryngo-Chirurgie, an. Wer die Sache vorurtheilsfrei beurtheilt, mufs auch zugeben, dafs diefe Inftrumente, von der Batterie angefangen, bis zu dem eigentlichen, in den Kehlkopf einzuführenden Theile, noch im Argen liegen. Sie find hier hauptfächlich durch die Apparate von Bouns und Voltolini vertreten. Aufser einem von Schrötter angegebenen Griffe, der den Vortheil der rafcheften Verkleinerung der Schlinge bei geöffnetem oder gefchloffenem Strome bietet und mit einer Hand zu dirigiren ift, fo dafs alfo ein Affiftent entbehrlich wird, findet fich nichts Neues.

Im Anhange feien hier noch die Inftrumente von Dr. F. Fie ber erwähnt, deren Zweck es ift, Tumoren mittelft Elektrolyfe zu zerftören, über deren proble. matifche Wirkung jedoch, abgefehen von der Umfändlichkeit und Langwierigkeit des Verfahrens, noch kein unbefangenes Urtheil vorliegt.

Unter den rhinofkopifchen Inftrumenten find nur der gebogene gedeckte Aetzmittel-Träger, und der gerade für Aetzungen von vorneher, beide von Schrötter angegeben, neu. Der letztere befteht aus einem I2 Centimeter langen, 2 bis 3 Millimeter im Durchmeffer haltenden Rohre aus Silber, das an einer Seite mit einem durch die ganze Länge verlaufenden Schlitze verfehen ift. In diefe Röhre wird ein mit einer Rinne verfehener Stab gefchoben, in die das Aetzmittel eingefchmolzen wird. Am Griffe ift bemerkt, ob das Aetzmittel dem Schlitze am äufseren Rohre entfpricht oder bei Umdrehung nicht. Nach vorheriger Mafsnahme mit der Sonde kann jede beliebige Stelle der Nafenmufchel etc. getroffen werden.

Vollkommen neu endlich find Schrötter's Inftrumente zur Erweiterung von Stricturen des Larynx nach gemachter Laryngatomie, zu dem Zwecke, um die 
Cannüle wieder entbehrlich zu machen, und die fämmtlichen Inftrumente für die Krankheiten der Trachea.

Erftere beftehen aus etwa 4 Centimeter langen Bougien aus Hartkautfchuk und fpäter aus Zinn von verfchiedener Dicke, welche an einem Faden befeftigt, mittelft eines ftarren Rohres von oben her durch die Strictur des Larynx und das obere Fenfter der Cannüle in diefe hineingefchoben und hier mit einer kleinen Pincette befeftiget werden, während nach oben aus der Mundhöhle nur der erwähnte Faden heraushängt. Diefe Bougie wird, ohne den Kranken im Athmen und Schlingen zu beläftigen, durch 24 Stunden bis zur nothwendigen Reinigung liegen gelaffen, worauf eine gröfsere eingeführt werden kann etc.

Hierher gehört auch ein Inftrument, an welchem durch Schraubenwirkung die von oben her in den Larynx eingeführten Branchen aus einander getrieben werden und fo die Strictur erweitert wird.

Die Inftrumente für die Trachea beftehen in einem Einblaferohr für pulverförmige Subftanzen, welches durch den Larynx hindurch bis in die Trachea gebracht wird, einem röhrenförmigen Inftrumente, aus welchem nach Art der Muzeux. fchen Zange gebaute Hacken zurEntfernung von Neubildungen entwickelt werden können, und endlich ein verlängerbares Dilatatorium aus Hartkautfchuk, das nicht nur mit Sicherheit bis an die Bifurcation der Trachea, fondern auch bis in die Bronchien felbft, und zwar nach Abficht des Operateurs in den rechten oder linken eingeführt werden kann.

Diefe fämmtlichen Inftrumente find bereits erprobt. (Siehe Bericht der Klinik für Laryngofkopie i870, Braumüller I87r.)

\title{
DIE APPARATE FÜR ELEKTROTHERAPIE.
}

\author{
Bericht von
}

\author{
DR. M O R I Z B E N E D I K T, \\ $K . k$. Univerfitäts-Profeffor in Wien.
}

Die Expofition medicinifch-elektrifcher Apparate erregt das Intereffe nach zwei Richtungen hin. Einmal, inwieferne die Production in den verfchiedenen Ländern den bereits bedeutenden heimifchen Bedarf deckt und den fremden Markt beherrfcht, und anderfeits in Bezug auf die Fortfchritte fowohl in technifcher Beziehung als in Bezug auf die praktifche Brauchbarkeit, wobei der Preis ebenfalls eine Rolle fpielt.

Inductionsapparate waren in den verfchiedenften Ländern ausgeftellt, und fowohl Deutfchland, Frankreich, Oefterreich-Ungarn, als Italien, Dänemark und England haben folche Inftrumente geliefert. Wefentliche Veränderungen in der Conftruction waren nicht zu bemerken, und als ein einigermafsen neuer Typus diefes Inftrumentes kann allenfalls der Apparat von Schivardi angefehen werden, der fich in der Ausftellung von $\mathrm{Baldinelli}$ aus Mailand und Batocchi aus Verona befand.

Der Schwerpunkt der Ausftellung lag in den galvanifchen Batterien zu therapeutifchen Zwecken. In früheren Jahren hat die Firma Siemens \& $\mathrm{Halske}$ mit den Daniel'fchen und fpäter den von ihnen verbefferten Elementen den Weltmarkt beherrfcht. Nicht minder find eine Reihe von Hilfs. apparaten, die aus diefer Fabrik hervorgegangen find, vor Allem der Strom- 
wender, der Stromwähler und Stromwechsler, ebenfo wie der Stöpfelrheoftat mafsgebend gewefen.

Da diefe Elemente durch ihre Gröfse und dadurch hervorgerufene fchwere Transportabilität der Batterien, ferner durch den Mangel an Conftanz bei längerem Gebrauche den Wünfchen der Aerzte nicht vollftändig entfprachen, wurden nach allen Richtungen neue Elemente, die in Vorfchlag kamen, verfucht. Es fei beiläufig bemerkt, dafs neben den Elementen von Siemens \& $\mathrm{Halske}$ auch noch die Elemente von Meidinger und die ihnen ähnlichen fich bei vielen Aerzten einer grofsen Beliebtheit erfreuten.

Herr Dr. Brunner aus Warfchau hat einen Apparat ausgeftellt, welcher die Periode von Siemens \& Holske in der glänzendften Weife abfchliefst, indem auf demfelben alle Leiftungen der berühmten Berliner Firma vereinigt und in deren Sinn fortgebildet erfcheinen. Zudem ift der Apparat unter den Augen des genannten Arztes mit technifcher Vollendung ausgeführt worden, und Rufsland dadurch in hervorragender Weife in diefer Gruppe repräfentirt. Mayer \& Wolf aus Wien haben ebenfalls ihre treue Anhänglichkeit an der Tradition jener Firma bewiefen.

Unter den Elementen, die in neuer Zeit aufgetaucht find, haben vor Allem zwei die Aufmerkfamkeit der Aerzte auf fich gezogen. Das erfte von diefen ift das Element von Leclanché, welches den Vortheil bot, nur eine Flüffigkeit zu benöthigen und den zweiten Elektrolyt in der Kohle felbft zu bergen. Diefes Element erfchien in Modificationen noch auf der Ausftellung. z. B. in jener von Mayer \& Wolf und von Teuchert in Wien. Eine Modification diefes Elementes wurde von Beetz vorgenommen und diefe nach dem Modificator benannten Elemente führt uns Dr. Edlmann aus München in der deutfchen Abtheilung in ihrer vollendetften Form vor. Statt Kohle wird ein mechanifches Gemenge von Kohle und doppelchromfaurem Kali verwendet und in diefe Maffe ragt ein Platindraht hinein. Die Elemente von Beetz haben die Gröfse eines gewöhnlichen chemifchen Reagenzgläschens, es läfst fich daher eine grofse Anzahl von Elementen in einem kleinen Raume anbringen, und die Batterie, wenn fie das hält, was ihr Erbauer fich von ihr verfpricht, wäre ein paffender Erfatz für alle früher in Gebrauch gezogene Elemente. Sartori in Wien hat modificirte Leclanche'fche Elemente conftruirt, wobei er das Zink durch Eifen und die Salmiaklöfung durch Chlornatrium erfetzte und die Form der urfprünglichen Leclanche'fchen Elemente beibehalten hat. Letzterer Producent hat die Batterie noch weiter dahin modificirt, dafs er durch ein Schlauchfyftem die in der Batterie entwickelten Gafe ableitet, und er nannte diefe modificirte Batterie die Gasabzugs-Batterie.

Ein anderes Element, welches in den letzten Jahren die Aufmerkfamkeit der Aerzte auf fich gezogen hat, ift jenes von Pincus - das Chlorfilber-Element. Das wichtigfte Chlorfilber-Element, das exponirt wurde, rührt von Ga iffe in Paris her; und wir wollen uns bei diefer Batterie umfomehr aufhalten, als fie der Zukunftsapparat in der Medicin zu werden verfpricht.

Keine andere Batterie erreicht die Gaiffe'fche an Compendiofität, da er 60 Elemente, worunter ro ftark elektrolytifch wirkende in einem einzigen Kaften vereinigt, da ferner diefe Batterie eine Modification des Stromwählers enthält, in allen Bedürfniffen entfpricht. Diefer neue Stromwähler ift nämlich dop p elt und hat fo den Vortheil, dafs man die Batterie auf eine beliebige Anzahl von Elementen nicht blofs von $\mathbf{I}$ an einfchleichen, fondern bei einem beliebigen Elemente beginnen kann; braucht man z. B. Io Elemente, fo bekommt man diefe Anzahl nicht nur, indem man auf dem einen Stromwähler auf ro geht, fondern auch, wenn man den einen Stromwähler auf 10 und den andern auf 20 einftellt. Sowie nämlich der eine Stromwähler mit dem Zinkpol aller Elemente in Verbindung fteht, fo fteht der andere mit dem Kupferpol aller Elemente in Verbindung. Diefe Einrichtung hat den Vortheil, dafs man nicht in Verlegenheit kommt, wenn gerade 
in den erften Elementen ein Fehler ift, und dafs man mit der gröfsten Leichtig. keit conftatiren kann, in welchem Elemente der Fehler fteckt. Die Elemente felbft enthalten keine Flüfligkeit, indem die Feuchtigkeit der Luft hinreicht, die Rolle der Flüffigkeiten in den Elementen zu fpielen; fie haben ferner nur ein Salz. Chlorfilber, und das ganze Element ift fo compendiös, wie keines bisher in Gebrauch gezogenes und fteckt in einer Kautfchukhülfe unverändert drinnen. Auch die Art der Verbindung der einzelnen Elemente durch hervorragende Metallftücke und ftarke Federn mit den Stromwählern hat nichts mit der mühfamen und ver. wirrenden durch Drähte gemein; aufserdem ift jede Serie von Elementen in eigenen Käftchen vereinigt, die leicht ausgehoben werden können und in diefen ift jedes Element zur weiteren Behandlung leicht zugänglich. Die gröfseren diefer Käftchen find auch mit einer Bouffole und dem Stromwender verfehen, fo dafs fie allen ärztlichen Bedürfniffen vollftändig entfprechen. Die Nachtheile des hohen Preifes der erften Füllung werden dadurch aufgewogen, dafs das koftbare Material des Silbers nicht verloren geht und leicht wieder in Chlorfilber überführt, werden kann. Die Batterie ift, wie ich aus Verfuchen weifs, fehr ftark, und wenn fie die Conftanz befitzt, die ihr Gaiffe zufchreibt, fo wird das Modell diefer Batterie fuir lange Zeit das herrfchende in der Medicin bleiben.

Eine Chlorfilber-Batterie wurde auch von Stöhrer in Dresden ausgeftellt und eine Beetz'fche von Heller in Nürnberg.

Von den älteren Modellen ift vor Allem die Kohlen-Zinkbatterie ohne Diaphragma mit Schwefelfäure-Füllung oder Clorfilber-Löfung zu erwähnen. Solche Batterien wurden von der altbewährten Firma Stöhrer in Dresden in ihrer bekannten technifchen Vollendung ausgeftellt. Neu an dem Stöhrer'fchen Modell ift die Einfügung von Inductionsapparaten in die galvanifche Batterie.

Ein alter aber werther Bekannter für die Fachmänner ift die platinifirte Bleizink-Batterie von F rom mold in Peft, welche durch ihre Verbindung mit einem bequemen Stromwähler ferner mit einem Stromwender und der Tauchvorrichtung die beften Dienfte geleiftet hat.

Von älteren Modellen if noch jenes der Sme e'fchen Batterie mit einem Stromwähler und einer Senkvorrichtung in der Expofition des Dänen Rasmufs aus Kopenhagen zu erwähnen. So compendiös diefer Apparat auch conftruirt ift und trotzdem derfelbe mechanifch nicht fchwer zu transportiren ift, fo dürfte das Modell wegen der Säuren und der mangelnden Feftigkeit der Verbindungen kaum viele Bewunderer finden.

Von neuen Ideen bei der Conftuction der Elemente ift noch Sartori zu erwähnen, welcher Kohlen-Zinkbatterien conftruirt hat, mit der Modification, dafs die genannten Metallplatten fenkrecht übereinander fich befinden und, was hervorzuheben ift, die Zinkplatte in Queckfilber getaucht ift.

Einen fehr fchönen Gedanken hat der gewandte Jofef Leiter in Wien in feinen Elementen zur Darftellung gebracht. Statt das Kohlen-Zinkelement nach dem Gebrauche aus der Flüffigkeit zu heben, beftrebt er fich die Flüffigkeit von den wirkfamen Platten zu verdrängen. Auf dem Grunde des Glafes befindet fich während der Thätigkeit ein Kautfchukcylinder, über dem die Flüffigkeit fich befindet. Wenn das Element aufser Gebrauch kommen foll, wird der genannte Cylinder gehoben, dadurch ftrömt die Flüffigkeit nach unten. In diefem Cylinder find zwei Spalten, die nach oben und unten offen find, durch welche die Flüffig. keit beim Heben hinabfliefst, und in welche die Kohlenplatte hineinpafst. Diefer Cylinder hat aufserdem eine mittlere Spalte, die nach unten gefchloffen ift, und in diefe kommt die Zinkplatte zu liegen. Da nun diefe mittlere Spalte immer etwas Queckfilber enthält, fo befindet fich der Zinkcylinder, wie beim Element Sartori hier nach dem Gebrauche in amalgamirender Umgebung. Die Hebung des Cylinders gefchieht durch einen doppelt zufammenlegbaren Kautfchukftab, der die Form der gewöhnlichen Mafsftäbe hat, deren einzelne Theile übereinander gefchoben werden können. 
Das Beftreben, die Unterbrechungs- und Wendungsvorrichtungen in die Rheophoren zu verlegen und dadurch eine manipulirende Hand zu erfparen, findet ihren Ausdruck in der Rheophorm von Rasmufs, von Edlmann und in neuer origineller Weife durch Drehung eines Rades im Rheophor bei Leiter.

Batocchi aus Verona hat eine modificirte Holz'fche Mafchine ausgeftellt.

Leiter \& Heller exponirten auch galvanokauftifche Apparate, ferner Leiter und Stöhrer, fehr gut gearbeitete Inftrumente für die Anwendung der Galvanokauftik.

Stöhrer exponirte noch einen Flüfigkeitsrheoftaten (beftimmt für eine Zinkvitriol-Löfung). 


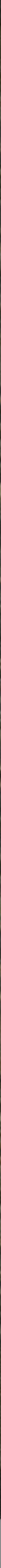


$7 \underset{\text { wifuthe }}{\operatorname{SLUB}}$

http://digital.slub-dresden.de/id $474026485 / 52$

輩 



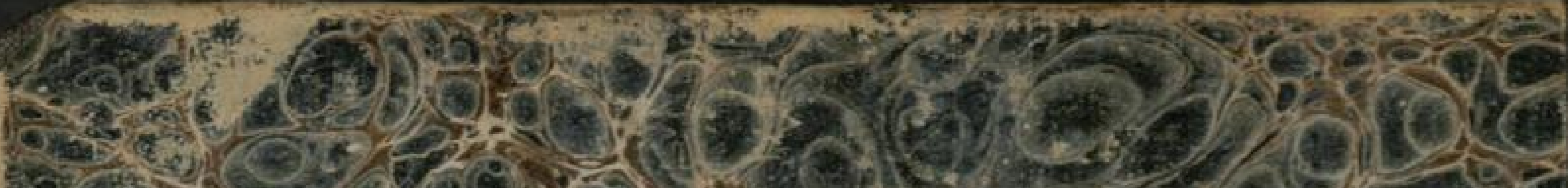

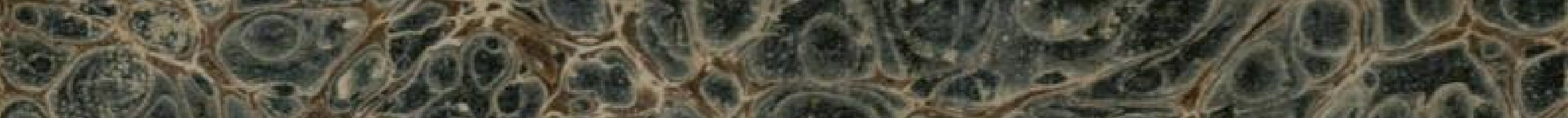

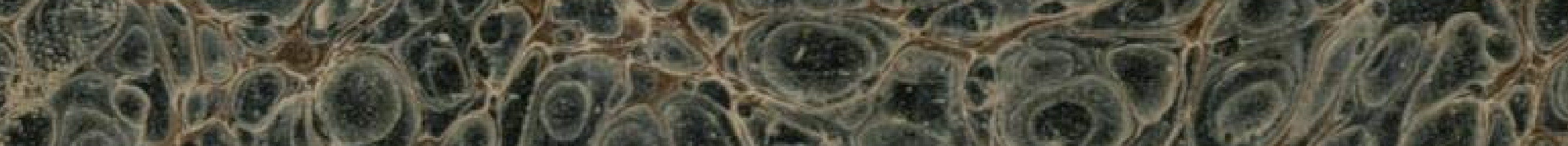

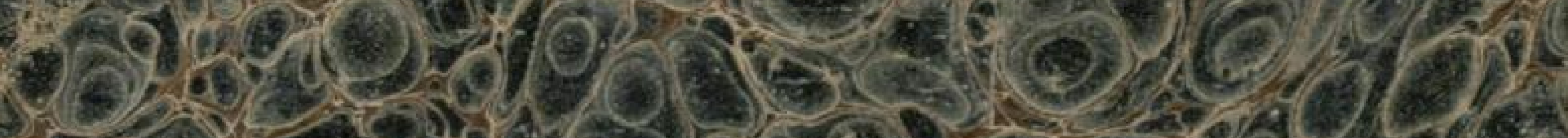

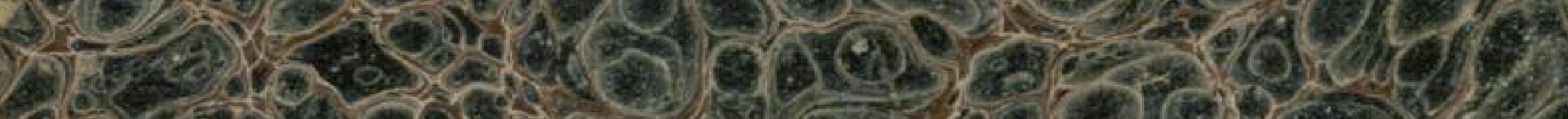

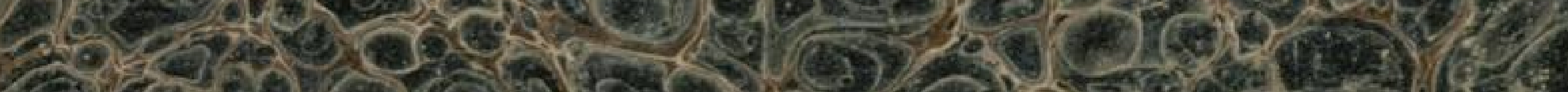

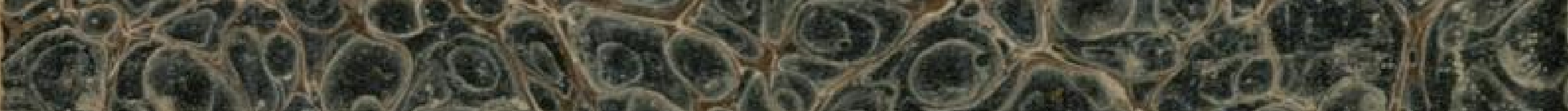

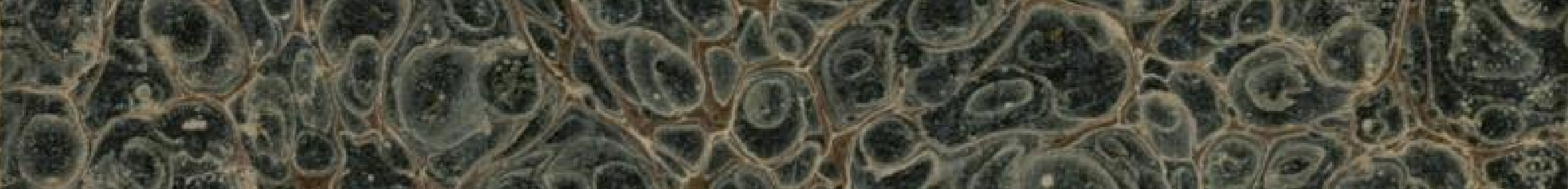

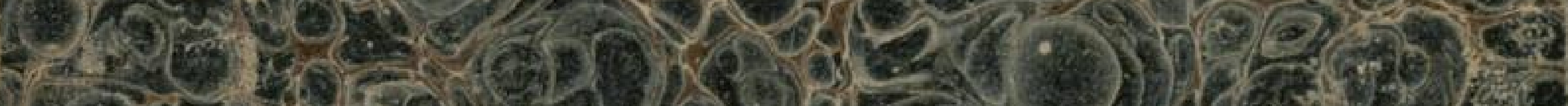

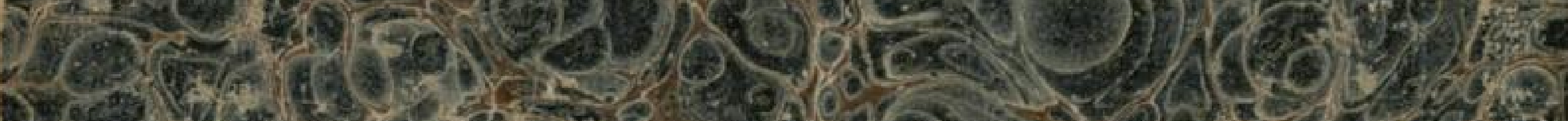

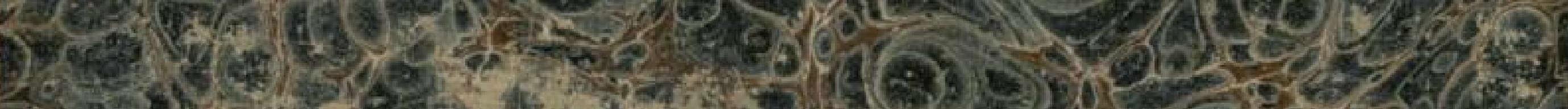

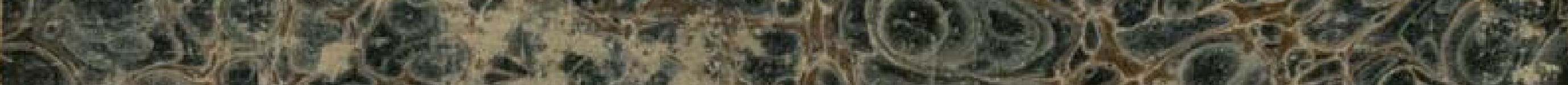

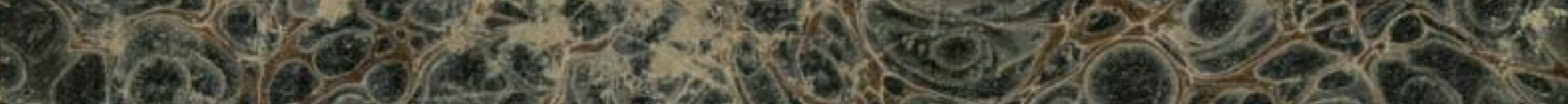

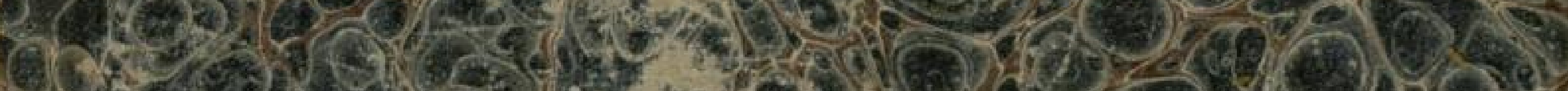

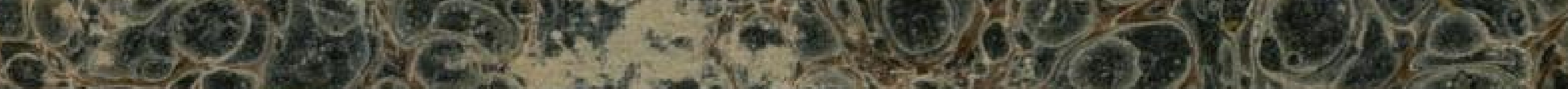

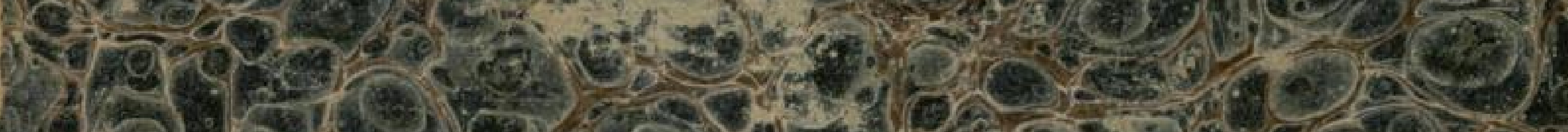

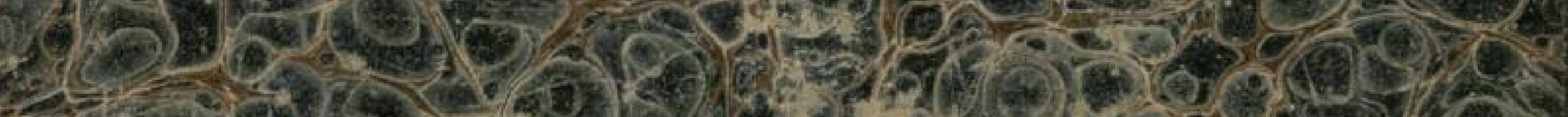

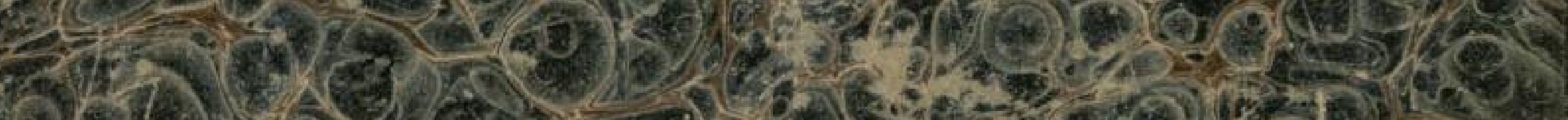

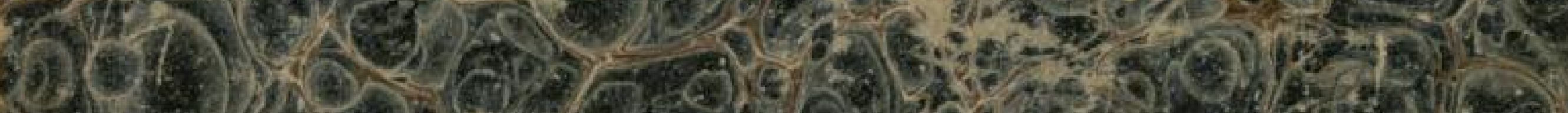

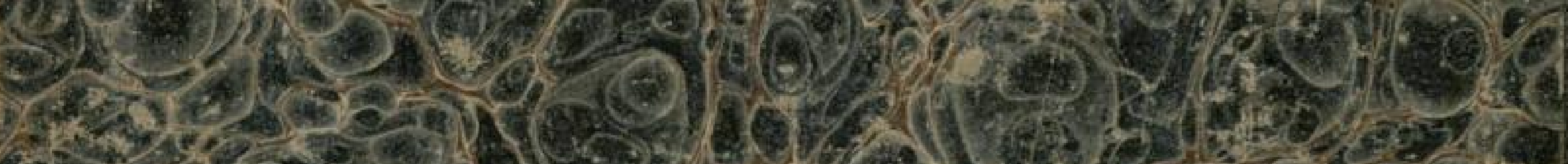

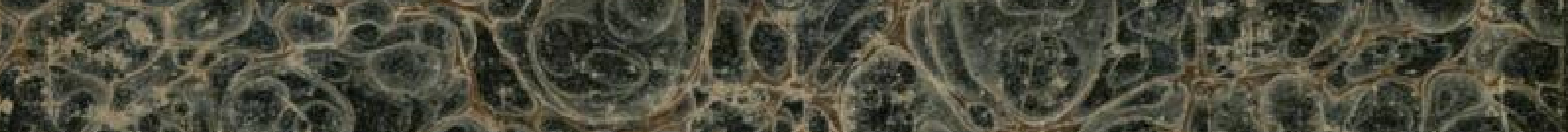

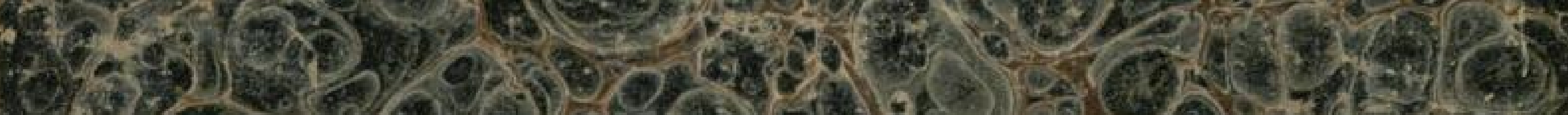
9.5. का

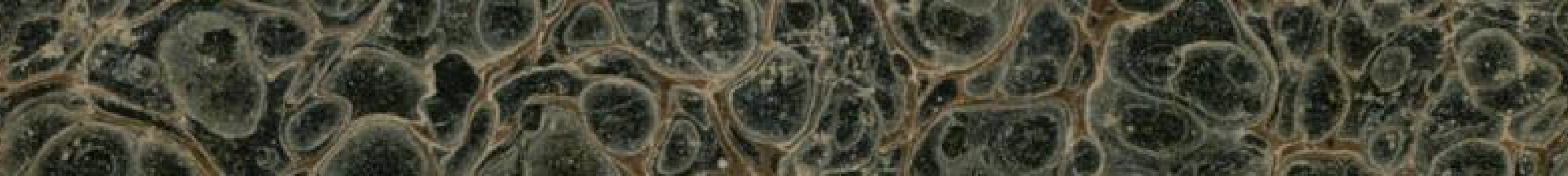

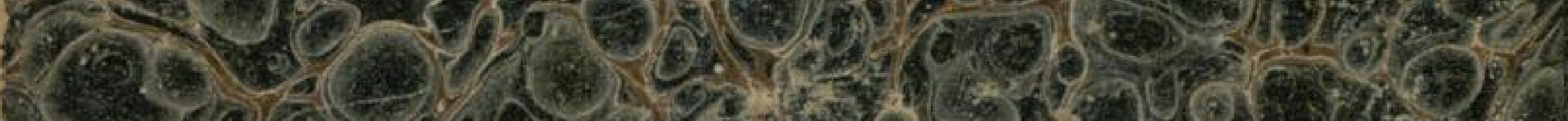
(2)

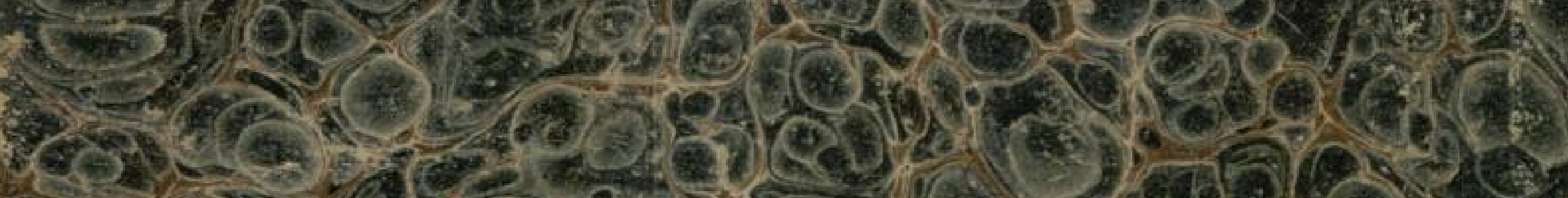

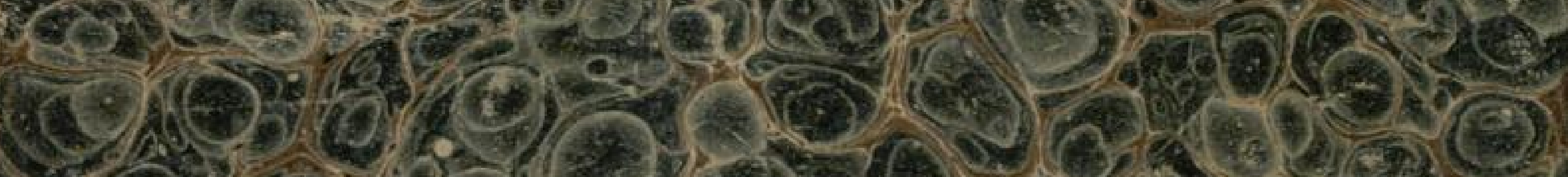

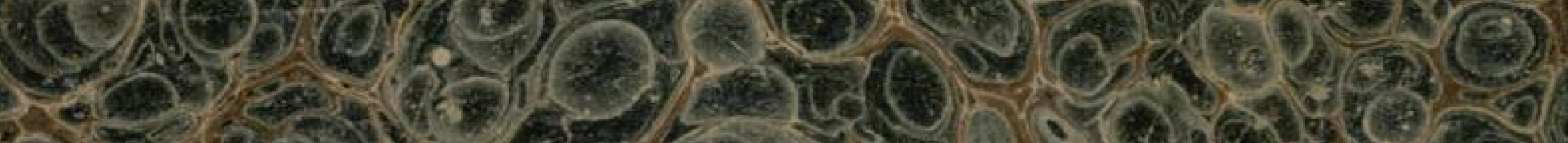

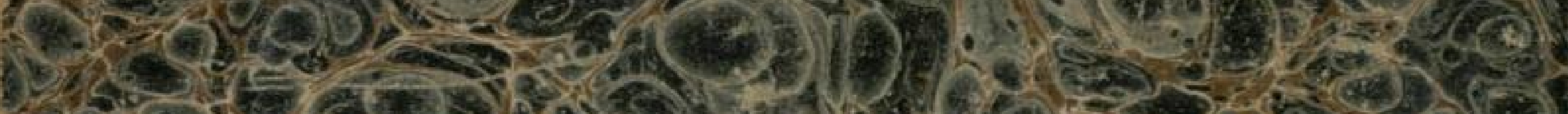

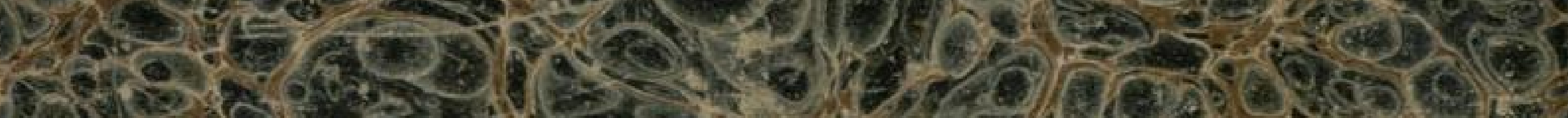

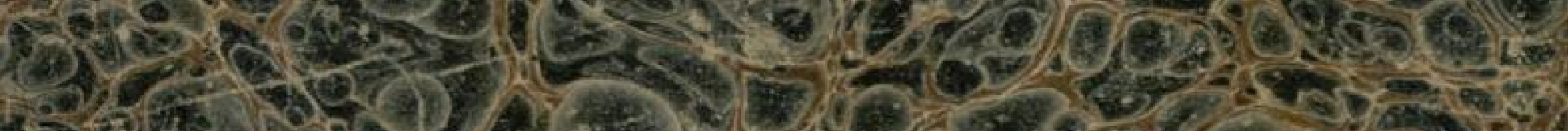

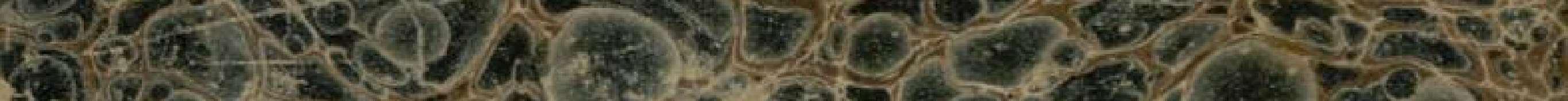

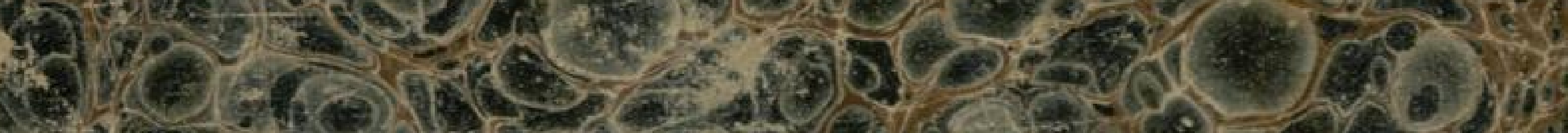

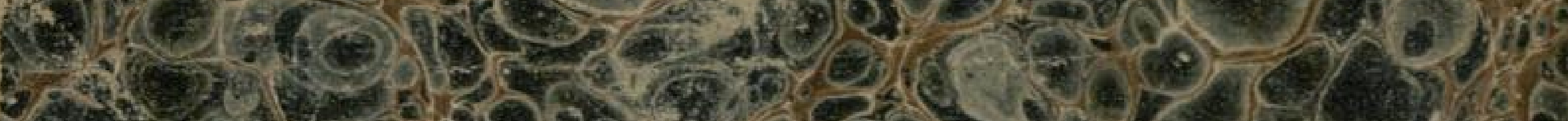

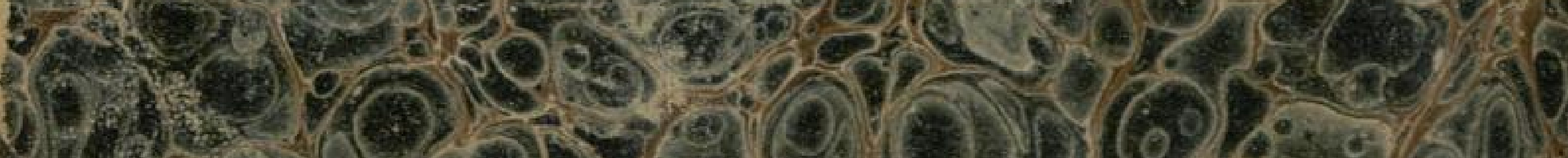

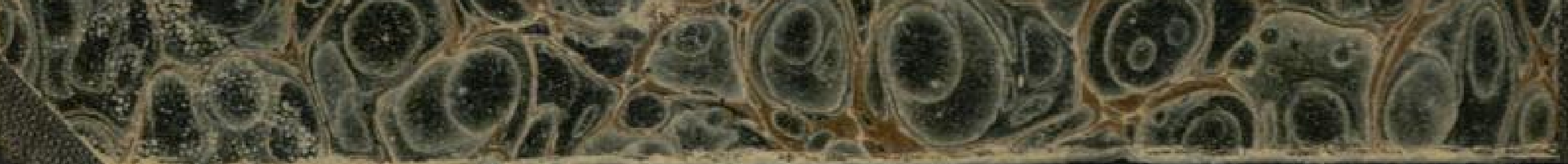

